\title{
USGS Spectral Library Version 7
}

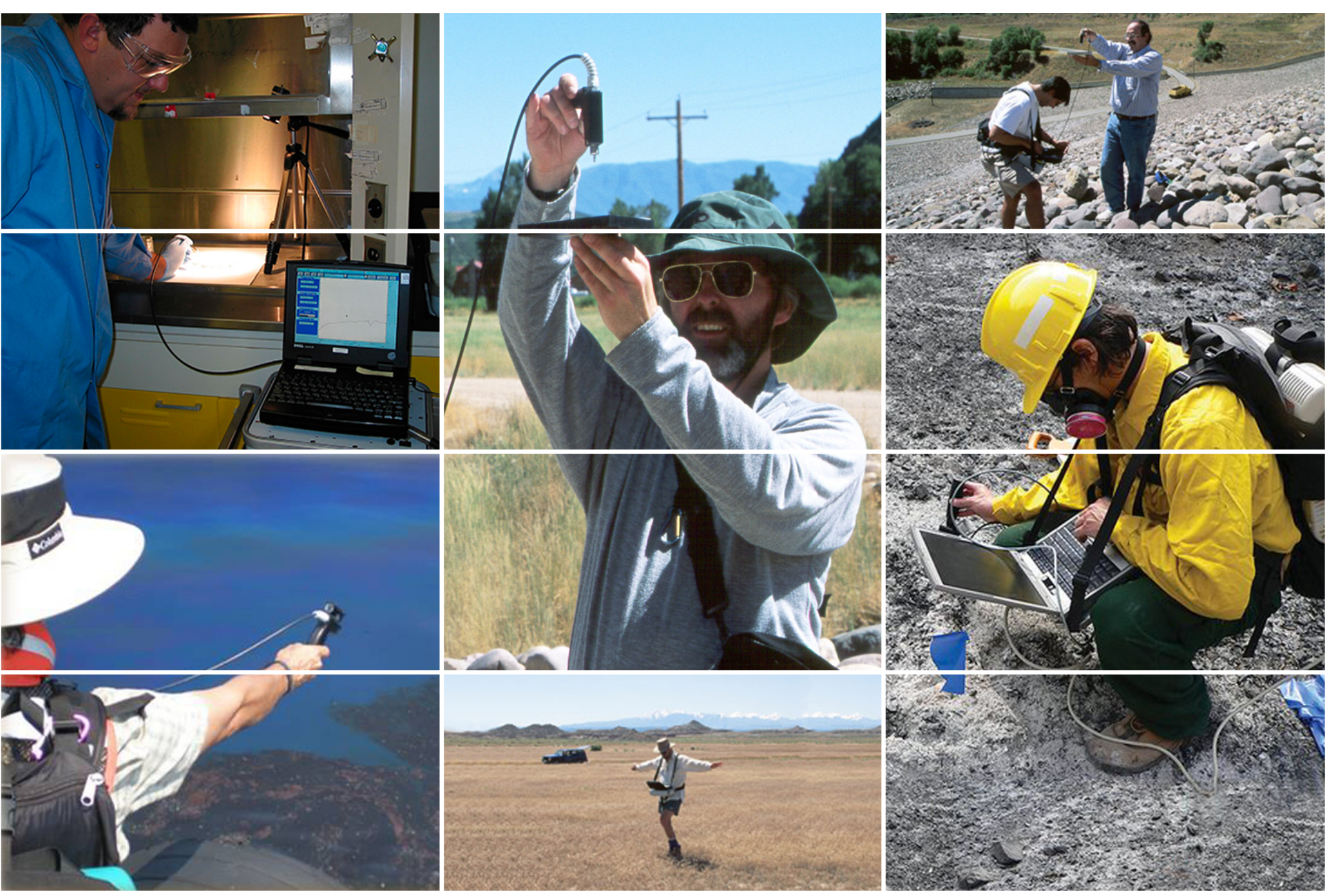

Data Series 1035 
Cover. Upper left, laboratory measurement of dust from the World Trade Center collapse (Photograph by Gregg Swayze). Upper middle, optimization of spectrometer settings for field measurements (Photograph by Gregg Swayze). Upper right, measurement of the white reference panel for collecting field reflectance data (Photograph by Roger Clark). Lower left, field measurement of spectra of oil from the Deepwater Horizon spill (Photograph by Robert Horton). Lower middle, field measurement of spectra for calibrating airborne imaging spectrometer data (Photograph by Gregg Swayze). Lower right, field measurement of spectra of ash and char following wildland fire (Photograph by Todd Hoefen). 


\section{USGS Spectral Library Version 7}

By Raymond F. Kokaly, Roger N. Clark, Gregg A. Swayze, K. Eric Livo, Todd M. Hoefen, Neil C. Pearson, Richard A. Wise, William M. Benzel, Heather A. Lowers, Rhonda L. Driscoll, and Anna J. Klein

Data Series 1035

U.S. Department of the Interior

U.S. Geological Survey 


\title{
U.S. Geological Survey William H. Werkheiser, Acting Director
}

\author{
U.S. Geological Survey, Reston, Virginia: 2017
}

For more information on the USGS - the Federal source for science about the Earth, its natural and living resources, natural hazards, and the environment—visit http://www.usgs.gov or call 1-888-ASK-USGS.

For an overview of USGS information products, including maps, imagery, and publications, visit http://store.usgs.gov/.

Any use of trade, firm, or product names is for descriptive purposes only and does not imply endorsement by the U.S. Government.

Although this information product, for the most part, is in the public domain, it also may contain copyrighted materials as noted in the text. Permission to reproduce copyrighted items must be secured from the copyright owner.

Suggested citation:

Kokaly, R.F., Clark, R.N., Swayze, G.A., Livo, K.E., Hoefen, T.M., Pearson, N.C., Wise, R.A., Benzel, W.M., Lowers, H.A., Driscoll, R.L., and Klein, A.J., 2017, USGS Spectral Library Version 7: U.S. Geological Survey Data Series 1035, 61 p., https://doi.org/10.3133/ds1035.

ISSN 2327-638X (online) 


\section{Contents}

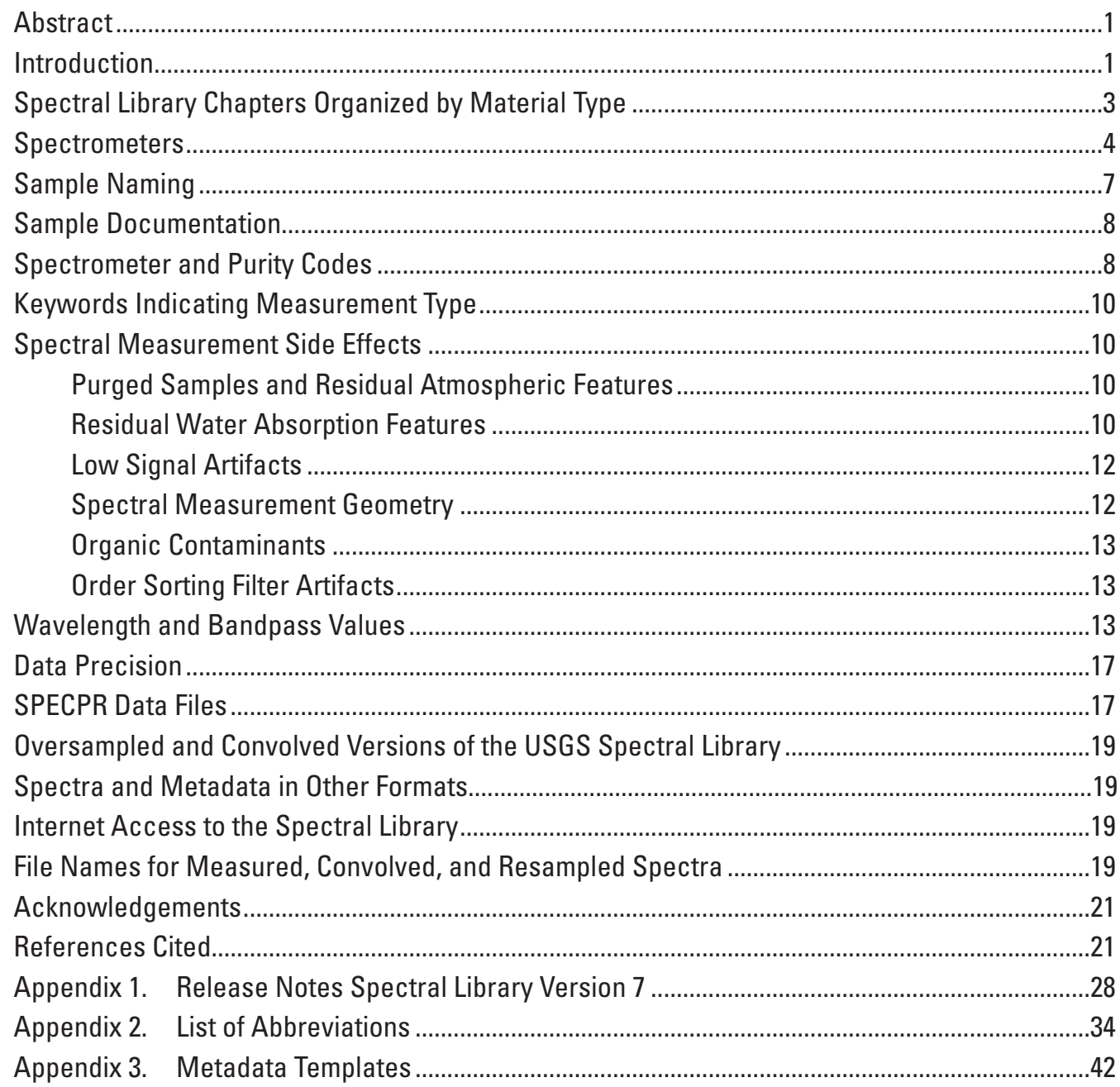

\section{Figures}

1-3. Graphs showing:

1. Bandpass values for spectrometers used to measure spectra in the library ...................5

2. Reflectance of Spectralon white reference panels ...........................................................6

3. Residual atmospheric absorption features in spectra .......................................................11

4. Schematic Nicolet spectrometer geometry....................................................................12

5-8. Graphs showing:

5. Comparison of a Nicolet measurement to a Beckman measurement of the same sample, Alunite GDS84........................................................................................................13

6. Organic contaminant in a spectrum measured on the Nicolet spectrometer .................14

7. Order sorting filter artifacts in spectra measured with the Analytical Spectral Devices spectrometer......................................................................................................15

8. Analytical Spectral Devices spectrometer bandpass functions and evaluations .........16 


\section{Tables}

1. String identifiers in spectrum titles and associated wavelength ranges, bandpasses, and spectrometers

2. Listing of records at the beginning of the splib07a SPECPR file ...................................... 18

\section{Conversion Factors}

\begin{tabular}{lcl}
\hline \multicolumn{1}{c}{ Multiply } & By & \multicolumn{1}{c}{ To obtain } \\
\hline & Wavelength & \\
\hline micron $(\mu \mathrm{m})$ & 1,000 & nanometer $(\mathrm{nm})$ \\
micron $(\mu \mathrm{m}), \lambda$ & $(1 / \lambda) * 10,000$ & wavenumber $\left(\mathrm{cm}^{-1}\right)$ \\
nanometer $(\mathrm{nm})$ & 0.001 & micron $(\mu \mathrm{m})$ \\
\hline
\end{tabular}




\title{
USGS Spectral Library Version 7
}

\author{
By Raymond F. Kokaly, ${ }^{1}$ Roger N. Clark, ${ }^{2}$ Gregg A. Swayze, ${ }^{1}$ K. Eric Livo, ${ }^{1}$ Todd M. Hoefen, ${ }^{1}$ Neil C. Pearson, ${ }^{3}$ \\ Richard A. Wise, ${ }^{4}$ William M. Benzel, ${ }^{1}$ Heather A. Lowers, ${ }^{1}$ Rhonda L. Driscoll, ${ }^{1}$ and Anna J. Klein ${ }^{1}$
}

\section{Abstract}

We have assembled a library of spectra measured with laboratory, field, and airborne spectrometers. The instruments used cover wavelengths from the ultraviolet to the far infrared (0.2 to 200 microns $[\mu \mathrm{m}])$. Laboratory samples of specific minerals, plants, chemical compounds, and manmade materials were measured. In many cases, samples were purified, so that unique spectral features of a material can be related to its chemical structure. These spectro-chemical links are important for interpreting remotely sensed data collected in the field or from an aircraft or spacecraft. This library also contains physically constructed as well as mathematically computed mixtures. Four different spectrometer types were used to measure spectra in the library: (1) Beckman ${ }^{\mathrm{TM}} 5270$ covering the spectral range 0.2 to $3 \mu \mathrm{m}$, (2) standard, high resolution (hi-res), and high-resolution Next Generation (hi-resNG) models of Analytical Spectral Devices (ASD) field portable spectrometers covering the range from 0.35 to $2.5 \mu \mathrm{m}$, (3) Nicolet ${ }^{\mathrm{TM}}$ Fourier Transform Infra-Red (FTIR) interferometer spectrometers covering the range from about 1.12 to $216 \mu \mathrm{m}$, and (4) the NASA Airborne Visible/Infra-Red Imaging Spectrometer AVIRIS, covering the range 0.37 to $2.5 \mu \mathrm{m}$. Measurements of rocks, soils, and natural mixtures of minerals were made in laboratory and field settings. Spectra of plant components and vegetation plots, comprising many plant types and species with varying backgrounds, are also in this library. Measurements by airborne spectrometers are included for forested vegetation plots, in which the trees are too tall for measurement by a field spectrometer. This report describes the instruments used, the organization of materials into chapters, metadata descriptions of spectra and samples, and possible artifacts in the spectral measurements. To facilitate greater application of the spectra, the library has also been convolved to selected spectrometer and imaging spectrometers sampling and bandpasses, and resampled to selected broadband

\footnotetext{
${ }^{1}$ U.S. Geological Survey, Denver, Colorado.

${ }^{2}$ Planetary Science Institute, Tucson, Arizona.

${ }^{3}$ University of Nevada, Reno.

${ }^{4}$ U.S. Geological Survey, Denver, Colorado (retired).
}

multispectral sensors. The native file format of the library is the SPECtrum Processing Routines (SPECPR) data format. This report describes how to access freely available software to read the SPECPR format. To facilitate broader access to the library, we produced generic formats of the spectra and metadata in text files. The library is provided on digital media and online at https://speclab.cr.usgs.gov/spectral-lib.html. A long-term archive of these data are stored on the USGS ScienceBase data server (https://dx.doi.org/10.5066/F7RR1WDJ).

\section{Introduction}

Spectroscopic interpretations of data from laboratory, field, airborne, and orbital sensors require reference spectra of purified and well-characterized materials. Much of this library grew out of imaging spectroscopy studies of the Earth and other planets conducted by the authors of this report (for example, Clark, 1999; Swayze and others, 2000, 2009, 2014; Clark and others 2003a; Livo and others, 2007; Kokaly and others, 2009, 2013a). Imaging spectrometers, with many contiguous spectral channels having narrow bandwidths, allow accurate identification and discrimination of a variety of materials based on absorption features within their spectra. Examples of these sensors are the National Aeronautics and Space Administration (NASA) Airborne Visible/Infrared Imaging Spectrometer (AVIRIS), Mars Reconnaissance Orbiter's Compact Reconnaissance Imaging Spectrometer for Mars (CRISM), and Cassini's Visual and Infrared Mapping Spectrometer (VIMS). Analysis of data from these sensors requires a comprehensive reference spectral library of minerals, vegetation, manmade materials, and other substances. The spectral library described here forms a knowledge base for the characterization and mapping of materials and provides compositional standards of importance to a variety of research programs being conducted at the U.S. Geological Survey (USGS).

Each spectrum in the library has a companion description, in other words, metadata associated with that spectrum. The metadata describe what was measured and can include photographs of samples, details of how measurements were made, warnings about impurities, and other supporting information about the character and composition of that material. Ideally, sample analyses of minerals could include X-ray diffraction 
(XRD), electron microprobe (EM), X-ray fluorescence (XRF), and petrographic microscopic analyses. It can take more than one week to perform the basic spectral measurements, make and assemble supporting XRD, EM, XRF, and microscopic analyses, document the results, and complete the entry of one individual sample into the library. Plant samples and vegetated areas can also have exacting demands for data collection and documentation. For leaf samples measured in the laboratory or field spectra of single plants, documentation can be as simple as noting the dates of sample collection and measurement, species identification, and providing a sample description. For field-level measurements of vegetated areas (plant communities), the species in the measured area need to be identified and the associated percent cover of each species quantified. Therefore, a single plot can take many hours to measure. As is the case for mineral samples, data reduction, compilation, review and entry of vegetation spectra into the library likewise require large time investments.

The quality of spectra required to successfully perform an investigation depends on the scientific questions to be answered and the type of algorithms to be used for analysis. The samples and spectra collected in this library were assembled for the purpose of using spectral features for remote identification and mapping of materials. In order to map a mineral using imaging spectroscopy with a diagnostic absorption feature, reference spectra must have high signal-to-noise ratio and well-characterized wavelength and bandpass characteristics (Clark and others 1990a, 2003a; Hoefen and others, 2003; Swayze and others, 2003, 2014; Kokaly, 2011; Kokaly and others, 2013b). Nevertheless, spectral features for such algorithms could come from a spectrum of a sample containing large amounts of contaminants that may add other spectral features, as long as the shape of the diagnostic feature of interest is not modified. But, a user must understand the location of the contaminant spectral features. To support such use of spectral features, a comprehensive reference database of spectra with detailed supporting descriptions is needed. If spectral data are needed for radiative transfer models then completely pure samples and artifact-free spectra are required, for example, to derive mineral abundances from reflectance spectra. In this library, each spectrum has a purity indicator and a metadata description that can be used to decide whether to use it for a particular application. Before using any spectrum, we strongly recommend reviewing its associated metadata.

The native file format of the spectral library is the SPECtrum Processing Routines (SPECPR) data format (Clark, 1993). We have published a variety of software to work with and conduct scientific analysis using spectra in this format (Clark, 1993; Kokaly, 2011; Livo and Clark, 2014). In addition to their spectral feature analysis and feature comparison functions, these programs allow the complete contents of the spectral library to be viewed and searched (in other words, providing access to both the spectra and the associated metadata). To support access to the library without specialized programs, simple text versions of the spectra, images of plots of the spectra, and text files in HyperText Markup
Language (HTML) format with the metadata are supplied (see the Spectra and Metadata in Other Formats section of this report). The library is provided in both SPECPR and generic formats on digital media and can be accessed and downloaded from https://speclab.cr.usgs.gov/spectral-lib.html. A long-term archive of these data are stored on the USGS ScienceBase data server (https://dx.doi.org/10.5066/F7RR1WDJ).

Two fundamental spectrometer characteristics significant for interpreting and utilizing spectral measurements are sampling position (the wavelength value of each spectrometer channel) and bandpass (a parameter describing the wavelength interval over which each channel in a spectrometer is sensitive). Bandpass is typically reported as the Full Width at Half Maximum (FWHM) response at each channel (in wavelength units, for example nanometers $[\mathrm{nm}]$ or microns $[\mu \mathrm{m}])$. Data for the sampling positions and the bandpass values (for each channel in the spectrometers) are included in the library. These data are in the SPECPR files, as separate data records, and in the American Standard Code for Information Interchange (ASCII) text files, as separate files for wavelength and bandpass.

Spectral measurements and sample characterizations for this library have been ongoing for more than 30 years. In our view, an ideal spectral library consists of samples covering a comprehensive set of materials, has a large wavelength range, and contains spectra measured with high precision. The metadata should include sufficient sample analyses and documentation to establish the quality of the spectra. However, available time and resources limit what can be achieved. While this release of the USGS Spectral Library does not have all its samples completely described, characterization of samples will continue as resources allow for subsequent releases of the library. When possible, error bars accompany the spectra. In this library, the standard deviation of the mean is used to represent the measurement error, computed for each spectrometer channel.

This report describes the USGS spectral library version 7. The digital file containing the spectra and metadata descriptions of samples has the filename splib07a. The splib07a library includes almost all spectra from the previous splib06a version (Clark and others, 2007) along with more than 1,000 new measurements. Spectra of grain size series of select minerals have been added including minerals bearing rare earth elements (REEs) and Lanthanide series compounds. Nanophase minerals and other materials deemed important for remote sensing of planetary surfaces were also added. Spectra of vermiculite insulation from the four main historical sources (Louisa, Virginia; Enoree, South Carolina; Libby, Montana; and Palabora, South Africa) were added. Also added is a set of powdered paint pigments spanning the range of classical artisanal colors. Compared to the previous version, this release adds field spectra of mixed vegetation plots in the Louisiana saltmarshes. Leaf level and plant level spectra of single species from the Louisiana saltmarsh and California chaparral have also been added. Spectra of oil emulsions, residues and oil-contaminated marsh plants from the Deepwater Horizon oil spill are included. The spectra of select biochemical 
constituents of plants have been added to a new chapter along with spectra of more than 200 other organic compounds. Selected organic compounds were measured at cryogenic temperature, as well as at room temperature.

Appendix 1 of this report lists changes made to spectra that were in previous releases of the USGS spectral library, including edits made to spectra, movement of samples from one chapter to another, and deletions of spectra from the library. Of significant note is that a high-resolution Next Generation model of the Analytical Spectral Devices (ASD) FieldSpec 4 instrument was used to remeasure more than 60 samples that have been used to identify and map minerals using spectral feature comparison methods applied to imaging spectrometer data (Kokaly, 2011; Clark and others, 2003a). These new measurements of mineral samples have high signal-to-noise ratio (SNR) and are at a spectral resolution fine enough for direct comparison with the latest generation of imaging spectrometers that have bandpass values near $6 \mathrm{~nm}$ in the wavelength region of reflected sunlight (for example, AVIRIS-Next Generation).

\section{Spectral Library Chapters Organized By Material Type}

The spectral library splib07a encompasses a broad range of materials organized in these chapters:

- Chapter 1: $\mathrm{M}=$ Minerals.

- Chapter 2: $\mathrm{S}=$ Soils (including rocks, and mineral mixtures).

- Chapter 3: $\mathrm{C}=$ Coatings.

- Chapter 4: $\mathrm{L}=$ Liquids (including mixtures of liquids, water and other volatiles, and frozen volatiles).

- Chapter 5: $\mathrm{O}=$ Organics (including biochemical constituents of plants and chemical compounds). This chapter includes mixtures of organic compounds with basalt as well as the reference basalt. The spectra of the mixtures with basalt show the fundamental absorptions of the organic compounds, which can be saturated in the spectra of the pure substances.

- Chapter 6: A = Artificial (manmade materials, including construction materials, fabrics, manufactured chemicals, processed materials, paint pigments, plastics, and materials introduced into the environment by human activity).

- Chapter 7: V = Vegetation (including biological materials, plant components such as leaves, flowers, and bark, vegetated areas having more than one species present, lichens, biological soil crusts, and mixtures with vegetation).
Native elements and minerals from arsenate, borate, carbonate, halide, hydroxide, nitrate, oxide, phosphate, silicate (cyclosilicate, inosilicate, phyllosilicate, nesosilicate, sorosilicate, and tectosilicate), sulfate, and sulfide classes are represented. The library also contains compositional endand intermediate-members for the olivine, garnet, scapolite, montmorillonite, muscovite, jarosite, and alunite solidsolution series. We have included representative spectra of kerogen, ammonium-bearing minerals, Lanthanide element oxides, desert varnish coatings, kaolinite crystallinity series, kaolinite-smectite series, zeolite series, and an extensive evaporite series. We tried to include spectra with a particular focus on those important to remote sensing in the wavelengths of reflected sunlight ( 0.4 to $2.5 \mu \mathrm{m}$ on the Earth, and 0.4 to more than $[>] 5 \mu \mathrm{m}$ for outer Solar System bodies). In some cases, the library has a series that spans a compositional solidsolution series or a grain size series or both. In other cases, we have studied particular solid-solution series because we are mapping them with imaging spectroscopy or studying that mineral in detail. This explains, for example, the many alunite, olivine, and topaz samples in the database.

Some samples were not easily placed into a specific chapter. For example, pure minerals are often difficult to find, or it may be difficult to process the sample to purify the mineral. Such a sample could be considered a mixture. Some samples of this type were put in the minerals chapter (Chapter 1: M) because they have spectral features that are representative of one mineral in the sample. The mixture chapter (Chapter 2: S) contains spectra of multiphase samples used for identifying and mapping mixtures. Usually, the materials in these mixtures have overlapping absorption features in their spectra. The samples in the coatings chapter (Chapter 3: C) are also mixtures. However, the mineral coatings on the surfaces of the rock samples may be optically thick and obscure the spectral signatures of the underlying minerals. Frozen water, in the form of snow and ice, are included in Chapter 4: L.

Organic compounds are a vast category with great chemical diversity. We have added more than 200 organic compounds to a new chapter in this release of the library (Chapter 5: O). The additions are focused on compounds of smaller molecular weight that form the functional groups for larger molecules. Major groups represented include alkanes, alkenes, alkynes, aromatic hydrocarbons based on the benzene ring, and amino acids. Many of these compounds are known by multiple names because of different naming conventions and use of the common name before systematic naming conventions were created. We endeavored to use the name that was in most common use in the spectrum titles. The sample description has the Chemical Abstract Services (CAS) Registry Number. The metadata descriptions also list the various names that have been applied to a particular chemical. Biochemical constituents of plants are also in this chapter of the library. Spectra of major components of plants, including lignin, cellulose, amylose, and starch, and less abundant components, including many plant phenolics, were added. 
Terrestrial remote sensing may be used in urban areas covered by manmade materials, so the library includes spectra of plastics, roofing materials, processed wood, paint, and other artificial materials (Chapter 6: A). Also in this chapter are materials that might be considered natural, for example oil and vermiculite insulation; however, they are present in the environment because of human activity or they have been altered or concentrated during a manufacturing process. In the splib07a release of the library, spectra of oil residues from the British Petroleum (BP) Deepwater Horizon spill (DWH) have been added. Materials that we use to process spectra and monitor the performance of our spectrometers have been added, specifically, Spectralon ${ }^{\mathrm{TM}}$ and Mylar ${ }^{\circledR}$ plastic.

The spectra in the vegetation chapter (Chapter 7: V) are representative of areas in which we have conducted research and for which we have published results, including: grasslands, semiarid shrublands, biological soil crusts, temperate evergreen forests, California chaparral, and coastal wetlands. The spectra span a range of measurement scales, from laboratory spectra of leaves, stems, flowers, and other plant components to remotely sensed spectra of vegetated areas of mixed species. Because the SPECPR database file format has a limitation of 40 characters for spectrum titles, scientific names of organisms are rarely used in spectrum titles. Instead, scientific names are specified in the metadata descriptions of spectra. Spectra of leaves or a plant of a single species are often listed by a generic common name of the plant (for example, "manzanita" to represent Arctostaphylos viscida Parry). Field and AVIRIS spectra of mixed vegetation areas (plant communities) are sometimes listed by the common name of the dominant species (for example, lodgepole pine), by biome (such as grassland or shrubland), or by a land-use term (such as rangeland). In some cases, the title contains the biome name and the dominant species indicated by symbols comprising the genus and species of the dominant plant, for example, "Marsh_SPAL80\%..." in the title describing a coastal wetland area where the most abundant species is Spartina alterniflora Loisel. with 80 percent (\%) cover.

\section{Spectrometers}

Four different spectrometer types were used to measure spectra in the library: (1) Beckman ${ }^{\mathrm{TM}} 5270$ covering the spectral range 0.2 to $3 \mu \mathrm{m}$, (2) standard, high resolution (hi-res), and high-resolution Next Generation (hi-resNG) models of ASD field portable spectrometers covering the range from 0.35 to $2.5 \mu \mathrm{m}$, (3) Nicolet ${ }^{\mathrm{TM}}$ Fourier Transform Infra-Red (FTIR) interferometer spectrometers covering the range from about 1.12 to $216 \mu \mathrm{m}$, and (4) the NASA Airborne Visible/Infra-Red Imaging Spectrometer AVIRIS, covering the range 0.37 to $2.5 \mu \mathrm{m}$. Bandpass is a parameter describing the wavelength interval over which each channel in a spectrometer is sensitive, commonly reported as the Full Width at Half Maximum (FWHM) response. Plots of the spectrometer bandpass are shown in figures $1 A$ and $B$. Nicolet measurements were made with 4 wavenumber (wavenumber has units of $\mathrm{cm}^{-1}$, equivalent to 10,000 /wavelength in microns) bandpass over the wavelength range of the instrument, sampling every $2 \mathrm{~cm}^{-1}$.

Spectra measured on our modified Beckman 5270 spectrometer were corrected to absolute reflectance. Measurements from this instrument are described in Clark and others (1990b). Measurements of powdered mineral samples were made using a special attachment to the integrating sphere to allow particulate materials to be measured in a horizontal position, typically in a 31.7-millimeter (mm) diameter sample cup (Hunt, 1980). Because the effect of the sample holder walls, these Beckman measurements are described as biconical reflectance factors (BCRF) using traditional terms (Nicodemus and others, 1977) and the more recent definitions proposed in Schaepman-Strub and others (2006). Beckman measurements of rock samples were placed directly over the sample port of the integrating sphere and are bihemispherical reflectance (BHR) measurements according to traditional terminology and the definitions in Schaepman-Strub and others (2006). Samples were typically measured over the 0.2 to $3.0 \mu \mathrm{m}$ range with a signal-to-noise ratio of at least 500 at a reference reflectance level of 1.0. A few minerals were also run over a slightly smaller wavelength range because of sample size limitations. For example, small sample quantities, necessary for purity, were measured by using apertures in the beam to restrict the spot size of the spectrometer on the sample cup. The resulting reduction of incoming light made integration times longer, and the achievable wavelength range was sometimes reduced, typically to 0.3 to $2.7 \mu \mathrm{m}$. In some cases, this also limited the signal-to-noise ratio that was achievable for small volume samples.

Laboratory spectra measured on the ASD spectrometers used a directional light source and fiber-optic probe to collect light. The incidence angle was variable but typically ranged from 20 to 40 degrees, as did the viewing angle. Measurements of this type are described as BCRF in Schaepman-Strub and others (2006). Traditionally, these measurements have been referred to as bidirectional reflectance factors (BRF) or bidirectional reflectance distribution function (BRDF).

Spectrometer data collection with the ASD involved a Spectralon white reference panel. Reference panels are not completely reflective and absorb incident radiation to a small degree in some wavelength regions. Conversion of spectral measurements made with an ASD spectrometer to absolute reflectance removes the artifacts caused by weak absorptions in the spectralon reference panel. In this study, absolute reflectance $(R)$ as a function of wavelength $(\lambda)$ was obtained by multiplying the reflectance measurement made relative to Spectralon $\left(\mathrm{R}_{\mathrm{rel}}\right)$ by the reflectance of Spectralon itself $\left(\mathrm{R}_{\text {Spectralon }}\right)$ :

$$
\mathrm{R}(\lambda)=\mathrm{R}_{\text {rel }}(\lambda) * \mathrm{R}_{\text {Spectralon }}(\lambda)
$$

The reflectance of Spectralon was determined using the procedure described for halon in Clark and others (1990b). The reflectance spectrum used to convert all ASD spectra is included in the splib07a release of the USGS spectral library. 


\section{A. Spectrometer bandpass values}

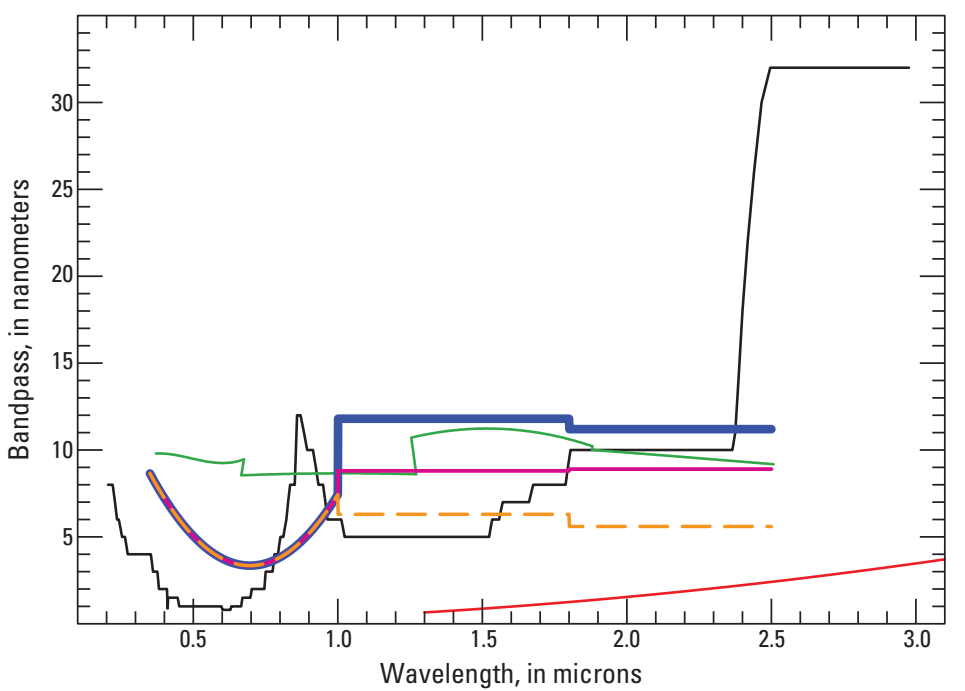

EXPLANATION

Analytical Spectral Devices (ASD)

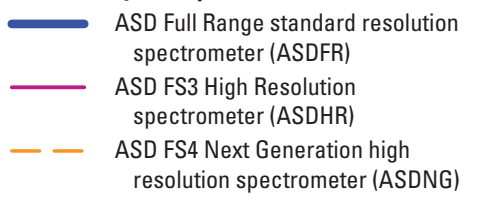

— Beckman 5270 spectrometer (Beckman)

_ Airborne Visible/Infrared Imaging

Spectrometer (AVIRIS-classic)

— Nicolet Fourier Transform Infra-Red

interferometer spectrometer (Nicolet)

resolution spectrometer (ASDNG)

\section{B. Nicolet bandpass}

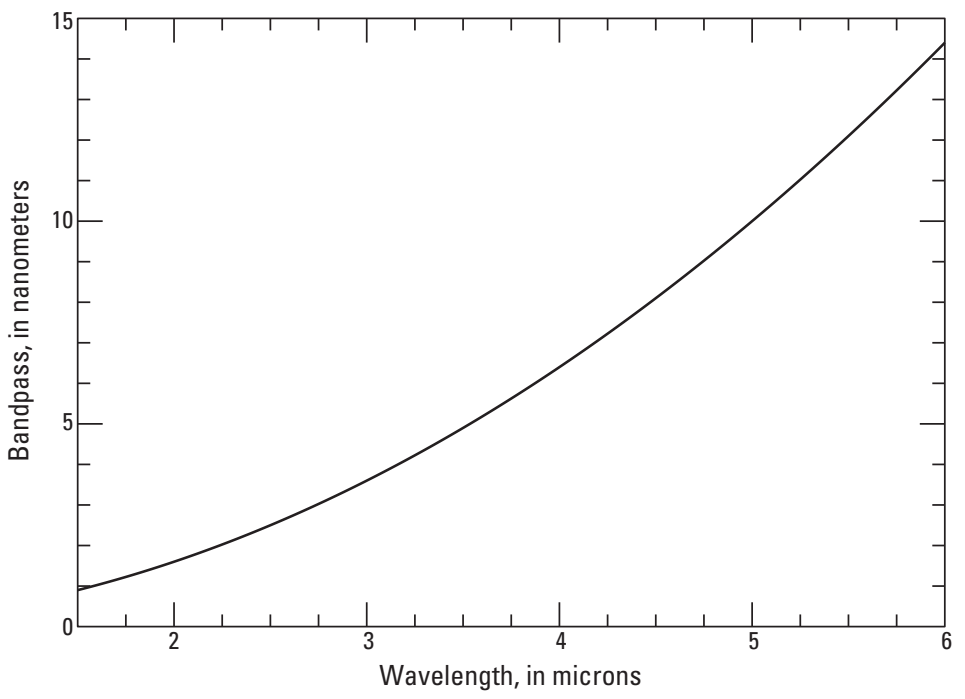

Figure 1. Bandpass values for spectrometers used to measure spectra in the library: $A$, all spectrometers in the visible to near-infrared wavelength region; and $B$, details of the Nicolet bandpass in the near-infrared wavelength region. Bandpass is characterized as the full-width at half maximum (FWHM) of each spectrometer channel. 
This updated Spectralon spectrum was made using new, higher spectral resolution measurements in the visible region compared to previous versions of the library. The updated spectrum is based on measurements of Spectralon relative to brushed aluminum, sand-blasted platinum, and gold-coated, sand-blasted aluminum. These metals were used as references because they have no fine spectral structure over the 0.3 to 0.7 micron region. These relative reflectance measurements were used to confirm that the Spectralon reflectance also had no fine spectral features. The Spectralon measurements, relative to the metallic reference materials, were used in combination with the supplied National Institute of Standards and Technology (NIST)-traceable reflectance values to update the Spectralon reflectance.

The original and updated Spectralon reflectance curves are shown in figure 2, along with the NIST-traceable values for three Spectralon reference panels. The absorption features in Spectralon are weak over most wavelengths. However, there is a significant absorption in the wavelengths between 1.95 and $2.21 \mu \mathrm{m}$ and at wavelengths greater than $2.25 \mu \mathrm{m}$. By converting to absolute reflectance, artifacts in relative reflectance measurements caused by the absorption of Spectralon are removed.
The field spectra in this library were collected over more than 20 years. During that time, a variety of ASD field spectrometer models have been used, including FullRange (FR), FieldSpec ${ }^{\circledR}$ Pro, FieldSpec 3, and FieldSpec 4 models. These spectrometers all span the wavelength range of 0.35 to $2.50 \mu \mathrm{m}$ using three detectors, with reflectance reported every $1 \mathrm{~nm}$. Generally, the detectors cover the wavelength ranges $0.35-1,1.001-1.8$, and $1.801-2.5 \mu \mathrm{m}$. In the past, the exact splice positions between detectors vary by instrument and depend on detector performance and manufacturer settings. In the last few years, ASD has used standard splice points in their field spectrometers. Offsets in reflectance at these splice points arise from the spectrometer design, where optical fibers lead to different detectors. Although the fibers are randomized in the fiber optic cable, there is still the possibility that fibers leading to the different detectors may, on average, be viewing slightly different parts of a measured surface. The main factor responsible for spectral offsets is the slightly different field of view solid angles of the fibers leading to the visible/nearinfrared (VNIR) detector compared to those leading to the two short-wave infrared (SWIR) detectors. We corrected residual spectral offsets by simple multiplicative factors. The second detector has been observed to be more stable at the ends of

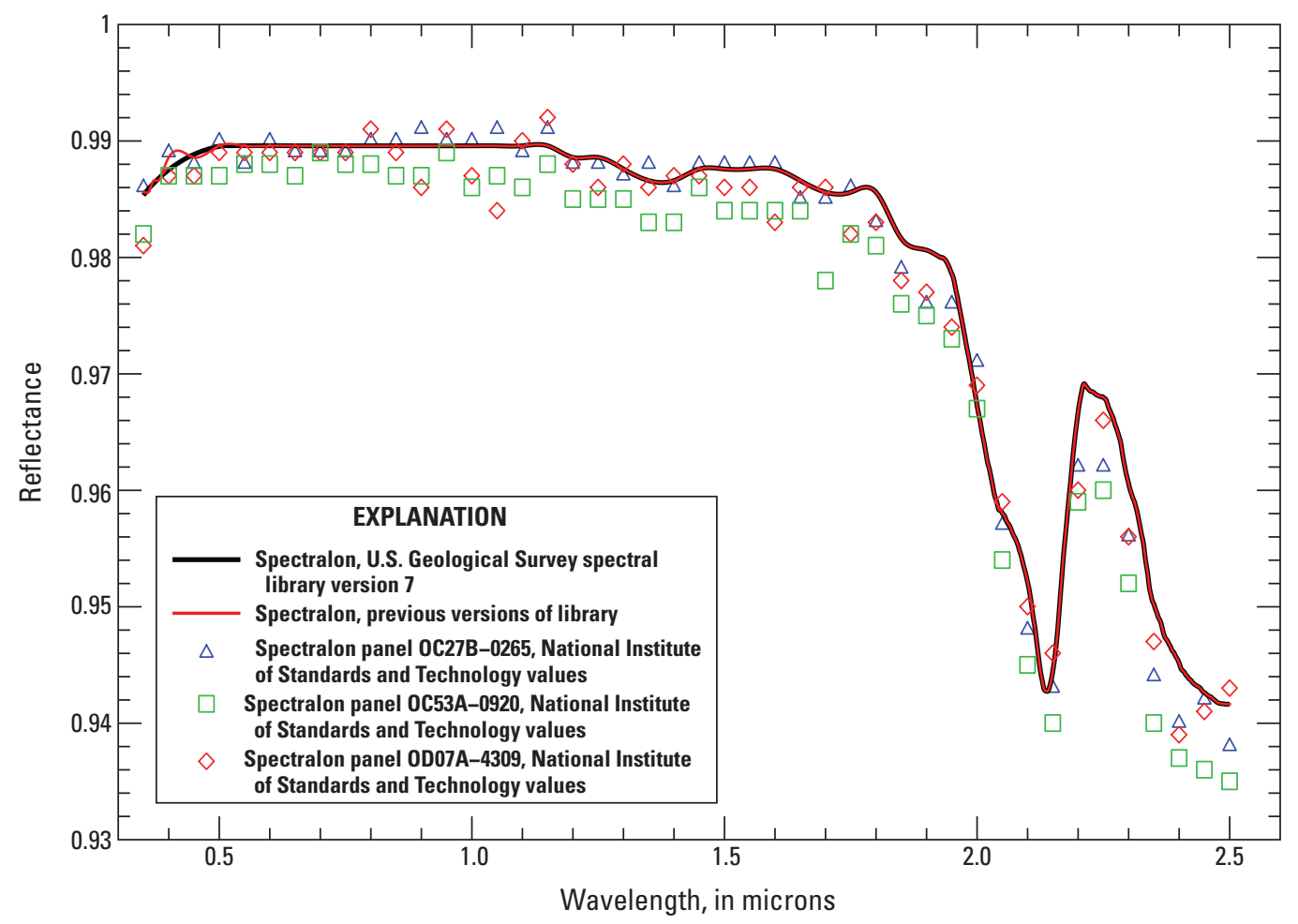

Figure 2. Reflectance of Spectralon white reference panels: the black line indicates the updated spectrum used in splib07a for converting Analytical Spectral Devices spectra from relative reflectance to absolute reflectance, the red line indicates the spectrum used in previous versions of the spectral library, and the symbols are plotted at the widely spaced National Institute of Standards and Technology-traceable values of reflectance for three Spectralon panels. 
its wavelength coverage, compared to the other detectors. As a result, reflectance levels from the first and third detectors were adjusted to be consistent with that of the middle detector. A linear extrapolation of reflectance level was made from the last two channels of the stable detector to the output of the end channel of the detector to be adjusted. A multiplicative factor was calculated by dividing the extrapolated reflectance value by the actual recorded reflectance value. This factor was then applied to outputs from all channels of the detector being adjusted. Typically, the reported and the extrapolated reflectance levels differed by a few percent or less. The offset correction procedure is described and illustrated in Kokaly (2011) and Kokaly and Skidmore (2015). This offset correction procedure was used in the previous version of the USGS spectral library (Clark and others, 2007).

The ASD instruments used in the laboratory to measure samples typically had an incidence angle of about 20 degrees, with the illuminating lamp subtending a cone of 4 to 5 degrees, and an emission angle of about 30 degrees with an azimuth angle of about 90 degrees. The emitted cone angle was the angular size of the field of view of the bare optic fibers, about 20 degrees.

Field spectra measured using the ASD spectrometers have been collected under various sky conditions. Many were collected under optimum conditions of clear skies and within an hour of local solar noon. Sometimes, in order to maximize data collection during field work, spectra were collected under partly cloudy skies and up to 3 hours before or after local solar noon. Viewing geometry and sky conditions are often noted in the metadata descriptions associated with each spectrum. Field measurements of this type have been described traditionally as BRDF or BRF and, more recently, as hemispherical-conical reflectance factors (HCRF) by Schaepman-Strub and others (2006), who apply the term hemispherical to the combination of direct sunlight and diffuse light scattered by the atmosphere, nearby terrain, and surrounding objects.

Nicolet Fourier Transform Infra-Red (FTIR) interferometer spectrometers were used to measure spectra in a laboratory setting. Before 1998, mineral spectra were run on a Nicolet model 740 FTIR. From 1998 to 2008, spectra were collected using a Nicolet Magna-IR 760 spectrometer. Since October 2008, spectra have been collected using a Thermo Scientific ${ }^{\circledR}$ Nicolet 6700 FTIR spectrometer. Nicolet spectra were not measured with an integrating sphere. These measurements are described as BCRF using both traditional terms and the more recent terminology of Schaepman-Strub and others (2006). Often, samples were measured two times with each measurement consisting of 200 scans. The replicate scans were averaged.

Nicolet measurements of organic compounds, materials at cryogenic temperatures, and analogs of planetary materials, were measured in a custom-built purged chamber external to the Nicolet instrument. The measurement incidence angle was 20 degrees and emission angle was 35 degrees, with an azimuth angle of 65 degrees. The incident light cone subtended 8 degrees. The emission light cone was approximately 35 degrees.
Nicolet measurements ranged from 1.12 to as high as $216 \mu \mathrm{m}$. To cover this large wavelength range, various combinations of up to five detectors, InSb (Indium Antimonide), MCT (mercury cadmium telluride; MCT-A and MCT-B), DTGS (deuterated triglycine sulfate) with $\mathrm{KBr}$ window, and DTGS with polyethylene window, and three beam splitters, $\mathrm{KBr}$ (potassium bromide), extended range XT-KBR, and solid substrate far-infrared, were used in the Nicolet setups. For all samples, the Nicolet near-infrared (NIR) range (1.12 to $5 \mu \mathrm{m})$ and the Nicolet mid-infrared (MIR) range (approximately 2.0 to $25 \mu \mathrm{m}$ ) were measured with the same beam splitter and without removing the sample. On the Nicolet 740, only a change in light source from white light to infrared source was required. On the Nicolet Magna, an internal mirror automatically switched the light source and detector. For some samples, the different wavelength regions were measured at different times; thus, samples were put back in their storage bottles between measurements.

The AVIRIS spectra in this library covers areas where it would be difficult to make measurements with normal field portable spectrometers, such as in a forest with tall trees. The AVIRIS spectra were analyzed by Kokaly and others (2003) to map vegetation types in Yellowstone National Park. Conversion of imaging spectrometer data from radiance to reflectance is discussed, generally, in Clark and others (2003b), and specifically for these AVIRIS data in Kokaly and others (2003). As with the field spectrometer measurements, these remotely sensed data have been traditionally referred to as BRF or BRDF and, more recently, as HCRF as described by Schaepman-Strub (2006).

\section{Sample Naming}

For minerals, we have tried to use only proper mineral names as given in Fleischer (1980), Fleischer and Mandarino (1995), and Klein and Hurlbut (1999). Some users of the library may be unfamiliar with all the mineral names. For example, if you want to find all scapolites using just the SPECPR title field, you would have to know dipyre and all other scapolite group minerals by name. Because of a 40-character limit for the SPECPR title field, we could not include all common names; therefore, in the metadata descriptions other fields (described below) contain the common mineral names. These metadata descriptions can be searched for scapolite to find all library entries for "scapolite group" minerals (dipyre, marialite, meionite, and mizzonite). See the SPECPR Data Files section of this report for information about software that can be used to interactively search for keywords in spectrum titles and metadata descriptions.

We have used specific mineral names, except in a few cases where we still do not have sufficient data. For example, in the database, the general term "hornblende" is avoided whenever possible, instead ferro-hornblende and magnesiohornblende are used, which because of space limitation are called Hornblende_Fe and Hornblende_Mg, respectively. 
However, we do have two samples where the distinction cannot be made, so they are labeled hornblende (samples HS16.3B and HS177.3B).

As described earlier, in the Materials and the Spectral Library Chapters section, short names for vegetation are used in their spectrum titles. Full common and scientific names are found in the metadata descriptions linked to each spectrum.

Because the spectrum title is limited to 40 characters, some sample names, especially mixtures, are too long to fit in this space; thus, names are abbreviated. The abbreviations used in this library are listed in Appendix 2.

\section{Sample Documentation}

Each spectrum has metadata describing, among other things, sample origin and purity. The sample description metadata follow from templates in Clark and others (1993, 2003c, and 2007), with "keyword: value" or "keyword" followed by text and an "end_keyword" marker. The metadata descriptions are in HyperText Markup Language (HTML) formatted text. The HTML format still contains the keyword organization. Different sample types have different documentation formats. For example, minerals require different documentation than do plants. Templates for the different material types are found in Appendix 3.

For some samples, not all entries in the metadata templates have been completed. The metadata descriptions reflect the improving state of each release of the spectral library. The splib07a release of the library includes an updated set of sample descriptions that supersede earlier versions of the library (Clark and others, 1993, 2003c, and 2007).

Many sample descriptions include digital photographs. Unless accompanied by a scale bar, digital photographs of minerals are at a scale of $8 \mu \mathrm{m}$ per pixel. These photographs were obtained in the laboratory with a 180 -mm macro lens on a 6-megapixel digital camera (Canon ${ }^{\circledR}$ D60). Photographs were obtained in raw mode. They are provided as Joint Photographic Experts Group (JPEG) image conversions from the raw data with no manipulation. The photographs were obtained with standard meter settings using a Spectralon reflectance target, the same reference surface used for the ASD field spectrometer measurements. By using one reference target, intensities can be compared between photographs of samples. The photographs of vegetation were taken with various cameras and are at different scales. The photographs are not contained within the splib07a file but are located in subfolders, one for the thumbnail images and one for the full-resolution photographs (see the File Names for Measured, Convolved and Resampled Spectra section of this report). The metadata descriptions in HTML format have links to the thumbnail images and full-resolution photographs in the subfolders.

\section{Spectrometer and Purity Codes}

The title of each spectrum contains a string identifier with codes identifying the spectrometer used to make the measurement and the spectral purity. The string identifiers follow a five to seven character pattern: for example,

$$
\text { SSSSp or SSSSSp or SSSSppp or SSSSSSp }
$$

BECKa or ASDFRb or NIC4ccc or AVIRISd

The first set of characters specify the spectrometer, and the next set of characters indicate the spectral purity for various wavelength regions. Codes for the spectrometers used to measure spectra in the splib07a release of the USGS spectral library are given in table 1 . For all spectrometers except the Nicolet, the spectral purity is coded with only a single character. The meanings of the purity codes are defined below. For the Nicolet, spectral purity is designated either with a single character for the wavelength range 1.12-6 $\mu \mathrm{m}$, with two characters for the wavelength ranges 1.12-6 and 6-25 $\mu \mathrm{m}$, or with three characters for the wavelength ranges 1.12-6, 6-25, and $25-150 \mu \mathrm{m}$. For wavelengths longer than $150 \mu \mathrm{m}$, spectral purity has not been evaluated.

Spectral purity codes are:

a: The spectrum and sample are pure based on significant supporting data available to the authors. The sample purity from other methods (for example, XRD or microscopic examination) indicate that no contaminants are present. Spectrally, no contaminants are apparent. Analytical instruments are becoming more sensitive, and can detect contaminants at increasingly lower levels. If the reported contaminant does not affect the spectrum, we consider the sample to be spectrally pure and assign it an "a." In some cases, such as adsorbed water in minerals, or carbon dioxide $\left(\mathrm{CO}_{2}\right)$ fluid inclusions, this is a natural occurrence and the spectral purity is still considered an "a."

b: The spectrum of the sample appears pure. However, other sample analyses indicate the presence of other contaminants that may affect reflectance levels to some degree but do not add any significant spectral features in the region evaluated. The spectral features of the primary minerals may have slightly altered intensities, but the feature positions and shapes should be representative. For example, in the VNIR wavelength regions, quartz would tend to increase the reflectance level and decrease the strength of absorption features but would not add any measurable features to the spectrum. Such a sample would rate a "b." In a few cases, where we have little support data but the spectra for that mineral are well known, the spectral purity is based on the spectral data, alone or in conjunction with information derived from a microscopic examination of the sample. There are a few "b" ratings assigned this way. AVIRIS data of vegetated areas have been assigned a "b" rating because of the imperfect atmospheric correction that can be achieved for remotely sensed spectra.

c: The spectrum has some weak features with depths of a few percent or less caused by other contaminants. For example, some minerals may have slightly modified regions 
Table 1. String identifiers in spectrum titles and associated wavelength ranges, bandpasses, and spectrometers.

\begin{tabular}{|c|c|c|c|c|}
\hline $\begin{array}{l}\text { Spectrometer code } \\
\text { in spectrum title }\end{array}$ & $\begin{array}{l}\text { Wavelength range, } \\
\text { microns }(\mu \mathrm{m})\end{array}$ & $\begin{array}{l}\text { Wavelength range, } \\
\text { wavenumber }\left(\mathrm{cm}^{-1}\right)\end{array}$ & $\begin{array}{l}\text { Bandpass } \\
\text { description }\end{array}$ & Spectrometer manufacturer and models \\
\hline BECK & $0.2-3.0$ & $50,000-3,333$ & Standard setting & Beckman 5270 \\
\hline ASDHR & $0.35-2.5$ & $28,571-4,000$ & $\begin{array}{l}\text { High-resolution model, } \\
\text { average bandpasses of } \\
5,9 \text {, and } 9 \mathrm{~nm} \text { for the } \\
\text { three detectors }\end{array}$ & ASD FS3 hi-resolution \\
\hline ASDNG & $0.35-2.5$ & $28,571-4,000$ & $\begin{array}{l}\text { Next Generation model, } \\
\text { average bandpasses of } \\
5,6 \text {, and } 6 \mathrm{~nm} \text { for the } \\
\text { three detectors }\end{array}$ & ASD FS4 hi-resolution Next Generation \\
\hline NIC4 & $1.12-216.0$ & $8,928-46$ & $4 \mathrm{~cm}-1$ across the range & Nicolet 740, Magna-IR 760, and 6700 \\
\hline
\end{tabular}

that are apparent. Spectroscopic detection of altered minerals is easier for more transparent minerals. For example, some of the albite spectra show weak 2.2- $\mu \mathrm{m}$ features because of albite conversion to clay or mica. From the knowledge of the mineral formula, one can often tell which spectral features do not belong to the mineral. Albite, for instance, does not have $\mathrm{OH}$ in the formula, so water or hydroxyl features $(1.4,1.9$, and $2.2 \mu \mathrm{m}$ in the spectrum) are not because of albite. However, one could argue that incipient alteration because of weathering is common at the Earth's surface. Thus, spectral absorptions because of weathering of the sample are somewhat characteristic of many minerals (such as feldspars), even if they are not a property of the pure mineral. Spectral features of altered minerals might be useful in some cases, but such alteration of minerals and their spectral effects still reduce spectral purity as far as this library is concerned. Note, also, that almost every sample has some absorption near $3 \mu \mathrm{m}$ because of water in the sample. Water adsorbs onto mineral grains and is common. Water absorptions at $3 \mu \mathrm{m}$ are not considered to be contaminants and do not affect spectral purity ratings.

$\mathrm{d}$ : Significant spectral contamination. The spectrum is included in the library only because it is the best sample of its type currently available, and because the primary spectral features can still be recognized (it may also have a better spectral purity in another wavelength range). However, the spectrum should be used carefully. The sample description should be consulted as a guide to which spectral features are because of the actual mineral. Less than 20 spectra are d-rated in this release of the library. $\mathrm{u}$ : There are insufficient analyses or knowledge (or both) of the spectral properties of this material to evaluate its spectral purity. In general, we have included such samples because we believe their spectra to be representative. These are samples for which we plan future compositional analyses. Note that there may be sufficient knowledge to assign spectral purity in one spectral region but not in another.

Pure mineral samples are extremely rare. Spectroscopy is sensitive to low-level contaminants at some wavelengths. Considering the broad spectral range of this library, examination of spectral purity is an important part of its documentation. Spectroscopy can detect a trace contaminant even in samples ground from single crystals that appear pure. Thus, most samples in this library could be considered mixtures at some level. In other cases, deliberate mixtures are included because of the common associations in which they occur. Mixtures, soils, rocks, and coatings can be spectrally complex. The spectral purity of complex mixtures can still be high (assigned "a" status), if the goal is to document the spectral features in that exact mixture. Mixtures that have unintentional contamination have a lower spectral purity than if contaminants were not present, following the guidelines given above.

Before using a spectrum, the spectral purity code and metadata should be consulted in order to decide if the sample is appropriate for the intended purpose. For example, examination of the Beckman spectra for hypersthene PYX02 will show that their spectral purity is a "c," meaning contaminate spectral features overlap diagnostic hypersthene spectral features. As documented in the metadata, the pyroxene sample contains a 
small amount of the sample altered to an amphibole mineral. Amphibole absorption features are narrow at 1.4 and $2.3 \mu \mathrm{m}$, and the pyroxene absorption features are broad. Therefore, if your spectral analysis is not sensitive to the contaminant's narrow absorption features, then this sample's spectrum might be used as a reference spectrum for hypersthene.

For another example of spectral purity, consider the microcline sample HS151. The spectral purity is a "b." There are weak absorption features in the 2 to $2.5 \mu \mathrm{m}$ spectral region that are not indicative of feldspars. Many of the feldspars for which we have seen or measured spectra show evidence of alteration to muscovite at $1.4 \mu \mathrm{m}$ and at 2 to $2.5 \mu \mathrm{m}$. These absorption features are not because of feldspar and should not be used to identify feldspars, as indicated in the metadata for the sample.

Spectral purity codes have been updated in this release of the spectral library, version 7 (splib07a), compared to the previous releases (version 6 and earlier). If you intend to use a spectrum for a particular purpose, confirm the spectral purity to be sure it is appropriate for your needs. The spectrum for each material should be evaluated for contaminant features and how those features might interfere with a particular analysis. Always refer to the metadata description before using a spectrum.

\section{Keywords Indicating Measurement Type}

At the end of each spectrum title, a keyword indicates the measurement type. This keyword appears after the string identifier with codes identifying spectral wavelength range, bandpass, instrument, and spectral purity. Possible keyword values are: AREF, RREF, RTGC and TRAN. Whenever possible, reflectance data have been converted to absolute reflectance (AREF). However, Nicolet spectra were measured with a stainless steel mirror as the reference standard and are relative reflectance (RREF). RTGC stands for "Radiative Transfer Ground Calibrated," the method used to convert AVIRIS spectra from radiance to surface reflectance, as discussed in Clark and others (2003b). Transmission spectra are indicated with the keyword TRAN.

\section{Spectral Measurement Side Effects}

\section{Purged Samples and Residual Atmospheric Features}

Most Nicolet samples in this library were measured in the internal sample chamber using air scrubbed of $\mathrm{H}_{2} \mathrm{O}$ and $\mathrm{CO}_{2}$ by a Balston or Domnick Hunter air purification system. A subset of samples in the library, many of the organic compounds and samples measured at cryogenic temperatures, were measured in an external sample chamber that was also purged with air scrubbed of $\mathrm{H}_{2} \mathrm{O}$ and $\mathrm{CO}_{2}$. In addition to the air feed from the purge line, liquid nitrogen was used to assist in the displacement of $\mathrm{H}_{2} \mathrm{O}$ and $\mathrm{CO}_{2}$ from the external sample chamber. After a sample or the reflectance standard was placed in the sample chamber, a period of time was allowed to pass for the purging of $\mathrm{H}_{2} \mathrm{O}$ and $\mathrm{CO}_{2}$ before a measurement was made. Approximately the same time was allowed to pass after the placement of the standard and after the placement of a sample. Thus, any residual atmospheric gases which could cause absorptions were roughly comparable. Therefore, spectral artifacts from atmospheric gases were generally small. This method did not always work perfectly, and residual atmospheric absorption features $\left(\mathrm{H}_{2} \mathrm{O}\right.$ and $\left.\mathrm{CO}_{2}\right)$ are sometimes present in spectra at a low level. Such residual features (fig. $3 A$ and $B)$ are difficult to remove completely because of the intense nature of the absorptions. Similar features are reported in other databases covering this spectral region (for example, Salisbury and others, 1991).

In field and AVIRIS spectra of vegetation, spectral regions affected by $\mathrm{O}_{2}, \mathrm{H}_{2} \mathrm{O}$, and $\mathrm{CO}_{2}$ gases in the atmosphere have residual artifacts. Spectrometer channels that are strongly affected by atmospheric absorptions have been set to the SPECPR deleted channel value of $-1.23 \times 10^{34}$ (see the SPECPR Data Files section of this report for more information about the SPECPR deleted channel value).

\section{Residual Water Absorption Features}

Even anhydrous minerals show an absorption near $3 \mu \mathrm{m}$ because of water adsorbed onto the surfaces of mineral grains. Our experience has shown that these water absorption features are slightly weaker in $\mathrm{H}_{2} \mathrm{O}$ - and $\mathrm{CO}_{2}$-purged environments of the Nicolet sample chambers. Consequently, the spectra measured on the Nicolet will have reduced water absorption feature depths compared to measurements made on the Beckman and ASD spectrometers. Spectra of similar samples obtained at other facilities, for example, in Hawaii or on the East Coast of the United States, have shown that the water absorption features in the spectra measured at the USGS Spectroscopy Laboratory, in relatively dry Colorado, are small by comparison. Preparation of a sample by placing it in a dry nitrogen atmosphere or in a vacuum oven before measurement had little effect on the water absorption because water from the atmosphere readsorbed onto the sample by the time it reached the spectrometer. Experiments at the University of Hawaii have also shown that most of the adsorbed water remains, even under a strong vacuum at room temperatures (Clark, 1981). We decided not to heat our samples to remove water because we wanted to avoid any temperatureinduced alteration to the sample. 
A. Residual water vapor features

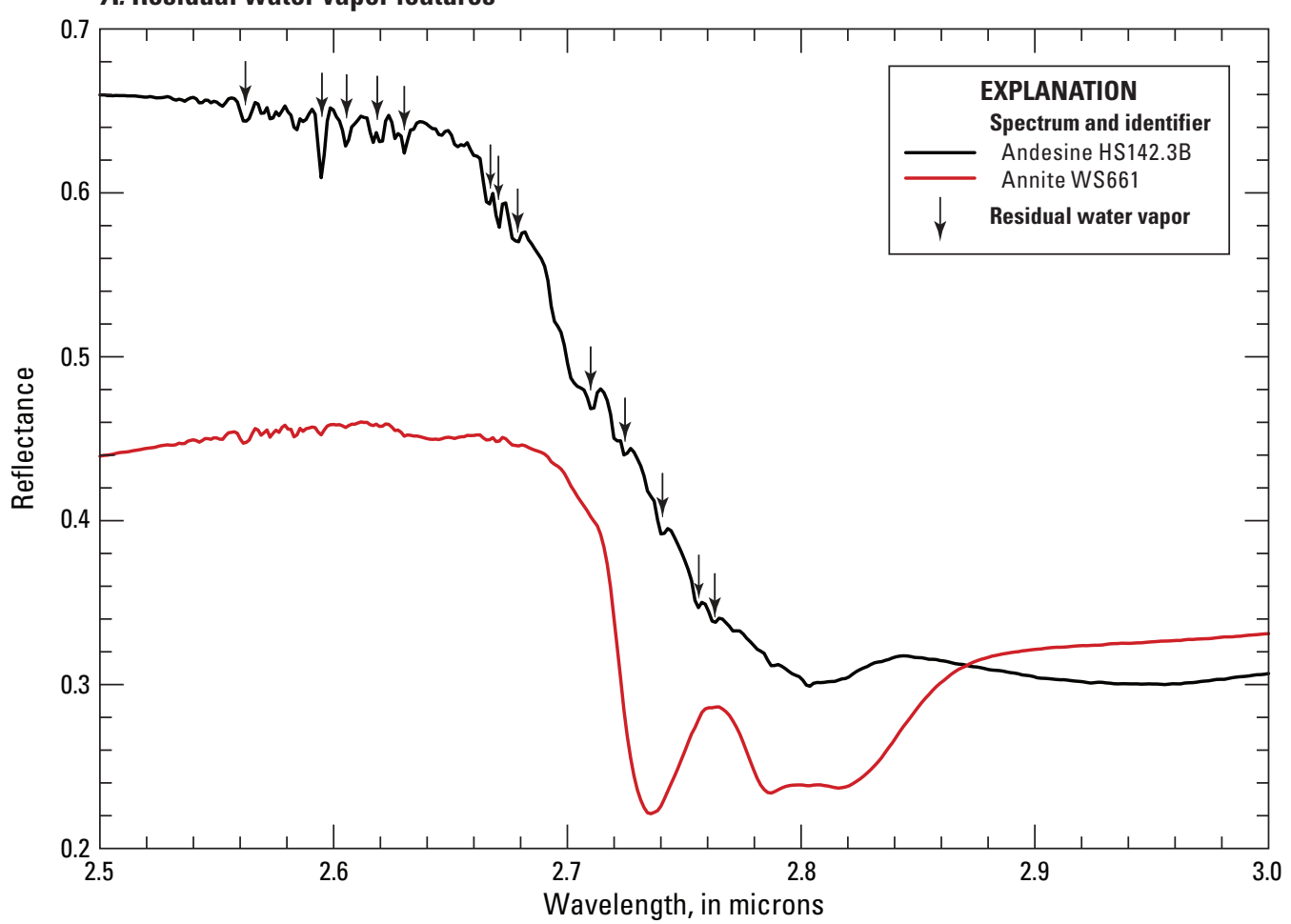

B. Residual carbon dioxide features

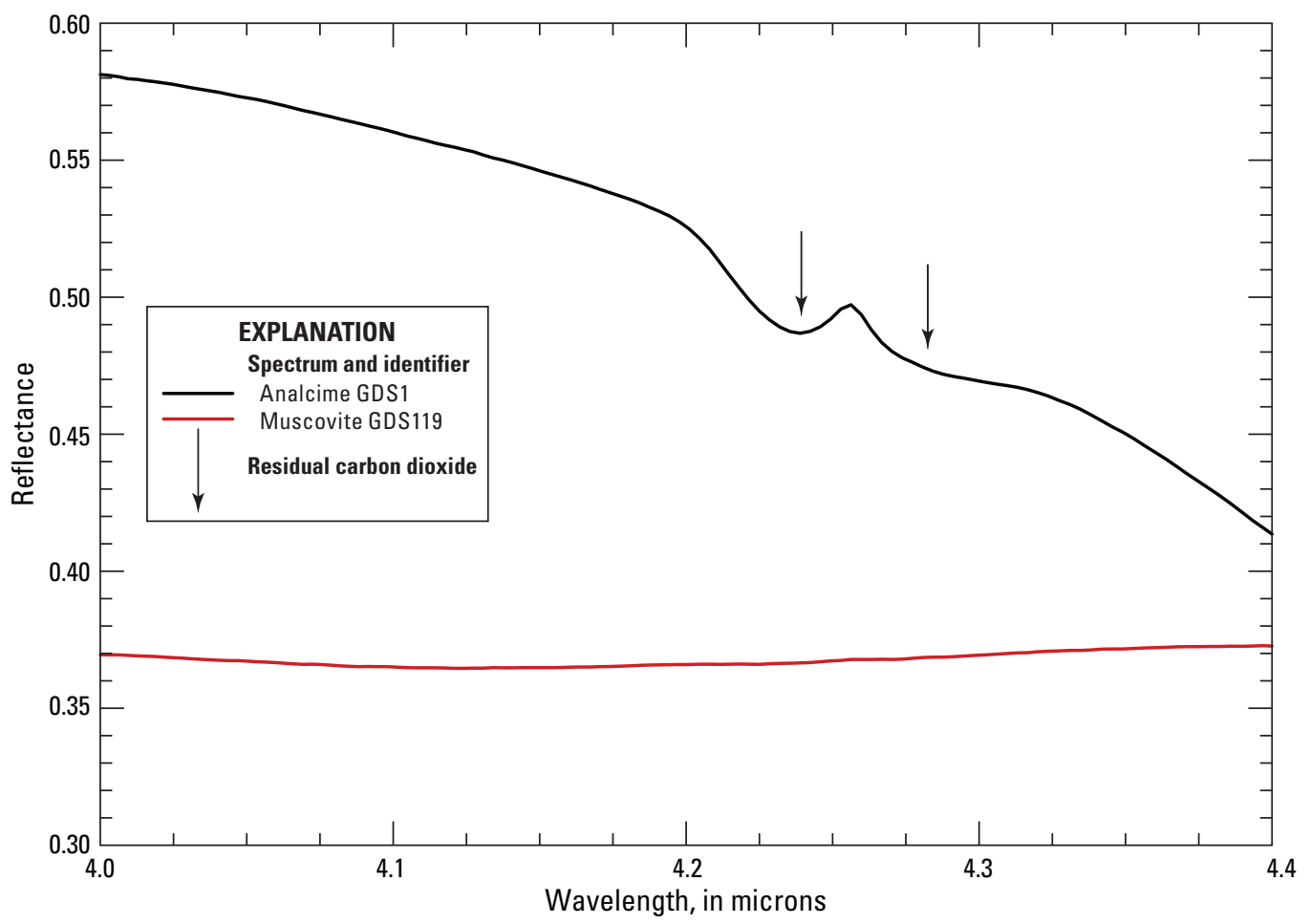

Figure 3. Residual atmospheric absorption features in spectra: $A$, residual water vapor features in the andesine spectrum are almost absent in the annite spectrum; $B$, residual atmospheric carbon dioxide absorption features are seen in the analcime spectrum but are absent in the muscovite spectrum. 


\section{Low Signal Artifacts}

The Nicolet FTIR NIR spectra have an artifact toward shorter wavelengths. From wavelengths of about $2 \mu \mathrm{m}$ down to $1.12 \mu \mathrm{m}$, the reflectance often decreases giving a convex shape to the spectrum. This rollover is not correct. Attempts to derive a correction have not been successful because the amount of rollover is variable from sample to sample. For some samples, we provide this spectral range because the high spectral resolution of the Nicolet can be still be useful for studying narrow spectral features. The rollover becomes more intense at wavelengths shorter than about $1.5 \mu \mathrm{m}$. When using Nicolet spectra with coverage in the $1.1-1.5 \mu \mathrm{m}$ region, the broad curvature should not be interpreted as spectral structure related to material or chemical composition.

\section{Spectral Measurement Geometry}

The measurement of reflectance with our Nicolet spectrometers resulted in a side effect because of the small beam size of the illumination. The basic geometry of the Nicolet spectrometer biconical reflectance attachment is shown in figures $4 A$ and $B$. The reflectance attachment focuses the spectrometer beam onto a spot about $2 \mathrm{~mm}$ in diameter (fig. $4 B$ ) by an elliptical mirror. A second mirror collects the reflected light and sends it to a detector. The small spot size produces side effects at wavelengths where the sample is weakly absorbing and multiple scattering of reflected photons is a significant portion of the signal. Some photons will scatter from grain to grain, leaving the surface outside the focus of the collection mirror. The scattered photons will not be seen by the detector (photon path "B" in fig. 4B). This results in a relative loss in signal and a lower measured reflectance at wavelengths where multiple scattering is significant. While an integrating sphere can be used for measurements of bihemispherical reflectance to derive emissivity (for example, Salisbury and others, 1991), the integrating sphere setup produces lower SNR spectra compared to the biconical reflectance attachment and limits the useable wavelength range of the Nicolet. Libraries of FTIR measurement made with an integrating sphere attachment are publicly available, see Christensen and others (2000) and Baldridge and others (2009).

This signal loss phenomenon encountered with the biconical attachment is illustrated in figure 5, where a Nicolet measurement is compared to a Beckman spectrum. The Nicolet measurement is lower in reflectance because of this scattering effect. The Nicolet measurement also has weaker $2.16,1.75$, and $2.3 \mu \mathrm{m}$ absorption features because of this light loss effect. The narrow focus range of the Nicolet measurement can cause large changes in reflectance level when small changes are made in the position of the surface of the sample. Because of this sensitivity in Nicolet measurements and the light loss effect described above, the reflectance levels of samples high in reflectance (greater than about 0.4) in the 1.5-2.5 $\mu \mathrm{m}$ spectral range are less accurate than darker samples. As a
A. Nicolet measurement geometry

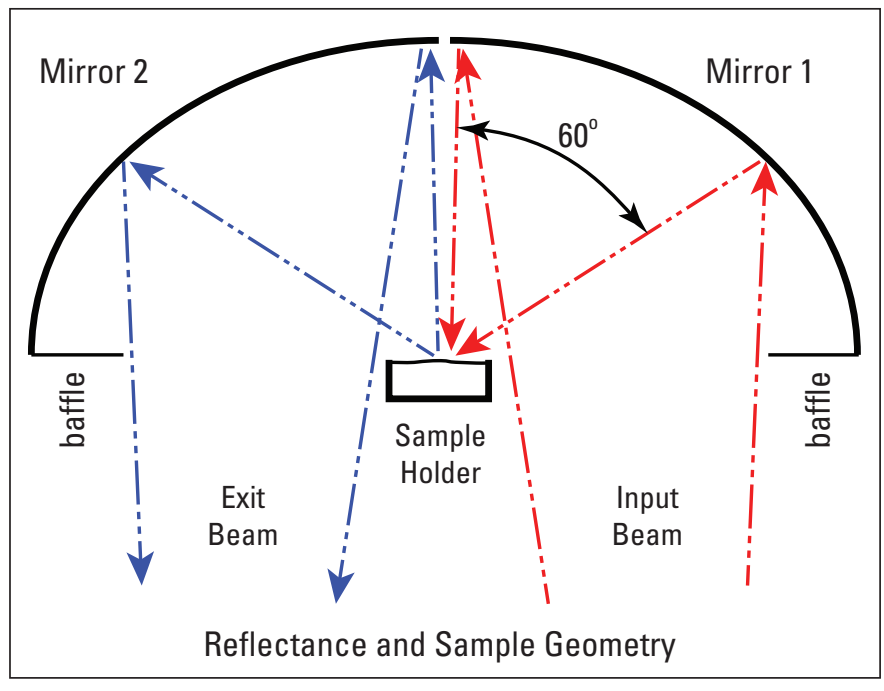

\section{B. Loss of photons by scattering}

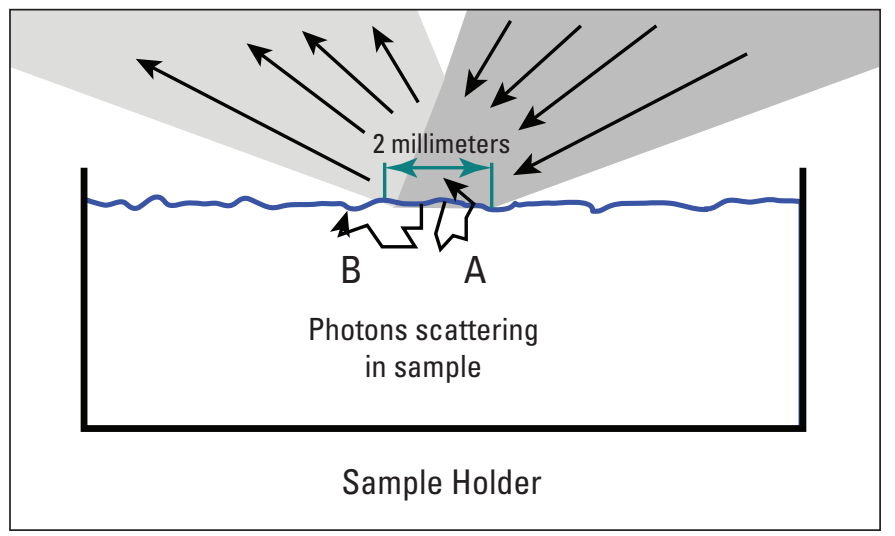

Figure 4. Nicolet spectrometer geometry: $A$, the sample viewing geometry for the Nicolet spectrometer is biconical with maximum 60-degree entrance and exit beams (30-degrees on average) and with an approximately 60 -degree phase angle; and $B$, the small spot measured by the Nicolet spectrometer results in some loss of photons (labeled B) when the photons are multiply scattered. Only photons scattered within the exit field of view (labeled A) are measured.

result, we have scaled Nicolet spectra to match the reflectance level measured with the Beckman and (or) ASD spectrometers at a point in the 1.8-2.5 micron region, often near $2.25 \mu \mathrm{m}$. Longer wavelength Nicolet measurements were then scaled to the shorter wavelength Nicolet measurement and merged. Merge points and scaling factors for the longer wavelength Nicolet spectra were selected between 2-5 and 14.3-25 $\mu \mathrm{m}$. 


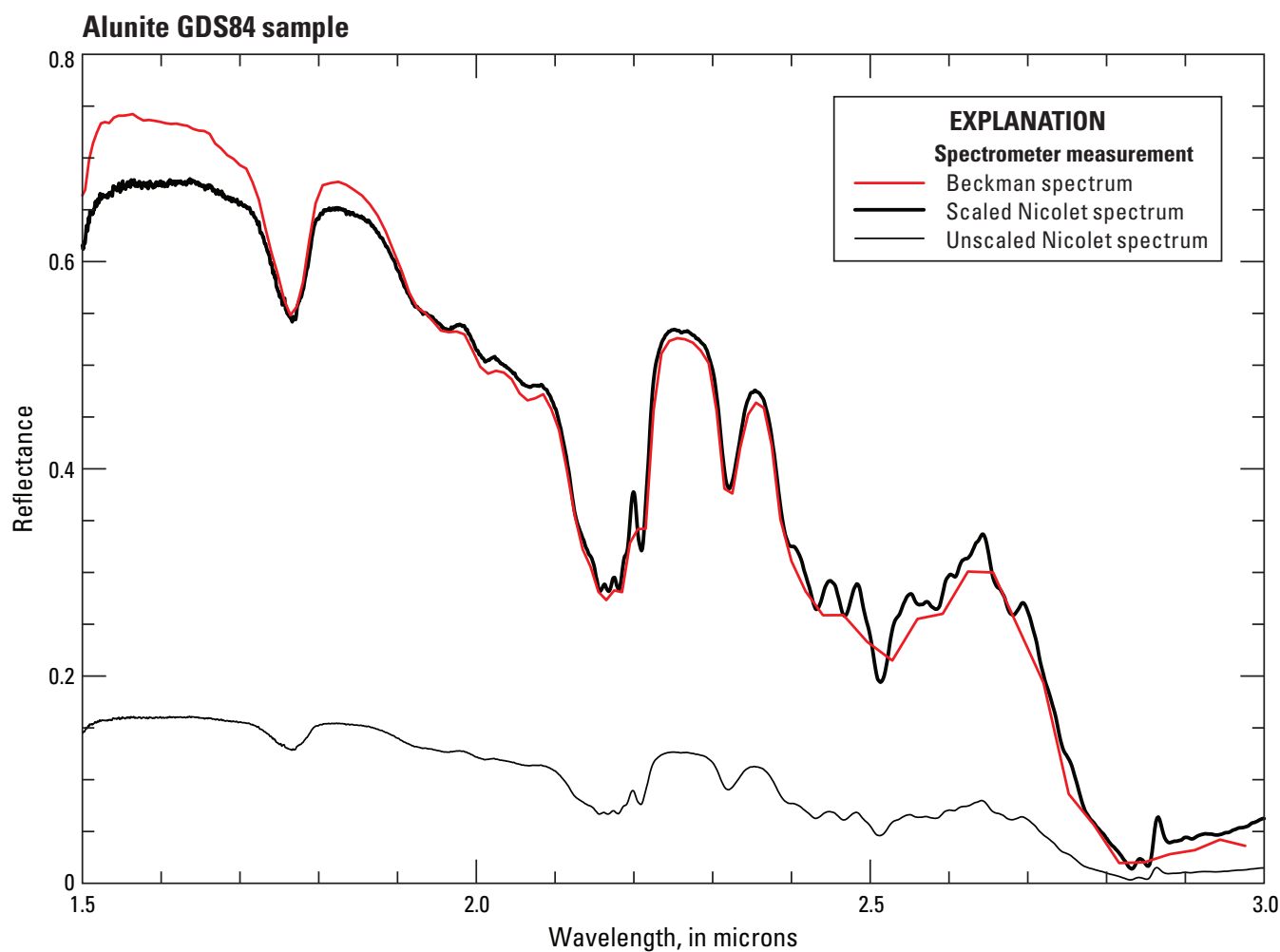

Figure 5. Comparison of a Nicolet measurement to a Beckman measurement of the same sample, Alunite GDS84. The unscaled Nicolet measurement shows lower reflectance level and weaker absorption features because of the light loss effect. The scaled Nicolet spectrum was matched to the Beckman reflectance at 1.935 microns.

\section{Organic Contaminants}

Contamination of the sample by organic materials at low concentrations can leave residual spectral features (fig. 6). This usually affects only spectral features in the region near $3.4 \mu \mathrm{m}$. However, organic compounds can be absorbing at other wavelengths, especially in the ultraviolet. Organic compounds can darken the spectrum from the ultraviolet to infrared, lowering reflectance levels. In reflectance, these effects are nonlinear, with a small abundance of dark material having a large effect on reflectance (Clark, 1983, 1999). Users of the library wanting to derive optical constants or to conduct other quantitative work should consult the sample documentation and evaluate the data for what effect contaminants would have on an analysis.

\section{Order Sorting Filter Artifacts}

In a small number of the nearly 1,200 ASD spectra in the library, we have observed an artifact in the wavelength region of 0.582 to $0.628 \mu \mathrm{m}$ (fig. 7). The artifact appears to be related to glint of light from the lamp off of shiny mineral grains and is attributed to the order sorting (separating) filter within the spectrometer. For a few spectra with significant artifacts, the data in the wavelength region of the artifact were set to the
SPECPR deleted channel value of $-1.23 \times 10^{34}$ (for a list of those spectra, see Appendix 1). When the artifact is small or minimal, no advisement of the artifact's presence is made in the metadata description and the channels in the artifact region are provided as measured. When using library spectra measured with an ASD spectrometer, users should be mindful of the potential effect of the artifact on spectra.

\section{Wavelength and Bandpass Values}

The wavelength accuracy of our custom-modified Beckman spectrometer was checked using holmium oxide filters in the visible and using the positions of known mineral absorptions in the near infrared. In particular, we developed pyrophyllite as a wavelength standard because it has many narrow absorption features (Clark and others, 1990b). The positions of the absorptions have been checked, using the same pyrophyllite standard, on three FTIR spectrometers. In general, the wavelength accuracy is on the order of $0.0005 \mu \mathrm{m}(0.5 \mathrm{~nm})$ in the NIR and $0.0002 \mu \mathrm{m}(0.2 \mathrm{~nm})$ in the visible, always a small fraction of the bandpass. Wavelength accuracy for the Beckman instrument is further discussed in Clark and others (1990a). 


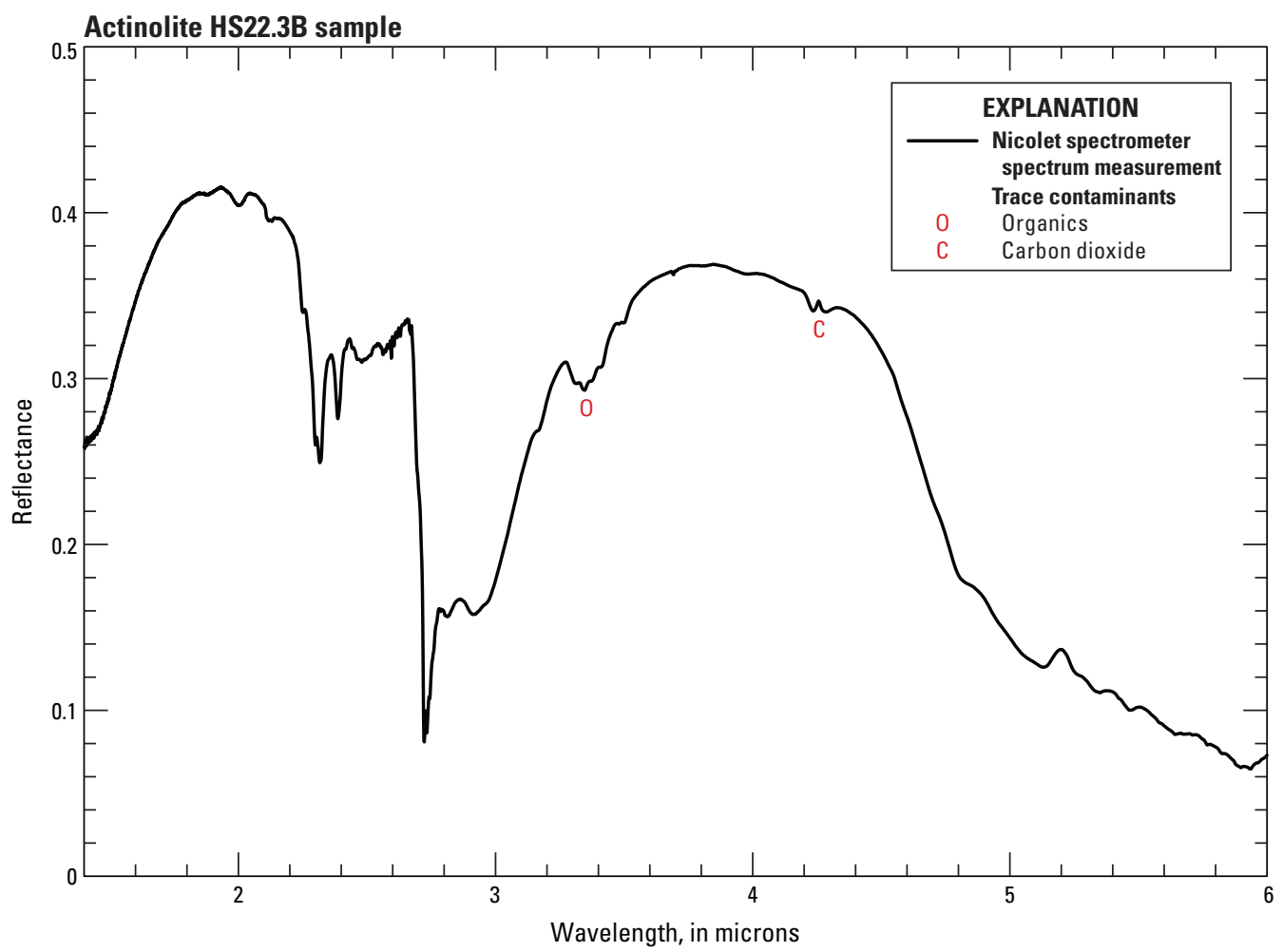

Figure 6. Organic contaminant in a spectrum measured on the Nicolet spectrometer.

The wavelength position and bandpass performance of the ASD spectrometers were evaluated using wavelength calibration materials with narrow absorption features. The evaluation procedure involved the measurement of onepass transmission through individual reference materials: Standard Reference Material 2035 from the National Institute of Standards and Technology (Choquette and others, 1998) which is a rare-earth doped glass, a Corning Glass REE-doped glass (CG5121), and a thin Mylar plastic sheet. Because the absorption features of these materials are narrow, transmission measurements made on higher resolution spectrometers (those with finer sampling intervals and bandpasses) can be numerically convolved to coarser bandpass and compared to the ASD measurements.

Kokaly (2011) describes the process of convolving and comparing the narrow absorption features to estimate the average ASD bandpass for each detector range. We applied this procedure to compute bandpass values for the standard, hi-res, and hi-resNG models of the ASD spectrometers we used to collect spectra. Our spectrometers were routinely maintained and adjusted by the manufacturer. After each annual servicing, we evaluated the bandpass performance using the procedure described in Kokaly (2011). For each ASD model, average bandpass values were calculated for spectral features of the reference materials. These features are situated at different wavelength positions over the detector ranges. Over the wavelength range of the VNIR detector in the ASD spectrometers ( 0.35 to $1.0 \mu \mathrm{m})$, the bandpass varied, with the finest bandpass near the center of the wavelength range and coarser bandpass at both ends of the detector range (fig. 8). A quadratic function was fit to the average bandpass values of all the ASD spectrometers over the wavelength range of the VNIR detector (fig. 8). The fitted bandpass function has a minimum value of $3.4 \mathrm{~nm}$ at $0.696 \mu \mathrm{m}$ and reaches $8.7 \mathrm{~nm}$ at $0.35 \mu \mathrm{m}$ and $7.4 \mathrm{~nm}$ at $1.0 \mu \mathrm{m}$.

The SWIR I and II detectors of the ASD spectrometers did not have as much variation in average bandpass as the VNIR detector (fig. 8). Therefore, constant bandpass values, equal to the average bandpass across each detector range, were used for the SWIR I and II detectors in each spectrometer. For standard resolution ASD spectrometers (ASDFR) used in this study, the average bandpass values were $11.7 \mathrm{~nm}$, and $11.4 \mathrm{~nm}$, for the SWIR I and II detectors, respectively. The wavelength ranges specified for the SWIR I and II were 1.001-1.8, and $1.8-2.5 \mu \mathrm{m}$ respectively. A high resolution ASD FieldSpec3 model (ASDHR) was also used to measure materials in the laboratory. This instrument had average bandpass values of 8.8 and $8.9 \mathrm{~nm}$, for the SWIR I and II detectors, respectively. Our most recent ASD model, a FieldSpec4 high-resolution Next Generation (ASDNG), had average bandpass values of 6.3 and $5.6 \mathrm{~nm}$ for its SWIR I and II detectors, respectively.

After ASD bandpass performance was characterized, the center wavelength positions of absorption features in the measured standards were calculated and compared to convolved 
A. Order sorting filter artifacts in Analytical Spectral

Devices (ASD) spectrum of brushed aluminum

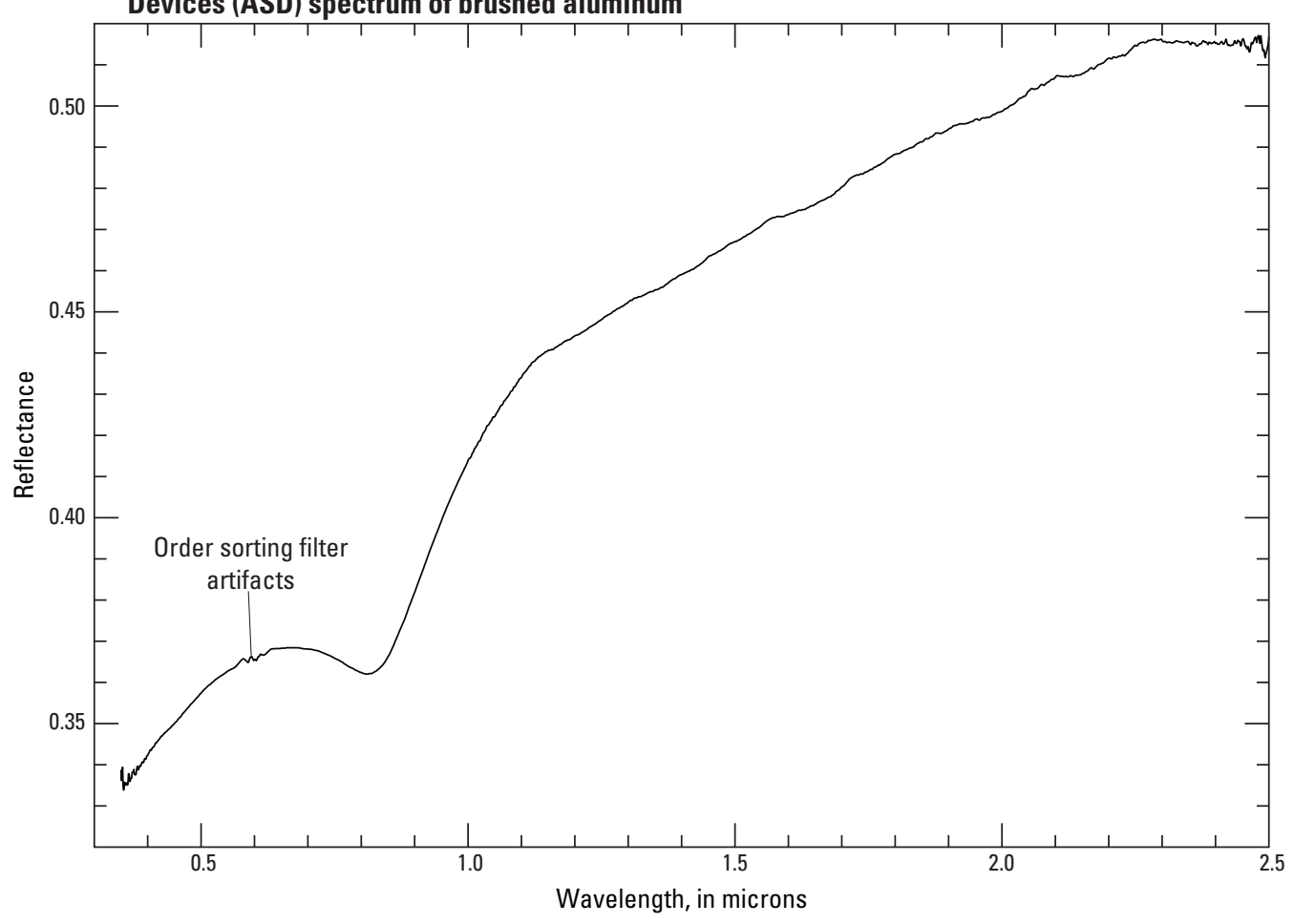

B. Order sorting filter artifacts in ASD spectra of minerals

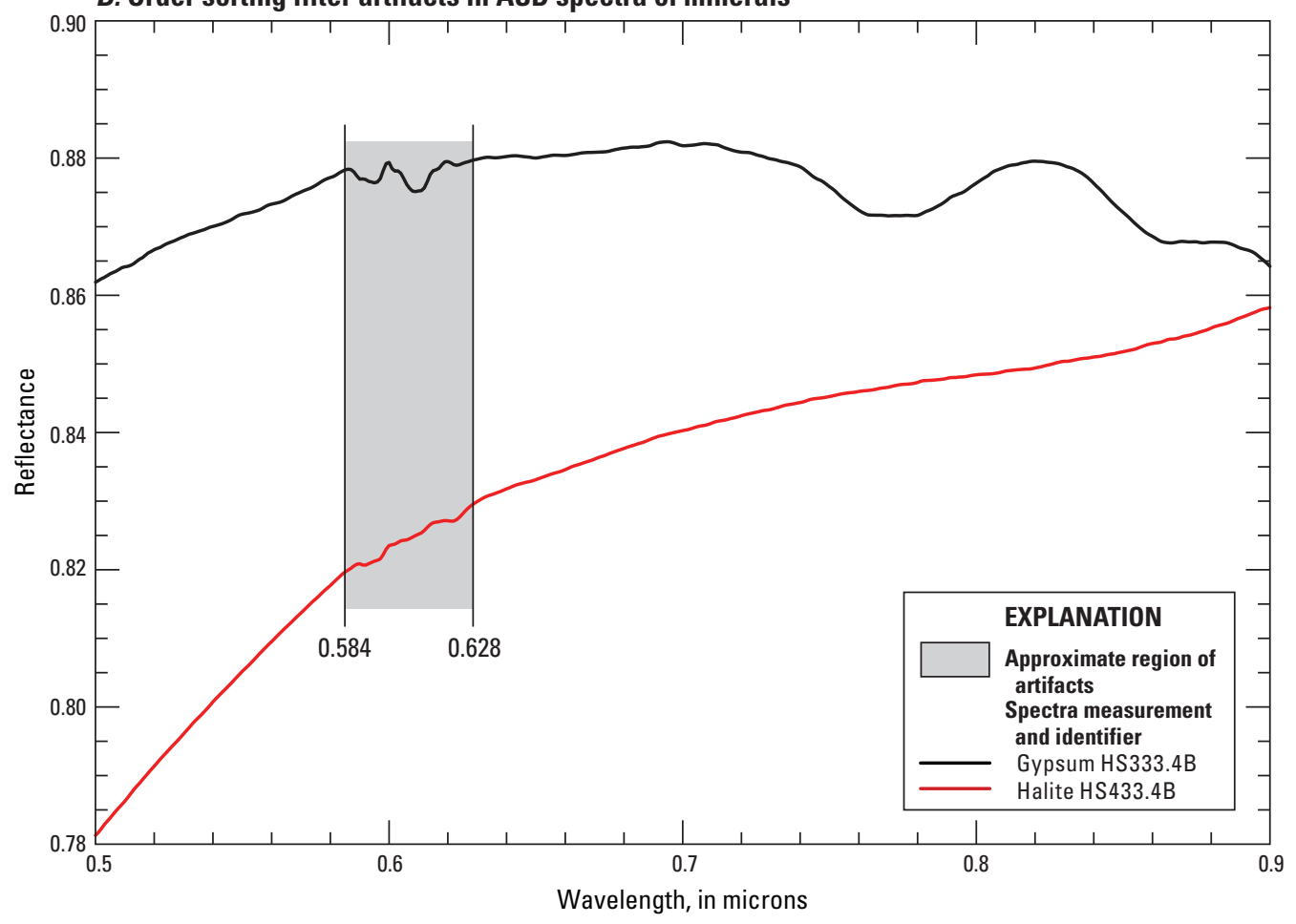

Figure 7. Order sorting filter artifacts in spectra measured with the Analytical Spectral Devices spectrometer. 


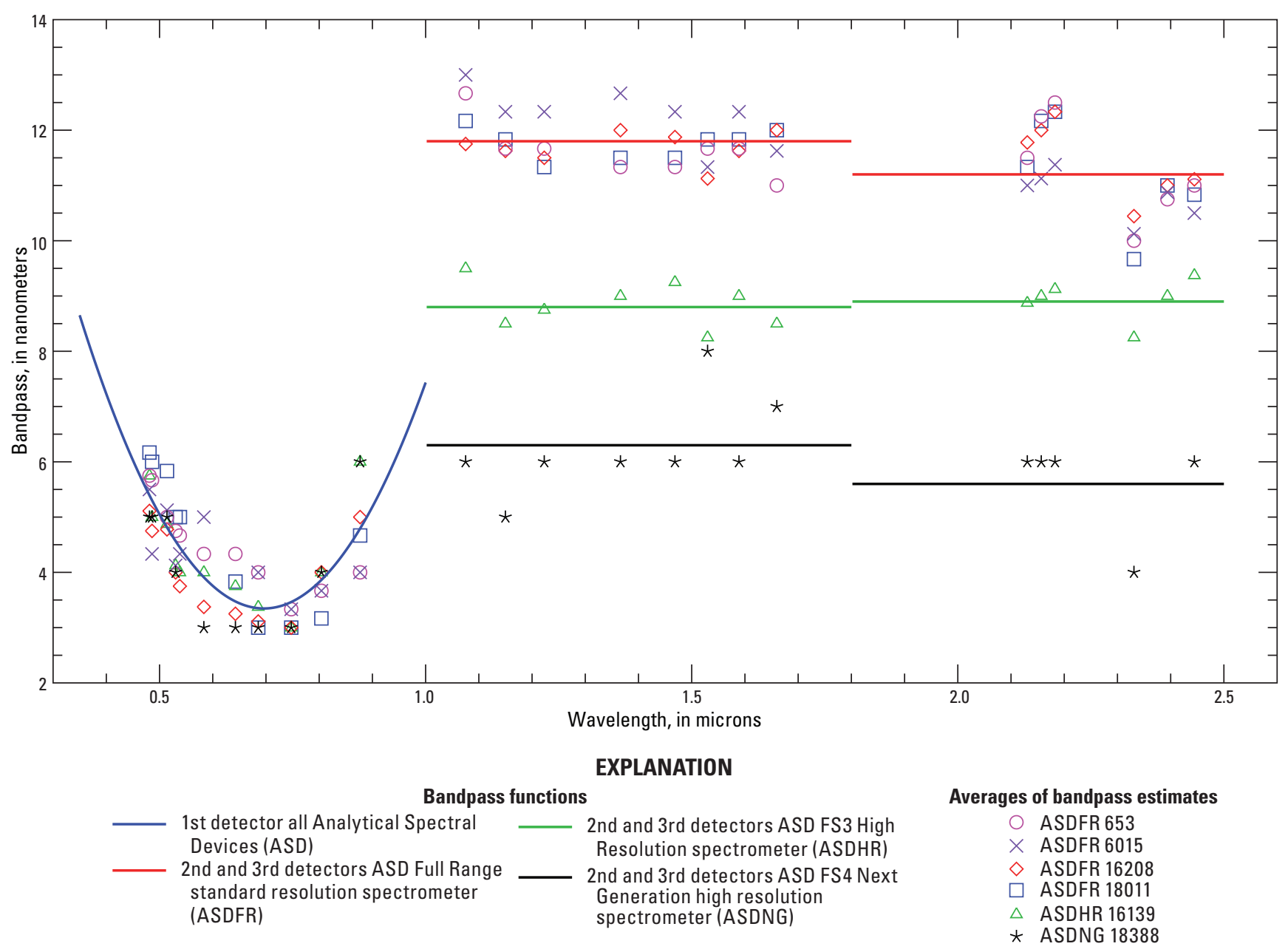

Figure 8. Analytical Spectral Devices spectrometer bandpass functions and evaluations.

reference spectra to check and correct for shifts in spectrometer wavelengths (Kokaly, 2011). If shifts were found, wavelength-corrected spectra were interpolated (using cubic spline interpolation) to the default ASD wavelength positions when they were incorported into the library. A transmission spectrum of the Mylar sheet used in the evaluations of ASD spectrometers is included in this release of the spectral library.

ASD spectra for all our spectrometer models are provided in the standard 2,151 channels reported by the manufacturer. These reported channels are at a uniform $1 \mathrm{~nm}$ sampling interval spanning 0.35 to $2.5 \mu \mathrm{m}$. The wavelength record containing the channel positions is included in the library (stored near the beginning of the splib07a file). Bandpass records for the various ASD models are included in the library and are also stored near the beginning of the splib07a file, following the ASD wavelength record.

The wavelength accuracy of an FTIR spectrometer is better than the bandwidth of the system. Annual tests conducted using transmission measurements of a polystyrene film standard indicate that the Nicolet 6700 FTIR spectrometer's wavelength is accurate to within $0.23 \mathrm{~cm}^{-1}$ at $3,060 \mathrm{~cm}^{-1}$, within $0.20 \mathrm{~cm}^{-1}$ at $1,601 \mathrm{~cm}^{-1}$, and within $0.08 \mathrm{~cm}^{-1}$ at $1,028 \mathrm{~cm}^{-1}$.
We also confirmed wavelength positions with our pyrophyllite standard (Clark and others, 1990b, 1993) and its many narrow absorption features, which were measured using three different FTIR spectrometers and our Beckman spectrometer and found to be consistent.

The wavelength calibration and bandpass determination for the NASA AVIRIS system was performed by the NASA Jet Propulsion Laboratory (JPL; Green and others, 1990, 1996).

In many cases for entries in the mineral chapter of the library, the same sample has been measured on multiple spectrometers. This allows us to compare the position of strong narrow features in spectra between measurements made by different spectrometers, where their wavelength coverage overlaps. During the evaluation of spectra included in this version of the library, we found discrepancies between some Beckman and ASD spectra for a handful of spectra. Because of our repeated, careful checking of the ASD spectrometer performance and observed consistency in the wavelength position of features across the various grain sizes of samples, the discrepancies were attributed to issues in some Beckman measurements. Appendix 1 lists the spectra where these discrepancies were observed. For these spectra, reflectance values 
were set to the SPECPR deleted channel value $\left(-1.23 \times 10^{34}\right)$ in wavelength regions of sharp features near $1.4 \mu \mathrm{m}$. In a few cases, Beckman spectra were removed from this release of the library because of the wavelength discrepancy.

\section{Data Precision}

Beckman spectra were collected with a desired SNR of at least 500 relative to unity reflectance. In practice, it would take too long to obtain such a signal-to-noise ratio in regions where the signal is low, so an upper limit to the integration time per channel was also specified with our Beckman spectrometer. Typically at the ends of the spectra (both short and long wavelength ends), the precision drops slightly. Refer to the error bars for each spectrum, if given, or examine the channel-to-channel noise to determine the precision at a given wavelength for any individual spectral channel. Compared to the Beckman, the ASD and Nicolet spectrometers typically have higher signal-to-noise ratios. Often, the Nicolet spectra do not have error bar data. Error bars can be estimated in the FTIR and ASD spectra without an accompanying error bar record by examining the channel-to-channel variations in reflectance.

\section{SPECPR Data Files}

The native form of the spectral library is a single data file of SPECPR format containing data records with the spectra and text records with the metadata (Clark, 1993). Files containing photographs of samples and field sites and other supporting images and figures are found in subfolders in the directory containing the splib07a file.

The splib07a release of the library was assembled using two spectral processing software packages: (1) SPECPR (Clark, 1993; Livo and Clark, 2014), and (2) the PRISM software (Kokaly, 2011). The SPECPR software is command line driven while the PRISM software is GUI (graphical user interface) based. Both software packages run on UNIX, LINUX, MicrosoftWindows, and Apple Macintosh OS computers. PRISM is easy to use and allows rapid, comprehensive data analysis. The SPECPR software is best used with its macroscripting capability.

PRISM, a set of Interactive Data Language (IDL ${ }^{\circledR}$; Harris Geospatial Solutions, formerly Exelis Visual Information Solutions, Inc., a subsidiary of Harris Corporation) programs, can be installed as a plug-in to the commercial software Environment for Visualizing Images (ENVI ${ }^{\odot}$; Harris Geospatial Solutions, formerly Exelis Visual Information Solutions, Inc., a subsidiary of Harris Corporation). PRISM works as plug-in on computers with a license for ENVI. Alternatively, a free program, the IDL virtual machine (IVM), can be installed in order to use PRISM. When installed, PRISM allows the user to list the contents of the splib07a spectral library file,
(1) plot spectra in the library, (2) view the supporting metadata descriptions and photographs, and (3) search the titles and associated metadata of the spectra to find user-defined keywords. In order to view the photographs and images linked to the metadata descriptions, the folders containing these photographs must be in the same directory as the splib07a file (see the File Names for Measured, Convolved and Resampled Spectra section of this report). SPECPR and PRISM have many additional functions for spectral feature analysis and spectral feature comparison.

A list of the records at the beginning of the splib07a SPECPR file is shown in table 2, illustrating the organization of the library records. The list shows the record number, title, length of the dataset (number of channels for data records; number of characters for text records), and the date of data acquisition. At the beginning of the file are text records describing the library and how to cite it (records 1 and 4). Both PRISM and SPECPR software can be used to view the README (record 4) and release notes (record 6) for the library. When the README record is viewed using the ViewSPECPR module of PRISM, an HTML-formatted version of this USGS report will be displayed in a Web-browser window, while SPECPR shows the text. Records containing the wavelength and bandpass data occur one time for each spectrometer, near the beginning of the file (records 18-89 in table 2).

The data record containing a spectrum is preceded by a text record, in HTML format, containing the sample metadata. These text records have the keyword "DESCRIPT" at the end of the their SPECPR titles. The information in these records is described in the Sample Documentation section of this report. The data record has a title containing a short sample name and a unique sample identifier number/code. At the end of each title are string identifiers with spectrometer and spectral purity codes, and a keyword indicating the measurement type (see the Spectrometer and Purity Codes and Keywords Indicating Measurement Type sections of this report). A record containing the error bars to the measurement, listed with the title "error bars to preceding," may follow the reference spectrum. If more than one spectrometer was used to make a measurement of a single sample or there are various grain size fractions of a sample, multiple spectra will be listed after the metadata DESCRIPT record. For example, see the data records 142-177 listed after DESCRIPT record 137 for the Actinolite HS22 sample in splib07a (see table 2).

In the spectral library, a value of $-1.23 \times 10^{34}$ is the SPECPR deleted channel value. In the SPECPR format, each spectrum can have its own unique group of channels set to this deleted channel value, in contrast to the ENVI.sli spectral library format which requires that bad bands pertain to all spectra stored in a library file. This flexibility in the SPECPR format allows us to customize the deleted channels for each spectrum based on instrument artifacts, low SNR, atmospheric contamination, and other factors observed in the spectrum. Because of the inherent floating point inaccuracies of single precision numbers, values in the range $-1.23001 \times 10^{34}$ to $-1.22999 \times 10^{34}$ should be considered deleted channels. 
Table 2. Listing of records at the beginning of the splib07a SPECPR file.

\begin{tabular}{|c|c|c|c|c|}
\hline $\begin{array}{l}\text { Record } \\
\text { number }\end{array}$ & \multicolumn{2}{|c|}{$\begin{array}{l}\text { Spectrum } \\
\text { title }\end{array}$} & $\begin{array}{l}\text { Number of channels or } \\
\text { characters, for data or text } \\
\text { records, respectively }\end{array}$ & $\begin{array}{l}\text { Date of acquisition } \\
\text { (present only for } \\
\text { data records) }\end{array}$ \\
\hline 1 & \multicolumn{2}{|c|}{ USGS Spectral Library Version 7 splib07a } & 550 & \\
\hline 2 & \multicolumn{2}{|c|}{$* * * * * * * * * * * * * * * * * * * * * * * * * * * * * * * * * * * * * * * * * * * *$} & 31 & \\
\hline 3 & \multicolumn{2}{|c|}{$* * * * * * * * * * * * * * * * * * * * * * * * * * * * * * * * * * * * * * * * * *$} & 31 & \\
\hline 4 & \multicolumn{2}{|c|}{ README SpectralLibrary Version 7 DESCRIPT } & 773 & \\
\hline 5 & \multicolumn{2}{|c|}{ 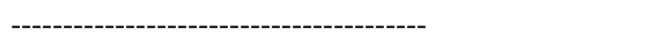 } & 31 & \\
\hline 6 & \multicolumn{2}{|c|}{ RELEASE NOTES Library Version 7 DESCRIPT } & 14,647 & \\
\hline 16 & \multicolumn{2}{|c|}{$* * * * * * * * * * * * * * * * * * * * * * * * * * * * * * * * * * * * * * * * * * * *$} & 31 & \\
\hline 17 & \multicolumn{2}{|c|}{$* * * * * * * * * * * * * * * * * * * * * * * * * * * * * * * * * * * * * * * * * * * *$} & 31 & \\
\hline 18 & \multicolumn{2}{|c|}{ Wavelengths BECK Beckman 0.2-3.0 microns } & 480 & $10 / 15 / 1985$ \\
\hline 20 & \multicolumn{2}{|c|}{ Bandpass (FWHM) BECK Beckman in microns } & 480 & $10 / 15 / 1985$ \\
\hline 22 & \multicolumn{2}{|c|}{-------------------------------------------- } & 31 & \\
\hline 23 & \multicolumn{2}{|c|}{ Wavelengths ASD $0.35-2.5$ microns $2151 \mathrm{ch}$} & 2,151 & $7 / 23 / 2016$ \\
\hline 29 & \multicolumn{2}{|c|}{ Bandpass (FWHM) ASDFR StandardResolution } & 2,151 & $7 / 23 / 2016$ \\
\hline 35 & \multicolumn{2}{|c|}{ Bandpass (FWHM) ASDHR High-Resolution } & 2,151 & $7 / 23 / 2016$ \\
\hline 41 & \multicolumn{2}{|c|}{ Bandpass (FWHM) ASDNG High-Res NextGen } & 2,151 & $7 / 23 / 2016$ \\
\hline 47 & \multicolumn{2}{|c|}{------------------------------------------- } & 31 & \\
\hline 48 & \multicolumn{2}{|c|}{ Wavelengths NIC4 Nicolet 1.12-216microns } & 4,595 & $6 / 5 / 2012$ \\
\hline 61 & \multicolumn{2}{|c|}{ Bandpass (FWHM) NIC4 Nicolet in microns } & 4,595 & $8 / 4 / 2005$ \\
\hline 74 & \multicolumn{2}{|c|}{ Wavenumber NIC4 Nicolet $8,900-46 \mathrm{~cm}^{\wedge}-1$} & 4,595 & $6 / 5 / 2012$ \\
\hline 87 & \multicolumn{2}{|c|}{---------------------------------------- } & 31 & \\
\hline 88 & \multicolumn{2}{|c|}{ Wavelengths AVIRIS 1996 0.37-2.5 microns } & 224 & $1 / 1 / 1996$ \\
\hline 89 & Bandpass (FWHM) AV & RIS 1996 in microns & 224 & $1 / 1 / 1996$ \\
\hline 90 & $* * * * * * * * * * * * * * * * * * *$ & $* * * * * * * * * * * * * * * * * * * * *$ & 31 & \\
\hline 91 & $* * * * * * * * * * * * * * * * * * *$ & $* * * * * * * * * * * * * * * * * * * * *$ & 31 & \\
\hline 92 & $* * * * * * * * * * * * * * * * * * *$ & $* * * * * * * * * * * * * * * * * * * *$ & 31 & \\
\hline 93 & Chapter M: Minerals & & 51 & \\
\hline 94 & ----------------------------- & ---------- & 31 & \\
\hline 95 & Acmite NMNH133746 & yroxene DESCRIPT & 5,227 & \\
\hline 99 & Acmite NMNH133746 & yroxene BECKa AREF & 480 & $3 / 23 / 1988$ \\
\hline 101 & error bars to preceding & & 480 & $3 / 23 / 1988$ \\
\hline 103 & 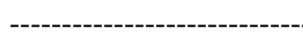 & ---------- & 31 & \\
\hline 104 & Actinolite HS116 & DESCRIPT & 6,014 & \\
\hline 108 & Actinolite HS116.1B & ASDFRb AREF & 2,151 & $2 / 13 / 2006$ \\
\hline 114 & Actinolite HS116.2B & ASDFRb AREF & 2,151 & $2 / 13 / 2006$ \\
\hline 120 & Actinolite HS116.3B & $\mathrm{BECKb} \mathrm{AREF}$ & 480 & 7/11/1991 \\
\hline 122 & error bars to preceding & & 480 & 7/11/1991 \\
\hline 124 & Actinolite HS116.3B & ASDFRb AREF & 2,151 & $2 / 13 / 2006$ \\
\hline 130 & Actinolite HS116.4B & ASDFRb AREF & 2,151 & $2 / 13 / 2006$ \\
\hline 136 & 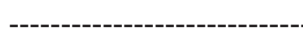 & -------- & 31 & \\
\hline 137 & Actinolite HS22 & DESCRIPT & 6,403 & \\
\hline 142 & Actinolite HS22.1B & ASDFRb AREF & 2,151 & $2 / 13 / 2006$ \\
\hline 148 & Actinolite HS22.2B & ASDFRb AREF & 2,151 & $2 / 13 / 2006$ \\
\hline 154 & Actinolite HS22.3B & BECKb AREF & 480 & $3 / 16 / 1987$ \\
\hline 156 & error bars to preceding & & 480 & $3 / 16 / 1987$ \\
\hline 158 & Actinolite HS22.3B & ASDFRb AREF & 2,151 & $2 / 13 / 2006$ \\
\hline 164 & Actinolite HS22.3B & NIC4bbb RREF & 4,595 & 7/6/1993 \\
\hline 177 & Actinolite HS22.4B & ASDFRb AREF & 2,151 & $2 / 13 / 2006$ \\
\hline 183 & ------------------------------' & ---------- & 31 & \\
\hline
\end{tabular}




\section{Oversampled and Convolved Versions of the USGS Spectral Library}

The intent of the spectral library is to serve as a reference for spectral analysis by providing a set of spectral standards for materials of known composition. Comparison of spectral data is best done when the wavelength sampling intervals and bandpasses of reference spectra and the observed spectra being analyzed are equitable. The SPECPR (Clark, 1993) and PRISM (Kokaly, 2011) programs have tools for convolving the spectra in the library to the wavelength sampling interval and bandpass values output by most spectrometers. To improve results when using convolution functions in PRISM and SPECPR, an oversampled version of the library was computed using simple cubic-spline interpolation. This oversampled version, with the filename splib07b, has a finer sampling interval for Beckman, and AVIRIS spectra (thus, data for these spectrometers have a greater number of channels in splib07b compared to splib07a).

To facilitate broader use, the spectra in the library have been convolved to selected spectrometer and imaging spectrometer characteristics: to ASDFR for field and laboratory applications, to AVIRIS-Classic, Hyperspectral Mapper (HyMap $^{\mathrm{TM}}$ ), and Hyperion for terrestrial applications, and to CRISM, M3 (pronounced M-cubed; Moon Mineralogy Mapper), and VIMS for planetary applications.

The spectra in the library have also been resampled to the spectral response functions of broadband multispectral sensors covering the 0.4 to 2.5 micron range, including: Advanced Spaceborne Thermal Emission and Reflection Radiometer (ASTER) VNIR and SWIR instruments, Landsat-8 OLI (Operational Land Imager), Sentinel-2 MultiSpectral Instrument (MSI), and WorldView3 Multispectral and SWIR instruments. See the File Names for Measured, Convolved and Resampled Spectra section of this report for the names and locations of these convolved libraries.

\section{Spectra and Metadata in Other Formats}

This release of the USGS spectral library includes alternate formats for accessing the spectra and metadata, including: American Standard Code for Information Interchange (ASCII) text files of each spectrum, metadata in HTML formatted ASCII text files for each sample, and Graphics Interchange Format (GIF) images of plots of spectra. See the File Names for Measured, Convolved and Resampled Spectra section of this report for the locations of these files. The ASCII data files have one column of values in scientific notation, containing the data value (reflectance or transmittance), and a number of rows equal to the number of channels in the spectrometer. Wavelength values corresponding to channels in the spectrometers used in this library are stored in separate single column text files. ASCII files containing the error bar metric, the standard deviation of the mean, will be present in a subdirectory if it was computed for the spectrum. In the ASCII listings, deleted channels also referred to as deleted points or bad bands are indicated by a value of $-1.23 \times 10^{34}$. The deleted points are not universal to every spectrum measured with a particular spectrometer. Each spectrum may have a unique set of spectrometer channels set to the deleted point value, dependent on a number of factors, including measurement conditions, sensor settings, and reflectance level.

GIF images of spectral plots have plot ranges that ensure the spectrum is framed well and shows spectral detail, customized for each spectrum. Error bars are not plotted. Each plot shows the spectrum title, SPECPR filename and record number, and associated wavelength record. For Nicolet spectra, GIF images of spectral data plotted compared to wavenumber $\left(\mathrm{cm}^{-1}\right)$ are also provided.

\section{Internet Access to the Spectral Library}

The library is provided in SPECPR and generic formats on digital media. It can be accessed and downloaded from https://speclab.cr.usgs.gov/spectral-lib.html.

\section{File Names for Measured, Convolved, and Resampled Spectra}

The data in this library are provided through the website https://speclab.cr.usgs.gov/spectral-lib.html and archived on the USGS ScienceBase data system (https://dx.doi. org/10.5066/F7RR1WDJ). The library is provided in SPECPR, ASCII, GIF, and HTML-formatted text files. The following list specifies the names and contents of SPECPR files provided in this version of the library (and related naming convention for ASCII data and GIF plots):

splib07a- the measured spectra with native spectrometer characteristics, stored in SPECPR format with linked metadata descriptions of spectra and samples. Spectra were measured on the Beckman, ASD, Nicolet, and AVIRIS spectrometers. The data are provided with their original sampling positions (wavelengths) and bandpass values. The prefix "splib07a_" is at the beginning of the ASCII and GIF files pertaining to the measured spectra.

splib07b - spectra interpolated to higher number of channels, stored in SPECPR format with linked metadata descriptions of spectra and samples. The results from using spectral convolution to convert measurements to other spectrometer characteristics can be improved by oversampling (increasing sample density). Thus, splib07b is an oversampled version of the library, computed using simple cubic-spline interpolation to produce spectra with fine sampling interval (therefore a higher number of channels) for Beckman and AVIRIS measurements. The spectra in this version of the library are the data used to create the convolved and 
resampled versions of the library. The prefix "splib07b " is at the beginning of the ASCII and GIF files pertaining to the oversampled spectra.

s07_ASD — spectra convolved to ASD FullRange standard resolution characteristics, stored in SPECPR format with linked metadata descriptions of spectra and samples. The standard, manufacturer reported wavelengths of the ASD spectrometers operated by the USGS were used $(2,151$ channels with wavelength positions starting at $350 \mathrm{~nm}$ and increasing in $1 \mathrm{~nm}$ increments). The bandpass values of each channel were determined by comparing measurements of reference materials made on ASD spectrometers in comparison to measurements made of the same materials on higher resolution spectrometers (the procedure is described in Kokaly, 2011, and discussed in Kokaly and Skidmore, 2015). The prefix "s07ASD_" is at the beginning of the ASCII and GIF files pertaining to this spectrometer.

s07_AV\#\# - spectra convolved to AVIRIS-Classic, where \#\# is a two character code indicating the year in which the spectra characteristics were derived. The SPECPR files include the spectra and linked metadata descriptions of spectra and samples. For example, s07_AV95 indicates AVIRIS-Classic 1995 spectral characteristics. The prefix "s07_AV95_" is at the beginning of the ASCII and GIF files pertaining to this spectrometer. The wavelength and bandpass values for the 224 channels of the AVIRIS data were determined by NASA/JPL and provided with the image data. This version of the library provides convolved spectra for AVIRIS-Classic for the years 1995-2001, 2005-2006, and 2009-2014.

s07_HY07-spectra convolved to HyMap 2007. The oversampled spectra in splib07b were convolved to HyMap with spectral characteristics determined in the year 2007 (wavelength and bandpass values for the 124 channels provided with HyMap data by HyVista Corp). The wavelength and bandpass values were validated by comparing USGS measurements of reference materials made using the HyMap 2007 imaging spectrometer to measurements of the same materials made on higher resolution laboratory spectrometers (the procedure is described in Kokaly, 2011, and discussed in Kokaly and others, 2013). The prefix "s07_HY07_" is at the beginning of the ASCII and GIF files pertaining to this spectrometer.

s07_HY14-spectra convolved to HyMap 2014). The oversampled spectra in splib07b were convolved to HyMap with spectral characteristics determined in the year 2014 (wavelength and bandpass values for the 126 channels provided with HyMap data by HyVista Corp). The wavelength and bandpass values were validated by comparing USGS measurements of reference materials made using the HyMap 2014 imaging spectrometer to measurements of the same materials made on higher resolution laboratory spectrometers (the procedure is described in Kokaly,
2011, and discussed in Kokaly and others, 2013). The prefix "s07_HY014_" is at the beginning of the ASCII and GIF files pertaining to this spectrometer.

s07HYPRN — spectra convolved to Hyperion. The oversampled spectra in splib07b were convolved to Hyperion's average spectral characteristics (accessed January 10, 2017, at https://eo1.usgs.gov/sensors/hyperioncoverage). The prefix "s07HYPRN_" is at the beginning of the ASCII and GIF files pertaining to this spectrometer.

s07CRSMg — spectra convolved to the global mapping mode of the Mars Reconnaissance Orbiter spacecraft's CRISM instrument. Spectral characteristics were determined by Murchie and others (2009), wavelength and bandpass values for the 72 channels. The prefix "s07CRSMg_" is at the beginning of the ASCII and GIF files pertaining to this spectrometer.

s07CRSMj - spectra convolved to the targeted mode, with joined visible and infrared sensors, of the Mars Reconnaissance Orbiter spacecraft's CRISM instrument. Spectral characteristics were determined by Murchie and others (2009), wavelength and bandpass values for the 489 channels. The prefix "s07CRSMj_" is at the beginning of the ASCII and GIF files pertaining to this spectrometer.

s07_M3t - spectra convolved to the target mode of the $\mathrm{M}^{3}$ spectrometer. Spectral characteristics were determined by Green and others (2011), wavelength and bandpass values for the 256 channels. The prefix "s07_M3t_" is at the beginning of the ASCII and GIF files pertaining to this spectrometer.

s07_VIMS - spectra convolved to Cassini spacecraft's VIMS instrument. VIMS spectral characteristics were determined by Clark and others (2016), wavelength and bandpass values for the 352 channels. The prefix "s07_VIMS_" is at the beginning of the ASCII and GIF files pertaining to this spectrometer.

s07ASTER - spectra resampled to response functions of ASTER. The spectral response functions for this sensor's nine bands covering the visible through shortwave infrared wavelengths came from NASA (ASTER instrument characteristics accessed January 3, 2017, at https://asterweb.jpl. nasa.gov/content/01_mission/03_instrument/archive/vnir.txt and https://asterweb.jpl.nasa.gov/content/01_mission/03 instrument/archive/swir.txt). The prefix "s07ASTER_" is at the beginning of the ASCII and GIF files pertaining to this spectrometer.

s07LSAT8 - spectra resampled to response functions of Landsat-8's OLI sensor. The spectral response functions for this sensor's seven bands covering the visible through shortwave infrared wavelengths came from spectral libraries included as part of the ENVI 5.3 software release. The ENVI data were compared to values of the pre-launch sensor response functions (Barsi and others, 2014; spreadsheet 
with values was accessed December 27, 2016, at http://landsat.gsfc.nasa.gov/?p=5779) and found to be identical. The prefix "s07LSAT8_" is at the beginning of the ASCII and GIF files pertaining to this spectrometer.

s07SNTL2 - spectra resampled to response functions of Sentinel-2's MSI sensor. The spectral response functions for this sensor's 13 bands covering the visible through shortwave infrared wavelengths came from the European Space Agency (ESA, 2015). The prefix "s07SNTL2_" is at the beginning of the ASCII and GIF files pertaining to this spectrometer.

s07_WV3 - spectra resampled to response functions of WorldView3. The spectral response functions for this sensor's 16 bands covering the visible through shortwave infrared wavelengths came from DigitalGlobe (2016). The prefix "s07_WV3_" is at the beginning of the ASCII and GIF files pertaining to this spectrometer.

Also provided with the spectra are folders containing information linked to from the metadata descriptions in the SPECPR files, including:

README: contains a HTML version of this USGS Data Series publication and a separate file with a HTML version of the release notes (Appendix 1).

photo_images: contains full resolution images of photos of samples and field sites.

photo_thumbs: contains low-resolution thumbnail versions of photos of samples and field sites.

In addition to the SPECPR files that contain the spectra and linked metadata descriptions, a separate folder (named "alternativeSPECPR") contains SPECPR files that store just the spectral data, without the associated metadata descriptions of the spectra and samples. These files have consistent data record numbering in all files.

\section{Acknowledgements}

This release of the spectral library was funded by the USGS Mineral Resources Program (MRP).

In measuring spectra, the authors have received the support of a variety of funding sources from within the USGS. External funds have also supported data compilation and documentation efforts, including: NASA Cassini VIMS (R.N. Clark, science team member), the NASA Cassini Data Analysis Program (R.N. Clark, Principal Investigator), the NASA Mars Reconnaissance Orbiter, Compact Reconnaissance Imaging Spectrometer for Mars (CRISM) team (R.N. Clark, CoInvestigator), and the NASA Mars Global Surveyor Thermal Emission Spectrometer Team (R.N. Clark, Co-Investigator).

This version draws from earlier releases of the spectral library, to which there have been many contributors. Steve Sutley and Richard Wise were authors on the last version (Clark and others, 2007), contributing XRD analysis and laboratory spectral measurements, respectively. We are indebted to J.S. Huebner and Judy Konnert of the USGS for their support in analyzing the X-ray diffraction data on minerals for version 4 of the library. We thank the late Norma Vergo for many of the earlier X-ray analyses. Norma's attention to detail has certainly made this spectral library a quality product, and we miss her.

A spectral library needs quality samples. We are indebted to Charlie Alpers, Jim Crowley, the late Skip Cunningham, Bernard Hubbard, Fred Kruse, the late Jim Post, Jack Salisbury, Richard V. Morris, and Roger Stoffregen for donating excellent samples. Thanks to the British Museum and the National Museum of Natural History for mineral samples. We thank Trude King, Brad Dalton, and Barnaby Rockwell for contributing samples and spectra. Vegetation spectra can be difficult to acquire in the field, even under the best weather conditions. We thank Laurie Morath, Susan Goodman, Michael Beland, David Heckman, Brett Patton, Sarai Piazza, and the late Ralph Root, to name just a few field companions that have assisted with these measurements.

Without these people providing superb analysis and unnamed colleagues we have interacted with at scientific conferences and meetings who provided valuable feedback, this library would not have been possible.

The late Robert R. McDougal, a kind colleague and field partner for nearly 20 years, assisted with the measurement and compilation of spectra and preparation of metadata for this release of the library.

\section{References Cited (in this document and in metadata)}

Akhundov, Y.A., Mamedov, K.S., and Belov, N.V., 1961, Crystal structure of clintonite: Journal of Structural Chemistry, v. 19, p. 244.

Akizuki, M., and Konno, Y., 1985, Crystal structure of the orthorhombic growth sector of stilbite: American Mineralogist, v. 70, p. 814-821.

Bailey, S.W., 1984, Reviews in mineralogy, Volume 13Micas: Mineralogical Society America, 584 p.

Bailey, S.W., 1988, Chlorites, structures and crystal chemistry: Reviews in Mineralogy and Geochemistry, v. 19, no. 1, p. $347-403$.

Baldridge, A.M., Hook, S.J., Grove, C.I., and Rivera, G., 2009, The ASTER spectral library version 2.0. Remote Sensing of Environment, v. 113, no. 4, p. 711-715.

Barsi, J. A., Lee, K., Kvaran, G., Markham, B.L., and Pedelty, J.A., 2014, The spectral response of the Landsat-8 operational land imager: Remote Sensing, v. 6 no. 10, p. $10232-10251$. 
Borg, I.Y., and Smith, D.K., 1969, Calculated X-ray powder patterns for silicate minerals: Geological Society of America, v. 122, p. 296-315.

Brindley, G.W., and Brown, G., 1980, Crystal structures of clay minerals and their identification: London, Mineralogical Society Monograph No. 5.

Chatterjee, N.D., 1974, Synthesis and upper thermal stability limit of 2M-margarite: Contributions to Mineralogy and Petrology, v. 34, p. 288-303.

Choquette, S.J., Travis, J.C., and Duewer, D.L., 1998, SRM 2035-A rare earth oxide glass for the wavelength calibration of near infrared dispersive and Fourier transform spectrometers, in Conference on optical diagnostic methods for inorganic transmission materials: SPIE's International Symposium on Optical Science, Engineering, and Instrumentation International Society for Optics and Photonics, p. 94-102.

Christensen, P.R., Bandfield, J.L., Hamilton, V.E., Howard, D.A., Lane, M.D., Piatek, J.L., Ruff, S.W., and Stefanov, W.L, 2000, A thermal emission spectral library of rockforming minerals: Journal of Geophysical Research Planets, v. $105,9,735$ p.

Clark, R.N., 1980, A large scale interactive one dimensional array processing system: Publications of the Astronomical Society of the Pacific, v. 92, p. 221-224.

Clark, R.N., 1981, The spectral reflectance of water-mineral mixtures at low temperatures: Journal of Geophysical Research, v. 86, p. 3074-3086.

Clark, R.N., 1983, Spectral properties of mixtures of montmorillonite and dark carbon grains-Implications for remote sensing minerals containing chemically and physically adsorbed water: Journal of Geophysical Research, v. 88, p. 10635-10644.

Clark, R.N., 1993, SPECtrum Processing Routines user's manual version 3 (program SPECPR): U.S. Geological Survey Open File Report 93-595, 210 p., software online, accessed November 3, 2016, at http://speclab.cr.usgs.gov/software.html.

Clark, R.N., 1999, Chapter 1-Spectroscopy of rocks and minerals and principles of spectroscopy: Manual of Remote Sensing, (A.N. Rencz, ed.), New York, John Wiley and Sons, p. 3-58.

Clark, R.N., and Lucey, P.G., 1984, Spectral properties of iceparticulate mixtures and implications for remote sensing, IIntimate mixtures: Journal of Geophysical Research, v. 89, p. 6341-6348.

Clark, R.N., King, T.V.V., and Gorelick, N.S., 1987, Automatic continuum analysis of reflectance spectra: Proceedings of the Third Airborne Imaging Spectrometer Data Analysis Workshop, JPL Publication 87-30, p. 138-142.
Clark, R.N., Gallagher, A.J., and Swayze, G.A., 1990a, Material absorption band depth mapping of imaging spectrometer data using a complete band shape least-squares fit with library reference spectra: Proceedings of the Second Airborne Visible/Infrared Imaging Spectrometer (AVIRIS) Workshop, JPL Publication 90-54, p. 176-186.

Clark, R.N., King, T.V.V., Klejwa, M., Swayze, G., and Vergo, N., 1990b, High spectral resolution reflectance spectroscopy of minerals: Journal of Geophysical Research, v. 95, p. 12653-12680.

Clark, R.N., Swayze, G.A., Gallagher, A., King, T.V.V., and Calvin, W.M., 1993, The U.S. Geological Survey, digital spectral library: version 1: 0.2 to 3.0 microns: U.S. Geological Survey Open-File Report 93-592, 1,340 p.

Clark, R.N., Swayze, G.A., Livo, K.E., Kokaly, R.F., Sutley, S. J., Dalton, J.B., McDougal, R.R., and Gent, C.A., 2003a, Imaging spectroscopy: Earth and planetary remote sensing with the USGS Tetracorder and expert systems: Journal of Geophysical Research, v. 108(E12), no. 5131, p. 5-1 to 5-44, accessed November 3, 2016, http://dx.doi. org/10.1029/2002JE001847.

Clark, R.N., Swayze, G.A., Livo, K.E., Kokaly, R.F., King, T.V.V., Dalton, J.B., Vance, J.S., Rockwell, B.W., Hoefen, T., and McDougal, R.R., 2003b, Surface reflectance calibration of terrestrial imaging spectroscopy data: a tutorial using AVIRIS: AVIRIS Workshop Proceedings, p. 43-63, accessed November 3, 2016, at http://speclab.cr.usgs.gov/ PAPERS.calibration.tutorial.

Clark, R.N., Swayze, G.A., Wise, Richard, Livo, K.E., Hoefen, T.M., Kokaly, R.F., and Sutley, S.J., 2003c, USGS digital spectral library splib05a: U.S. Geological Survey Open-File Report 2003-395, accessed November 3, 2016, at http://pubs.usgs.gov/of/2003/ofr-03-395.

Clark, R.N., Swayze, G.A., Wise, R.A, Livo, K.E., Hoefen, T.M., Kokaly, R.F., Sutley, S.J.,2007, USGS digital spectral library splib06a: U.S. Geological Survey Digital Data Series 231.

Clark, R.N., R.H. Brown, and D. M. Lytle, 2016, The VIMS Wavelength and Radiometric Calibration, NASA Planetary Data System, accessed December 23, 2016, at http://atmos. nmsu.edu/data_and_services/atmospheres_data/Cassini/ vims.html

Crowley, J.K., 1991, Visible and near-infrared (0.4-2.5 micron) reflectance spectra of playa evaporite minerals: Journal of Geophysical Research, v. 96, no. B10, p. 16231-16240.

Deer, W.H., Howie, R.A., and Zussman, J., 1962, Rockforming minerals, Volume 1 -Ortho-and ring silicates: London, Longmons, $333 \mathrm{p}$. 
Deer, W.H., Howie, R.A., and Zussman, J., 1963, Rockforming minerals, Volume 4-Framework silicates, London, Longmans, $435 \mathrm{p}$.

Despain, D.G., 1990, Yellowstone vegetation, consequences of environment and history in a natural setting: Boulder, Colo., Roberts Rinehart Publishing, 239 p.

DigitalGlobe, 2016, WorldView-3 Relative Radiometric Response Curves, Attachment A to Radiometric Use of WorldView-3 Imagery, accessed January 3, 2017, at https:// dg-cms-uploads-production.s3.amazonaws.com/uploads/document/file/208/WV03_technote_raduse_AttachmentA.pdf.

ESA (European Space Agency), 2015, Sentinel-2A Spectral Response Functions (S2A-SRF) COPE-GSEG-EOPGTN-15-0007, accessed December 28, 2016, at https:// earth.esa.int/documents/247904/685211/Sentinel2A+MSI+Spectral+Responses.

Fleischer, M., 1980, Glossary of mineral species: Tucson, Ariz., Mineralogical Record, 192 p.

Fleischer, M., and Mandarino, J.A., 1995, Glossary of mineral species 1995: Tucson, Ariz., The Mineralogical Record Inc., $280 \mathrm{p}$.

Ghose, S., Wan, C., and Clark, J.R., 1978, Ulexite, $\mathrm{NaCaB}_{5} \mathrm{O}_{6}(\mathrm{OH}) 6.5 \mathrm{H}_{2} \mathrm{O}$; Structure refinement, polyanion configuration, hydrogen bonding, and fiber optics: American Mineralogist, v. 63, no. 1-2, p. 160-171.

Green, R.O., Conel, J.E., Carrere, V., Bruegge, C.J., Margolis, J.S., Rast, M., and Hoover, G., 1990, Determination of the in-flight spectral and radiometric characteristics of the Airborne Visible/Infrared Imaging Spectrometer (AVIRIS): Proceedings of the Second Airborne Visible/Infrared Imaging Spectrometer (AVIRIS) Workshop, JPL Publication 90-54, p. 15-22.

Green, R.O., Roberts, D.A., and Conel, J.A., 1996, Summaries of the sixth annual JPL airborne earth science workshop: JPL Publication 96-4, p. 135-146.

Green, R. O., C. Pieters, P. Mouroulis, M. Eastwood, J. Boardman, T. Glavich1, S Besse, D. Barr, B. Buratti, D. Cate, A. Chatterjee, R. Clark, L. Cheek, J. Combe, D. Dhingra, V. Essandoh, S. Geier, R. Green, V. Haemmerle, J. Head, L. Hoveland, S. Hyman, P. Isaacson, R. Klima, T. Koch, G. Kramer, K. Lee, S. Lundeen, E. Malaret, T. McCord, J. Mustard, J. Nettles, N. Petro, K. Plourde, C. Racho, J. Rodriquez, C. Runyon, G. Sellar, C. Smith, H. Sobel, M. Staid, J. Sunshine, L Taylor, S. Tompkins, H. Tseng, G. Vane, P. Varanasi, M. White, and D. Wilson, 2011. The Moon Mineralogy Mapper (M3) Imaging Spectrometer for Lunar Science: Instrument Description, Calibration, OnOrbit Measurements, Science Data Calibration and Initial On-Orbit Validation, J. of Geophysical Research E00G19, doi:10.1029/2011JE003797.
Hapke, B., 1981, Bidirectional reflectance spectroscopy, 1-Theory: Journal of Geophysical Research, v. 86, p. 3039-3054.

Hawthorne, F.C., 1981, Crystal chemistry of the amphiboles, in Veblen, D.R., ed., Amphiboles: Reviews of Mineralogy, v. 9A, p. 1-102.

Hoefen, T., Clark, R.N., Bandfield, J.L., Smith, M.D., Pearl, J.C., and Christensen, P.R., 2003, Discovery of olivine in the Nili Fossae region of Mars: Science, v. 302, p. 627-630.

Holland, T.B.J., 1979, Experimental determination of the reaction paragonite $=$ jadeite + kyanite $+\mathrm{H}_{2} \mathrm{O}$, and internally consistent thermodynamic data for part of the system $\mathrm{Na}_{2} \mathrm{O}-\mathrm{Al}_{2} \mathrm{O}_{3}-\mathrm{SiO}_{2}-\mathrm{H}_{2} \mathrm{O}$, with applications to eclogites and blueschists: Contributions to Mineralogy and Petrology, v. 68 , p. $293-301$.

Hunt, G.R., 1977, Spectral signatures of particulate minerals, in the visible and near-infrared: Geophysics, v. 42, p. 501-513.

Hunt, G.R., 1979, Near-infrared (1.3-2.4 $\mu \mathrm{m})$ spectra of alteration minerals - Potential for use in remote sensing: Geophysics, v. 44, p. 1974-1986.

Hunt, G. R., 1980, Modifications of integrating sphere accessory to allow spectroscopic measurements of horizontal surfaces from above: Applied Optics, v. 19, p. 1746-1747.

Hunt, G.R., 1982, Spectroscopic properties of rocks and minerals, in Carmichael, R.S., ed., Handbook of physical properties of rocks - Volume I: Boca Raton, Fla., CRC Press, p. 295-385.

Hunt, G.R., and Salisbury, J.W., 1970, Visible and near infrared spectra of minerals and rocks, I-Silicate minerals: Modern Geology, v. 1, p. 283-300.

Hunt, G.R., and Salisbury, J.W., 1971, Visible and near infrared spectra of minerals and rocks, II-Carbonates: Modern Geology, v. 2, p. 23-30.

Hunt, G.R., Salisbury, J.W., and Lenhoff, C.J., 1971a, Visible and near infrared spectra of minerals and rocks, III-Oxides and hydroxides: Modern Geology, v. 2, p. 195-205.

Hunt, G.R., Salisbury, J.W., and Lenhoff, C.J., 1971b, Visible and near infrared spectra of minerals and rocks, IVSulphides and sulphates: Modern Geology, v. 3, p. 1-14.

Hunt, G.R., Salisbury, J.W., and Lenhoff, C.J., 1972, Visible and near infrared spectra of minerals and rocks, VHalides, arsenates, vanadates, and borates: Modern Geology, v. 3, p. 121-132.

Hunt, G.R., Salisbury, J.W., and Lenhoff, C.J., 1973, Visible and near infrared spectra of minerals and rocks, VIAdditional silicates: Modern Geology, v. 4, p. 85-106. 
Joint Committee on Powder Diffraction Standards (JCPDS), 1982, Powder diffraction files: International Center for Diffraction Standards, Swathmore, Pennsylvania.

Karnieli, A., Kokaly, R.F., West, N., and Clark, R.N.,2001, Remote sensing of biological soil crusts, in Biological Soil Crusts: Structure, Function and Management, Springer, p. 431-455.

Klein, C., and Hurlbut, Jr., C.S., 1999, Manual of mineralogy, 21st edition, New York, John Wiley, 681 p.

Kokaly, R.F., 2001, Investigating a physical basis for spectroscopic estimates of leaf nitrogen concentration: Remote Sensing of Environment, v. 75, p. 153-16, accessed November 3, 2016, at http://dx.doi.org/10.1016/S00344257(00)00163-2.

Kokaly, R.F., 2011, PRISM_Processing routines in IDL for spectroscopic measurements (installation manual and user's guide, version 1.0): U.S. Geological Survey Open-File Report 2011-1155, 432 p, accessed November 3, 2016, at http://pubs.usgs.gov/of/2011/1155/.

Kokaly, R.F., and Clark, R.N., 1999, Spectroscopic determination of leaf biochemistry using band-depth analysis of absorption features and stepwise multiple linear regression: Remote Sensing of Environment, v. 67, p. 267-287, accessed November 3, 2016, at http://dx.doi.org/10.1016/ S0034-4257(98)00084-4.

Kokaly, R.F., Despain, D.G., Clark, R.N., and Livo, K.E., 2003, Mapping vegetation in Yellowstone National Park using spectral feature analysis of AVIRIS data: Remote Sensing of Environment, v. 84, p. 437-456, accessed November 3, 2016, at http://dx.doi.org/10.1016/S00344257(02)00133-5.

Kokaly, R.F., Rockwell, B.W., Haire, S.L., and King, T.V.V., 2007, Characterization of postfire surface cover, soils, and burn severity at the Cerro Grande Fire, New Mexico, using hyperspectral and multispectral remote sensing: Remote Sensing of Environment, v. 106, p. 305-325, accessed November 3, 2016, at http://dx.doi.org/10.1016/j. rse.2006.08.006.

Kokaly, R.F., Asner, G., Ollinger, S., Martin, M., and Wessman, C., 2009, Characterizing canopy biochemistry from imaging spectroscopy and its application to ecosystem studies: Remote Sensing of Environment, v. 113(supplement 1), p. S78-S91, accessed November 3, 2016, at http://dx.doi. org/10.1016/j.rse.2008.10.018.

Kokaly, R.F., Couvillion, B.R., Holloway, J.M., Roberts, D.A., Ustin, Peterson, S.H., Khanna, S., and Piazza, S.C., 2013a, Spectroscopic remote sensing of the distribution and persistence of oil from the Deepwater Horizon spill in Barataria Bay marshes: Remote Sensing of Environment, v. 129, p. 210-230, accessed November 3, 2016, at http://dx.doi. org/10.1016/j.rse.2012.10.028.
Kokaly, R.F., King, T.V.V., and Hoefen, T.M., 2013b, Surface mineral maps of Afghanistan derived from HyMap imaging spectrometer data, version 2: U.S. Geological Survey Data Series 787, 29 p., accessed November 3, 2016, at http:// pubs.usgs.gov/ds/787/.

Kokaly, R.F., and Skidmore, A.K., 2015, Plant phenolics and absorption features in vegetation reflectance spectra near $1.66 \mu \mathrm{m}$ : International Journal of Applied Earth Observation and Geoinformation, v. 43, p. 55-83, accessed November 3, 2016, at http://dx.doi.org/10.1016/j.jag.2015.01.010.

Kroll, H., 1983, Lattice parameters and determinative methods for plagioclase and ternary feldspars - Feldspar Mineralogy (2d ed.): Reviews in Mineralogy, Mineralogical Society of America, v. 2, p. 101-119.

Livo, K.E., Kruse, F.A., Clark, R.N., Kokaly, R.F., and Shanks, W.C., III, 2007, Hydrothermally altered rock and hot spring deposits at Yellowstone National Park characterized using Airborne Visible Infrared Spectroscopy data: Integrated Geoscience Studies in the Greater Yellowstone Area-Volcanic, tectonic, and hydrothermal processes in Morgan, Lisa, ed., The Yellowstone geoecosystem: U.S. Geological Survey Professional Paper 1717-O, p. 493-507, accessed November 3, 2016, at http://pubs.usgs.gov/ pp/1717/downloads/pdf/p17170.pdf.

Livo, K.E., and Clark, R.N., 2014, The Tetracorder user guide: version 4.4: U.S. Geological Survey Open-File Report 2013-1300, 51 p., accessed November 3, 2016, at http:// dx.doi.org/10.3133/ofr20131300.

Matthews, H.E., lrvine, W.M., Friberg, P., Brown, R.D., Godfrey, P.D., 1984, Chemical evolution and the origin of life Solid State 15N NMR Investigations: Origins of Life, v. 14, p. 243-250.

Murchie, S. L., F. P. Seelos, C. D. Hash, D. C. Humm, E. Malaret, J. A. McGovern, T. H. Choo, K. D. Seelos, D. L. Buczkowski, M. F. Morgan, O. S. Barnouin-Jha, H. Nair, H. W. Taylor, G. W. Patterson, C. A. Harvel, J. F. Mustard, R. E. Arvidson, P. McGuire, M. D. Smith, M. J. Wolff, T. N. Titus, J.-P. Bibring, and F. Poulet (2009), The Compact Reconnaissance Imaging Spectrometer for Mars investigation and data set from the Mars Reconnaissance Orbiter's primary science phase, J. Geophys. Res., 114(CRISM special issue), doi:10.1029/2009JE003344.

Nicodemus, F.E., Richmond, J.C., Hsia, J.J., Ginsberg, I.W., and Limperis, T., 1977, Geometrical considerations and nomenclature for reflectance: Washington, D.C., National Bureau of Standards Report NBS MN-160, 52 p.

Parker, R.L., 1962, Isomorphous substitution in natural and synthetic alunite: American Mineralogist, v. 47, p. 127-136.

Ryuji, Tada, and Azuma, Iijima, 1983, Petrology and diagenetic changes of Neogene siliceous rocks in northern Japan: Journal of Sedimentary Research, v. 53, p. 911-930. 
Salisbury, J.W., Walter, L.S., Vergo, N., and D’Aria, D.M., 1991, Infrared (2.1-25 microns) spectra of minerals: Baltimore, Md., The Johns Hopkins University Press, 267 p.

Schaepman-Strub, G., Schaepman, M.E., Painter, T.H., Dangel, S., Martonchik, J.V., 2006, Reflectance quantities in optical remote sensing-definitions and case studies: Remote Sensing of Environment, v. 103, p. 27-42.

Srodon, J., and Eberl, D.D., 1984, Illite: Reviews in Mineralogy and Geochemistry, v. 13, no. 1, p. 495-544.

Swayze, G.A., 1997, The hydrothermal and structural history of the Cuprite mining district, southwestern Nevada-An integrated geological and geophysical approach: Boulder, Colo., University of Colorado Ph.D. thesis, 399 p.

Swayze, G.A., Smith, K.S., Clark, R.N., Sutley, S.J., Pearson, R.N., Rust, G.S., Vance, J.S., Hageman, P.L., Briggs, P.H., Meier, A.L., Singleton, M.J., and Roth, S., 2000, Using imaging spectroscopy to map acidic mine waste: Environmental Science and Technology, v. 34, no. 1, p. 47-54.

Swayze, G.A., Clark, R.N., Goetz, A.F.H., Chrien, T.G., and Gorelick, N.S., 2003, Effects of spectrometer bandpass, sampling, and signal-to-noise ratio on spectral identification using the Tetracorder algorithm: Journal of Geophysical Research, v. 108, no. E9, 5105, 30 p., accessed November 3, 2016, at http://dx.doi.org/10.1029/2002JE001975.
Swayze, G.A., Kokaly, R.F., Higgins, C.T., Clinkenbeard, J.P., Clark, R.N., Lowers, H.A., and Sutley, S.J., 2009, Mapping potentially asbestos-bearing rocks using imaging spectroscopy: Geology, v. 37, p. 763-766., accessed November 3, 2016, at http://dx.doi.org/10.1130/G30114A.1.

Swayze, G.A., Clark, R.N., Goetz, A.F., Livo, K.E., Breit, G.N., Kruse, F.A., Sutley, S.J., Snee, L.W., Lowers, H.A., Post, J.L., Stoffregen, R.E., and Ashley, R.P., 2014, Mapping advanced argillic alteration at Cuprite, Nevada, using imaging spectroscopy: Economic Geology, v. 109, p. 1179-1221.

Szymanski, J.T., 1985, International Centre for Diffraction Data: Joint Committee on Powder Diffraction Standards, \#18-698, 22-827, and 5-417.

Takeuchi, Y., 1965, Structures of brittle micas: Proceedings of the 13th national conference 1964Madison, Wisc.: Pergamon Press, Oxford, p. 1-25.

Tschernich, R.W., 1992, Zeolites of the world: Phoenix, Ariz., Geoscience Press, Inc., 563 p.

White, W.B., 1967, Diffuse-reflectance spectra of rare earth oxides: Applied Spectroscopy, v. 21, p. 167-171.

Wright, T.L., 1968, X-ray and optical study of alkali feldspars, II-An X-ray method for determining the composition and structural state from measurements of 20 values for three reflections: American Mineralogist, v. 53, p. 88-104.

Publishing support provided by:
Denver Publishing Service Center
For more information concerning this publication, contact:
Center Director, USGS Crustal Geophysics and Geochemistry
Science Center
Box 25046, Mail Stop 964
Denver, C0 80225-0046
http://crustal.usgs.gov 

Appendixes 


\section{Appendix 1. Release Notes Spectral Library Version 7}

The splib07a library includes almost all spectra from the previous splib06a version along with more than 1,000 new measurements. Spectra of grain size series of minerals have been added in addition to spectra of minerals bearing rare earth elements (REEs) and Lanthanide series compounds. Spectra of vermiculite insulation from the four main historical sources (Louisa, Virginia; Enoree, South Carolina; Libby, Montana; and Palabora, South Africa) were added. Also added is a new collection of powdered paint pigments spanning the range of classical artisanal colors. Compared to the previous version, this release adds field spectra of mixed vegetation plots in the Louisiana saltmarshes. Leaf level and plant level spectra of single species from the Louisiana saltmarsh and California chaparral have been added. Spectra of oil emulsions, oil residues, and oil-contaminated marsh plants from the Deepwater Horizon oil spill are included. The spectra of biochemical constituents of plants have been added to a new chapter along with spectra of more than 200 other organic compounds.

Itemized release notes for USGS Spectral Library Version 7 (splib07a), including changes made for spectra and samples that were in the previous release (splib06a):

I. Before using a spectrum, read its metadata description. The contents of some sample descriptions have been been changed to include new information about samples or to correct errors in previous releases.

II. Values of $-1.23 \mathrm{e}+34$ in data records indicate a "deleted channel," also known as a "bad band."

III. Spectrometer codes have been updated in this release of the spectral library, version 7, compared to the previous releases (splib06a and earlier).

New spectrometer codes:

BECK $=$ Beckman spectrophotometer (0.2 to 3.0 microns), replaces old code W1R1B

NIC4 = Nicolet FTIR spectrometer (data ranges from 1.12 to 216 microns with 4 inverse-cm resolution), replaces old codes W2R4N, W5R4N, and W9R4N

ASDFR = ASD Full Range standard resolution spectrometer (0.35 to 2.5 microns), replaces old code W1R1F

ASDHR = ASD FS3 High Resolution spectrometer ( 0.35 to 2.5 microns), a new spectrometer code

ASDNG $=$ ASD FS4 Next Generation high resolution spectrometer ( 0.35 to 2.5 microns), a new spectrometer code

AVIRIS $=$ AVIRIS imaging spectrometer ( 0.35 to 2.5 microns), replaces old code W1R1A

IV. The correction for the Spectralon ${ }^{\mathrm{TM}}$ white reference plate has been updated in splib07a, improving the conversion to absolute reflectance for ASD spectra in the wavelength region from 0.350 to 0.613 microns.

V. Spectral purity codes have been updated in this release of the spectral library, version 7, compared to the previous releases (splib06a and earlier). If you intend to use a spectrum for a particular purpose, check the spectral purity code and read the metadata description to be sure it is appropriate for your needs.

VI. Nicolet spectra were converted to a single 4595 channel wavelength set, compared to the two wavelength records used in splib06a for Nicolet spectra (of 3325 and 4208 channels).

VII. Spectra removed from library version 7 :

1. Beckman spectra removed because of wavelength shifts:

i. Carnallite HS430.3B W1R1Ba AREF

ii. Chlorite HS179.3B W1R1Bb AREF

iii. Chromite HS281.3B W1R1Bb AREF

iv. Chrysocolla HS297.3B W1R1Bb AREF

v. Heulandite NMNH84534 W1R1Ba AREF

vi. $\quad$ Natrolite+Zeolite HS168.3B W1R1Bb AREF

2. Beckman spectra removed because of poor signal-to-noise ratio:

i. $\quad$ Dry_Long_Grass AV87-2 brown W1R1Ba AREF

ii. $\quad$ Fir_Tree IH91-2 W1R1Ba AREF

3. Removed because the sample has too many contaminants to be representative of a single mineral or simple mixture (spectra measured on all spectrometers were removed):

i. Holmquistite HS291

ii. Mizzonite HS350

iii. Mizzonite HS351

iv. Nickeline HS264 
v. Orthoclase HS13.3B

vi. Riebeckite HS326

vii. $\quad$ Rutile HS137

viii. $\quad$ Sillimanite HS186

VIII. Spectra with data values that were edited:

1. Beckman spectra that were edited to set deleted channel values because of anomalies and in areas of strong features that showed wavelength shift compared to other measurements of the same sample:

i. $\quad$ Anthophyllite HS286.3B = channels $1.365-1.433$ microns

ii. $\quad$ Illite GDS4 = channels 1.3635-1.4335 microns

iii. $\quad$ Lepidolite HS167.3B = channels $1.3635-1.4335$ microns

iv. $\quad$ Microcline HS103.3B = channels 2.0 - 3.1 microns

v. Montmorillonite STx-1 = channels $2.05-3.1$ microns

vi. Muscovite HS146.3B = channels $1.3935-1.4385$ microns and at 0.4091 microns

vii. Stilbite HS482.3B = channels $0.7-1.5$ microns

viii. Vermiculite WS681 $=$ channels $1.3-1.5$ microns

ix. Chabazite+Thom+Wair HS193.3B = channels 0.8590-1.5985 microns

2. Nicolet spectra that were edited to set deleted channel values in areas at the end of the wavelength coverage:

i. $\quad$ Almandine WS479 $=$ channels $>180.0$ microns

ii. Alunite GDS82 Na82 = channels $<1.6$ microns

iii. Copiapite GDS21 = channels $<1.41$ microns

iv. Diaspore HS416.3B $=$ channels $<1.58$ microns

v. Ilmenite HS231.3B = channels $<2.4$ microns

vi. Jadeite $\mathrm{HS} 343.3 \mathrm{~B}=$ channels $<1.8$ microns

vii. Magnetite HS78.3B $=$ channels $>132.0$ microns

viii. Microcline $\mathrm{HS107.3 \textrm {B }}=$ channels $>132.0$ microns

ix. Microcline HS108.3B $=$ channels $>132.0$ microns

x. $\quad$ Microcline HS82.3B $=$ channels $>172.8$ microns

xi. Muscovite HS146.3B $=$ channels $>168.0$ microns

xii. Muscovite HS24.3B $=$ channels $>168.0$ microns

xiii. Olivine GDS70. $\mathrm{a}=$ channels $<1.356$ and $>140.0$ microns

xiv. Olivine GDS70. $b=$ channels $>148.0$ microns

xv. Olivine GDS70. $\mathrm{c}=$ channels $>148.0$ microns

xvi. Olivine GDS70. $\mathrm{d}=$ channels $>148.0$ microns

xvii. Olivine GDS70.e $=$ channels $>148.0$ microns

xviii. Olivine HS285.4B $=$ channels $<1.356$ and $>24.92$ microns

xix. Olivine KI3054 = channels $>148.0$ microns

xx. Olivine KI3188 = channels $>148.0$ microns

xxi. Olivine KI3189 = channels $>148.0$ microns

xxii. Olivine KI3377 = channels $>148.0$ microns

xxiii. Olivine KI4143 $=$ channels $<2.079$ and $>148.0$ microns

xxiv. Orthoclase NMNH142137 $=$ channels $<1.97$ microns

xxv. Pigeonite HS199.3B $=$ channels $<1.9$ microns

xxvi. Polyhalite NMNH92669- $4=$ channels $<1.7$ microns

xxvii. Pyrite GDS483.c $=$ channels $>148.0$ microns

xxviii. Pyrophyllite PYS1A $=$ channels $>186.0$ microns

xxix. Rhodonite NMNHC6148 $=$ channels $>186.0$ microns

xxx. Sanidine GDS19 $=$ channels $<2.1$ microns

xxxi. Sanidine NMNH103200 $=$ channels $<2.1$ microns

xxxii. Sauconite GDS135 = channels $<1.7$ microns

xxxiii. Sodium Bicarbonate GDS55 $=$ channels $>24.92$ microns

xxxiv. Spessartine HS112.3B $=$ channels $<1.7$ microns

xxxv. Spessartine NMNH14143 $=$ channels $>186.0$ microns

xxxvi. Spessartine WS481 $=$ channels $<2.1$ microns

xxxvii. Stilbite HS482.3B $=$ channels $>186.0$ microns

xxxviii. Sulfur GDS94 $=$ channels $<2.1$ microns 
xxxix. Syngenite GDS139 = channels $<1.59$ microns

xl. Thenardite GDS146 = channels $<1.6$ microns

xli. Tincalconite GDS142 = channels $>186.0$ microns

xlii. $\quad$ Ulexite GDS138 = channels $<1.55$ microns

xliii. Wollastonite HS348.3B $=$ channels $<2.4$ microns

3. ASD spectra that were edited to set deleted channel values in the wavelength region of the order sorting filter artifact ( 0.584 to 0.628 microns):

i. Arsenopyrite HS262 =.4B grain size fraction

ii. Axinite HS342 $=.1 \mathrm{~B}$, and $.2 \mathrm{~B}$ grain size fractions

iii. Magnetite HS195 =.4B grain size fraction

iv. Stilbite HS482 Zeolite $=.1 \mathrm{~B}, .2 \mathrm{~B}, .3 \mathrm{~B}$, and $.4 \mathrm{~B}$ grain size fractions

$\mathrm{v}$. Thenardite HS450 =.4B grain size fraction

vi. Vesuvianite HS446 Idocras $\quad=.1 \mathrm{~B}, .2 \mathrm{~B}, .3 \mathrm{~B}$, and $.4 \mathrm{~B}$ grain size fractions

vii. Wollastonite $\mathrm{HS} 348.4 \mathrm{~B}=.4 \mathrm{~B}$ grain size fraction

IX. Samples and spectra that were moved from chapter M (minerals) to chapter S (mixtures):

1. Clinozoisite HS299 = moved to ClinozoisiteEpidote HS299

2. Cordierite HS346 = moved to Cordierite-QtzMus HS346

3. Covellite HS477 = moved to Covellite-Pyrite HS477

4. Magnesite+Hydroma HS47 = moved to Magnesite+Hydromag HS47

5. Mordenite+Clinopt GDS $151=$ moved to Mordenite+Clinopt. GDS151

6. Natrolite+Zeolite HS168 = moved to Natrolite+Zeolite HS168

X. Samples with significant title changes:

1. Ammonio-Jarosite SCR-NHJ W1R1Ba AREF had incorrect sample identification number, now Ammonio-Jarosite SCF-NHJ BECKa AREF

2. Albite GDS30 had an incorrect sample identification number, now Albite NMNHC5390

XI. Mineral and mineral mixture samples with new ASD (hi-resNG) spectra:

1. Alunite HS295.3B

2. Alunite RES-9 Summitv (400C)

3. Antigorite NMNH96917.b 165um

4. Antigorite NMNH96917.a $>250$

5. Aragonite GDS1073

6. Calcite WS272

7. Chalcedony CU91-6A

8. Chrysotile HS323.1B

9. Clinochlore GDS158 Flagstaff

10. Dickite NMNH106242

11. Dolomite HS102.1B

12. Dolomite HS102.3B

13. Dolomite HS102.4B

14. Epidote GDS26.a 75-200um

15. Epidote GDS26.b $<75 \mathrm{um}$

16. Gypsum HS333.3B (Selenite)

17. Halloysite NMNH106237

18. Hectorite SHCa-1

19. Illite GDS4 (Marblehead)

20. Illite GDS4.2 (Marblehead)

21. Illite IMt-1.a

22. Illite IMt-1.b $<2$ um

23. Jarosite GDS635 Na Cyprus

24. Jarosite GDS636 K Pena $<325 \mathrm{um}$

25. Jarosite GDS732 K 200CSyn6hr

26. Kaolinite CM9

27. Kaolinite KGa-1 (wxl)

28. Kaolinite KGa-2 (pxl) 
29. Montmorillonite SAz-1

30. Montmorillonite SWy-1

31. Muscovite GDS113 Ruby

32. Muscovite GDS113a Ruby

33. Muscovite GDS116 Tanzania

34. Muscovite GDS116a Tanzania

35. Nontronite NG-1.a

36. Pyrophyllite PYS1A $>250$ um

37. Pyrophyllite PYS1A $<850 u m$

38. Pyrophyllite PYS1A $<5$ um

39. Siderite HS271.3B

40. Talc GDS23

41. Topaz HS184.1B

42. Topaz HS184.3B

43. Topaz HS184.4B

44. Alun.33+Kaol.33+Musc.33 AMX2

45. Alunite.5+MuscCU91-250A AMX4

46. Alunite $0.5+\mathrm{Kaol} / \mathrm{KGa}-1 \mathrm{AMX} 3$

47. Calc.25+Dolo.25+Ca-Mont AMX7

48. Calc.25+Dolo.25+Na-Mon AMX18

49. Calcite+.33Muscov AMX5 Ruby

50. Calcite.5+.Ca-Mont.5 AMX6

51. Calcite.5+.Na-Mont.5 AMX43

52. Calcite.5+Dolomite.5 AMX8

53. Calcite. $33+$ Ca-Mont.67 AMX19

54. Calcite.33+Na-Mont.67 AMX44

55. Calcite.7+Kaolin-wxl.3 AMX9

56. Calcite.80+Mont_Swy-1 GDS212

57. Calcite.80wt+Kaol_CM9 GDS213

58. Chlorite+Muscovite CU93-65A

59. Dolomite.5+Ca-Mont.5 AMX10

60. Dolomite.5+Na-Mont.5 AMX21

61. Kaol+Muscov_intimate CU93-5C

62. Kaol.5+MuscCU91-250A AMX13

63. Kaol_Wxl+0.5Musc_Ruby AMX12

64. Kaolwxl.75+Alun_HS295 AMX14

65. Muscov+Jaros CU93-314 coatng

66. Muscovite CU91-250A med Al

67. Muscovite-medhi-Al CU91-252D

68. Pyrophyl.25+wxlKaol.75 AMX17

69. Pyrophyl.50+Ca-Mont.50 AMX16

XII. Mineral and mineral mixture samples with new ASD (standard resolution) spectra of grain size fractions:

1. Actinolite HS116

2. Actinolite HS22

3. Actinolite HS315

4. Albite HS66 Plagioclase

5. Albite HS143 Plagioclase

6. Albite HS324 Plagioclase

7. Allanite HS293

8. Almandine HS114

9. Alunite HS295

10. Andesine HS142

11. Andradite HS111

12. Anorthite HS349

13. Anthophyllite HS286 
14. Arsenopyrite HS262

15. Axinite $\mathrm{HS} 342$

16. Beryl HS180

17. Bronzite HS9

18. Brookite HS443

19. Brucite HS247

20. Bytownite HS105

21. Carnallite HS430

22. Cassiterite HS279

23. Celestite HS251

24. Chalcopyrite HS431

25. Chlorite HS179

26. Chromite HS281

27. Chrysocolla HS297

28. Corundum HS283

29. Cummingtonite HS294

30. Cuprite HS127

31. Datolite HS442

32. Diaspore HS416

33. Diopside HS15

34. Diopside HS317

35. Gibbsite HS423

36. Glauconite HS 313

37. Glaucophane HS426

38. Gypsum HS333

39. Halite HS433

40. Hedenbergite HS10

41. Hematite HS45

42. Hornblende HS16

43. Hornblende HS177

44. Ilmenite HS231

45. Jadeite HS343

46. Kieserite KIEDE1

47. Knebelite HS419

48. Labradorite HS17

49. Lazurite HS418

50. Lepidolite HS167

51. Magnetite HS195

52. Magnetite HS78

53. Malachite HS254

54. Microcline HS103 Feldspar

55. Microcline HS151 Feldspar

56. Monazite HS255

57. Monticellite HS339

58. Muscovite HS146

59. Natrolite HS169 Zeolite

60. Nepheline HS19

61. Nephrite HS296

62. Olivine HS285

63. Olivine HS420

64. Perthite HS415

65. Phlogopite HS23

66. Pigeonite HS199

67. Prehnite GDS613

68. Psilomelane HS139

69. Pyrite GDS483 
70. Pyrolusite HS138

71. Pyroxene HS119

72. Pyrrhotite HS269

73. Quartz HS32

74. Rhodochrosite HS338

75. Richterite HS336 Amphibole

76. Serpentine HS318

77. Serpentine HS8

78. Siderite HS271

79. Smaragdite HS290 Amphibole

80. Sphalerite HS136

81. Spodumene HS210

82. Staurolite HS188

83. Stilbite HS482 Zeolite

84. Strontianite HS272

85. Talc HS21

86. Thenardite HS450

87. Topaz HS184

88. Tremolite HS18

89. Ulexite HS441

90. Uralite HS345

91. Vesuvianite HS446

92. Witherite HS273

93. Wollastonite HS348

94. Zoisite HS347

95. Clinozoisite-Epidote HS299

96. Cordierite-Quartz-Muscovite HS346

97. Covellite-Pyrite HS477

98. Magnesite+Hydromagnesite HS47

99. Natrolite+Zeolite HS168

100. Talc + Clinochlore HS327

101. Zincite+Franklinite HS147 


\section{Appendix 2. List of Abbreviations}

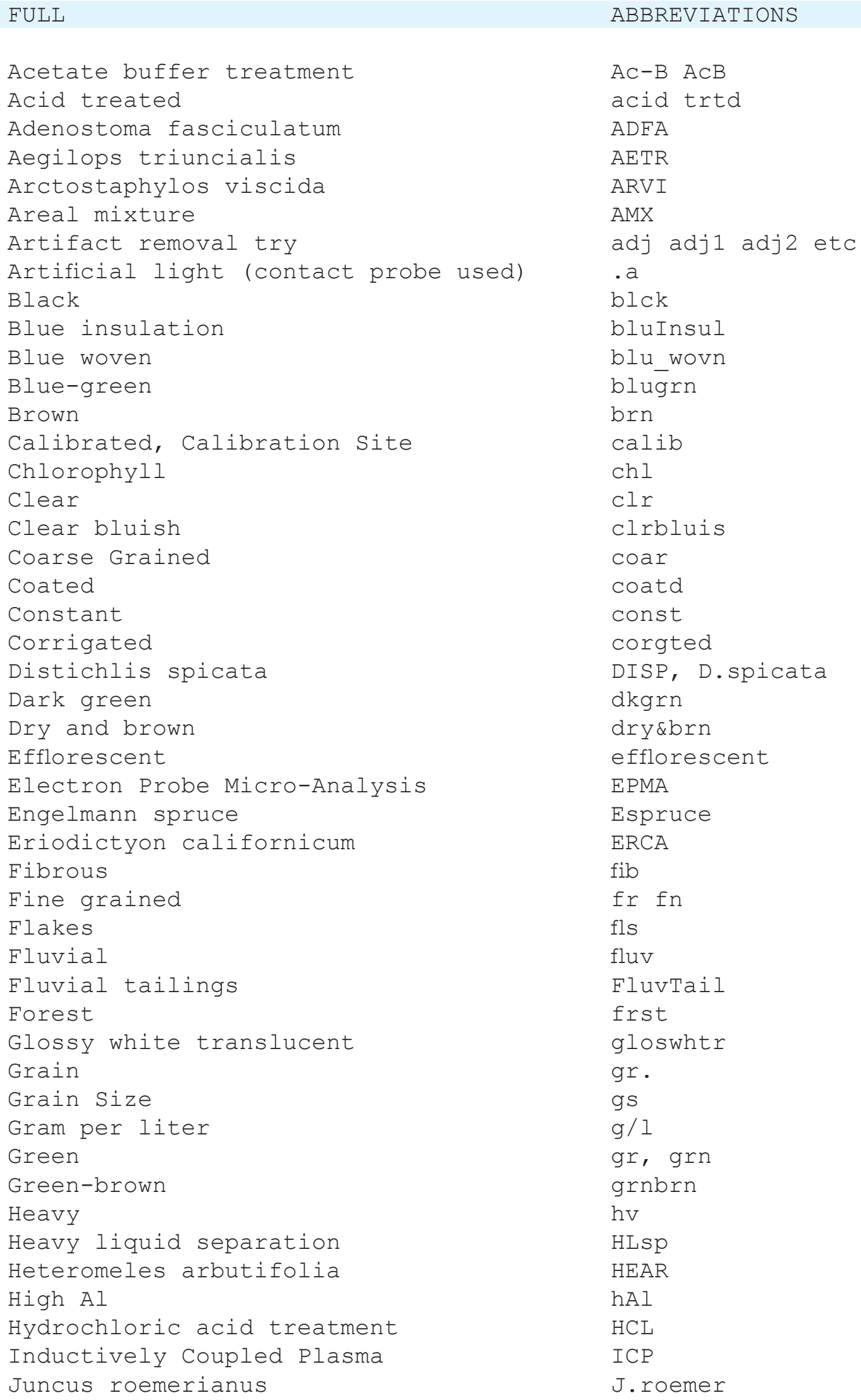




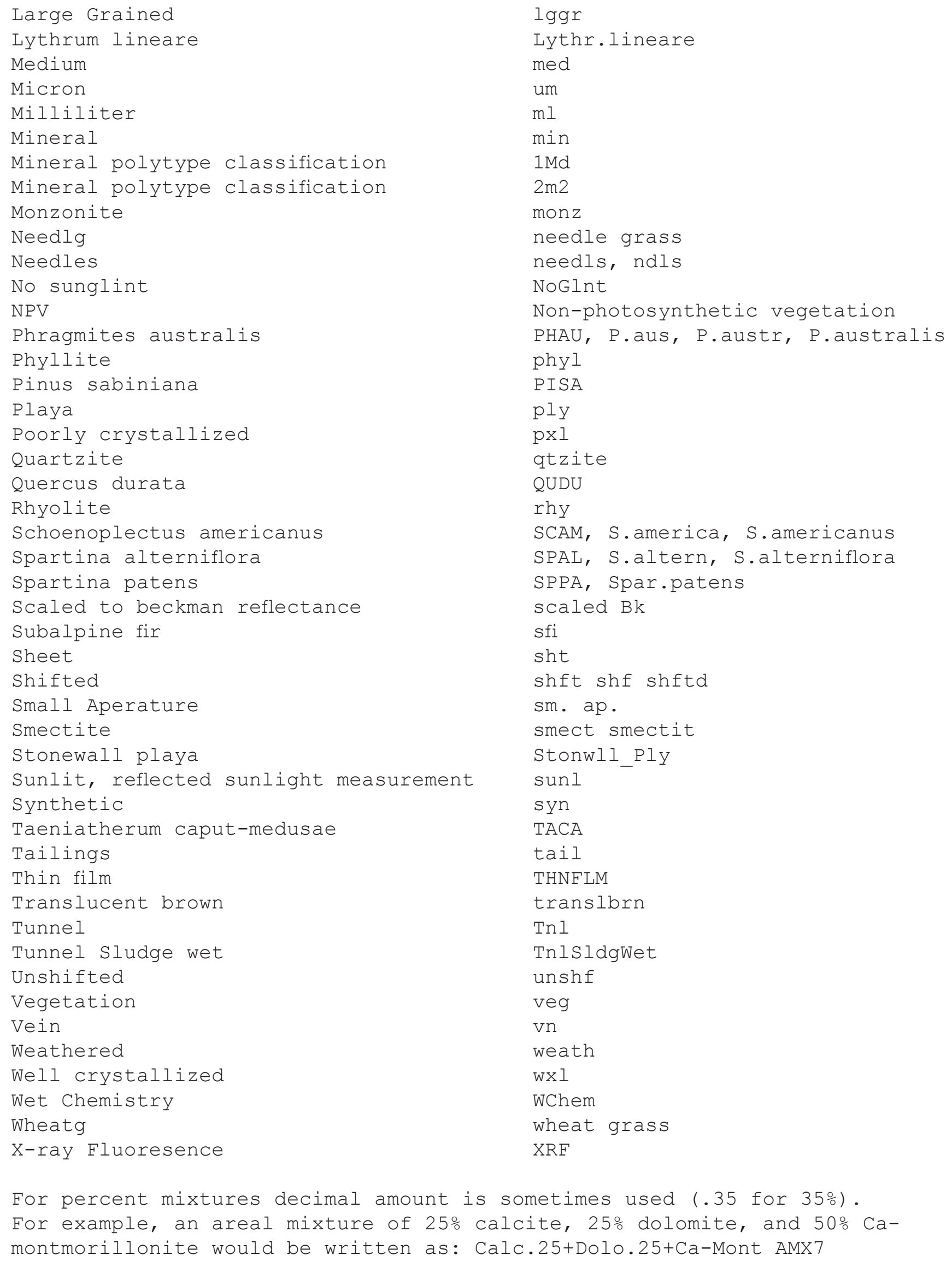

For percent mixtures decimal amount is sometimes used (.35 for 35\%). For example, an areal mixture of 25\% calcite, 25\% dolomite, and 50\% Camontmorillonite would be written as: Calc.25+Dolo.25+Ca-Mont AMX7 
halite

halloysite

hectorite

hedenbergite

hematite

heulandite

holmquistite

hornblende

howlite

hydrogrossular

hydromagnesite

hydroxyl-apatite

hypersthene

idocrase

illite

ilmenite

jadeite

jarosite

kainite

kaolinite

kaolinite/smectite

kerogen

labradorite

laumontite

lazurite

lepidocrosite

lepidolite

limonite

lizardite

maghemite

magnetite

malachite

manganite

margarite

marialite

mascagnite

meionite

mesolite+hydroxyapophyll

microcline

mirabilite

mizzonite

monazite

monticellite

montmorillonite

mordenite

muscovite hlt

hal

hec

hed

hem hemat

heu

hlm

hrb

how

hyg

hms hydroma

hya hydroxyapop

hyp

idocras

ill

ilm

jad

jar jr

kan

kao kaol

$\mathrm{ksm}$

ker

lab

lau

laz

lpc

lpd

lim

liz

mgh

mag

mal

mng

mrg

mrl

mcg

mei

$\mathrm{msh}$

mer

$\operatorname{mir}$

miz

mnz

mtc

mon mont montmor

mrd

msc musc muscov 
natrolite

natrolite+zeolites

neodymium oxide

nepheline

nephrite amphibole

niter

nontronite

oligoclase plag

olivine

opal

orthoclase

palygorskite attapulgite

paragonite

pectolite

perthite

phlogopite

pigeonite

pinnoite

pitch limonite

plagioclase

polyhalite

praseodymium oxide

prochlorite

psilomelane

pyrite

pyrope

pyrophyllite

pyroxene

pyrrhotite

quartz sand

quartz

quartz aventurine

rectorite

rhodochrosite

rhodonite

richterite

riebeckite

rivadavite

roscoelite

rutile

samarium oxide

sanidine

saponite

sauconite

scolectite zeolite

scapolite

sepiolite nat

ntz

neo

nph

npa

nit

ntr

olg

olv

opl

ort

ply

prg

pec

prt

phl

pgn

pin

plm

plag, plagio

plh

prs

prc

psi

pyt

pyp

pyr pyrop pyroph pyrophyl

pyx

prh

qts

qtz

qta

rec

rhd

rdn

ric

rbk

riv

ros

rut

sam

snd

sap

sau

$\mathrm{scl}$

scap, scapolte

sep 
USGS Spectral Library Version 7

\begin{tabular}{|c|c|}
\hline serpentine & $\operatorname{srp}$ \\
\hline siderite & sid \\
\hline siderophyllite & $s d r$ \\
\hline sillimanite & sil \\
\hline smaragdite amphibole & $\operatorname{smr}$ \\
\hline smectite & smc smect smectit \\
\hline sodium bicarbonate & sod \\
\hline spessartine garnet & $\operatorname{sps}$ \\
\hline sphalerite & sph \\
\hline sphene, titanite & spn \\
\hline spodumene & spd \\
\hline staurolite & sta \\
\hline stilbite & stl \\
\hline strontianite & str \\
\hline sulfur & sul \\
\hline syngenite & syng \\
\hline talc & tal \\
\hline teepleite+trona & tpl \\
\hline tephroite & tph \\
\hline thenardite & thn \\
\hline thuringite chlorite & thr \\
\hline tincalconite & $\operatorname{tin}$ \\
\hline topaz & tpz \\
\hline tourmaline & tou \\
\hline tremolite & trm \\
\hline trona & trn tron \\
\hline ulexite & ulx \\
\hline uralite & url \\
\hline uvarovite garnet & uvr \\
\hline vermicullite & vrm \\
\hline vesuvianite & ves \\
\hline witherite & wth \\
\hline wollastonite & wol \\
\hline zeolite & zeo \\
\hline zincite+franklinite & $\mathrm{znc}$ \\
\hline zircon & zir \\
\hline zoisite & zoi \\
\hline
\end{tabular}

zoisite zoi 
fir tree

ftr

juniper bush

jun

lawn grass

lng

maple leaves

mpl

pinon pine

pnp

rabbitbrush

rbt

russian olive

rso

sage brush

sgbo

saltbrush

slb

tumb leweed

tmb

walnut leaf

wn 1 


\section{Appendix 3. Metadata Templates}

\section{3-1. Template for $\mathrm{M}=$ Minerals}

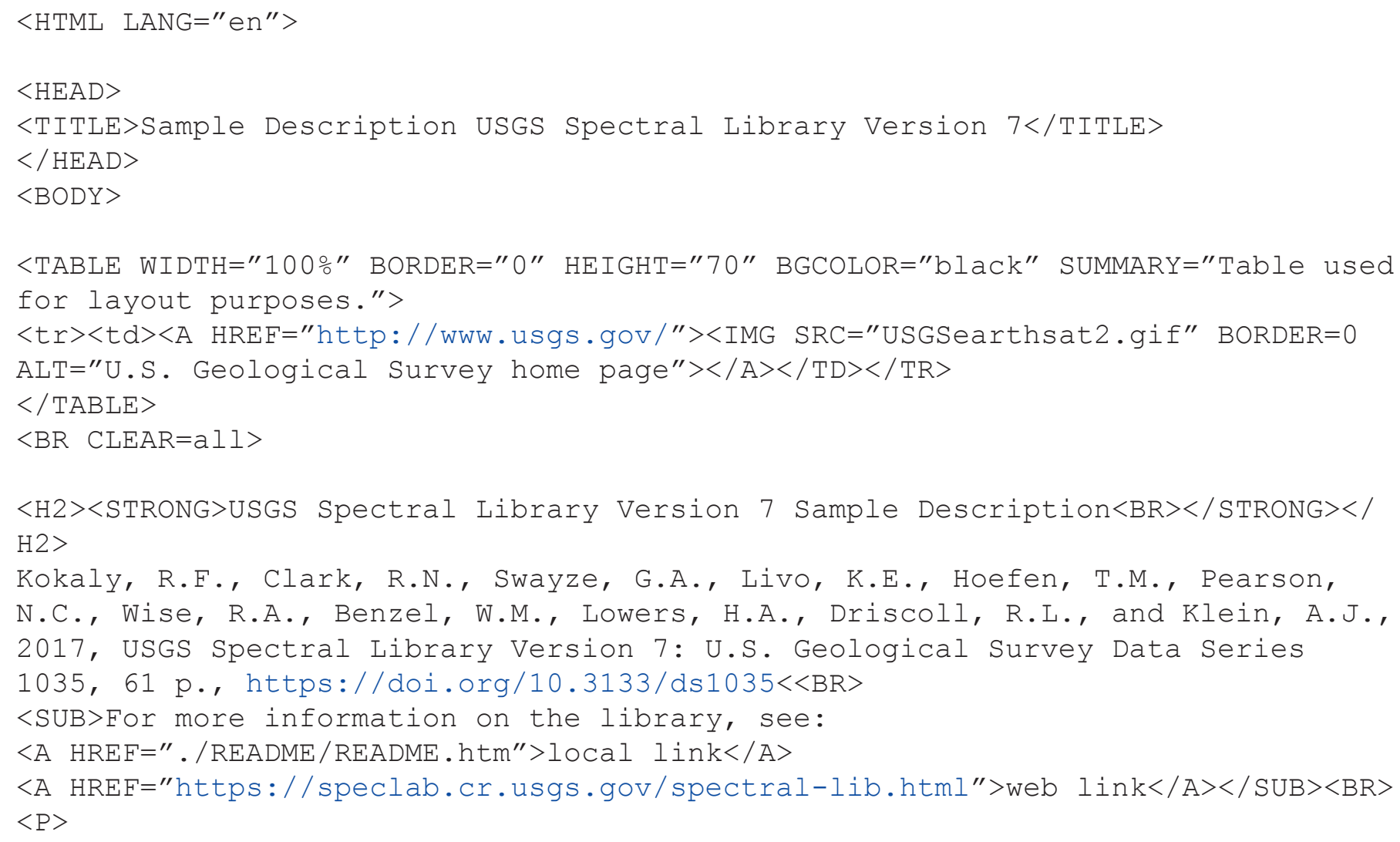




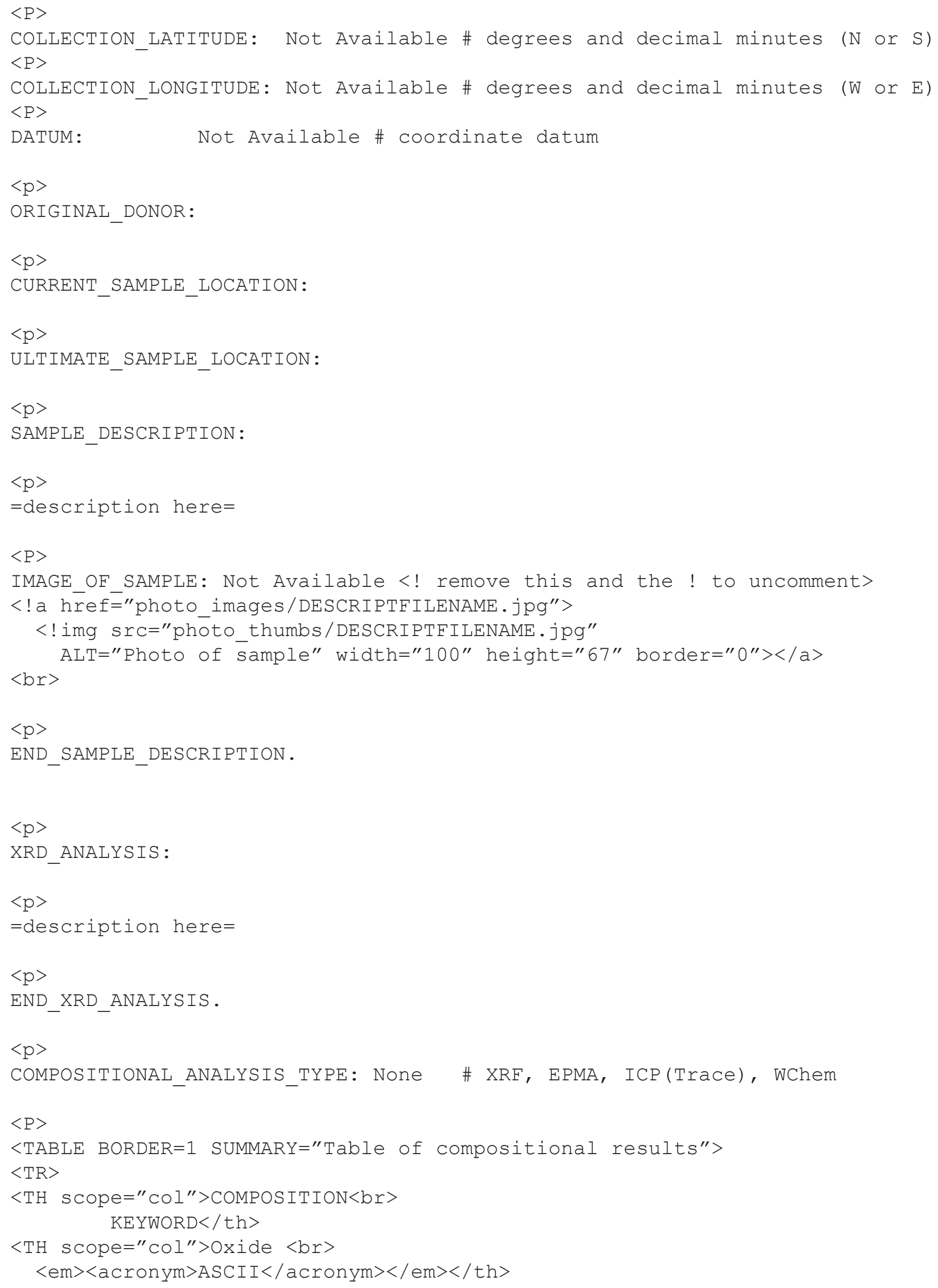




\section{$44 \quad$ USGS Spectral Library Version 7}

$<\mathrm{TH}$ scope="COl" $>$ Amount $</$ th $>$

$<\mathrm{TH}$ scope $=" \mathrm{COl} ">$ Weight $<\mathrm{br}>$

Percent, $:</$ th $>$

$<\mathrm{TH}$ scope="COl" $>$ Oxide $<$ br $><$ acronym $>$ html $</$ acronym $></$ th $>$

$</ \mathrm{TR}>$

$<$ tr $><$ td scope="row" $>$

COMPOSITION: $</$ TD $><$ TD $>\quad$ SiO2: $</$ TD $><$ TD $>\quad</$ TD $><$ TD $>$ wto $</$ TD $><$ TD $>$ SiO $<$ sub $>2</$

sub $></ T D></ T R>$

$<$ tr $><$ td scope $="$ row" $>$

COMPOSITION: $</$ TD $><$ TD $>\quad$ TiO2 $:</$ TD $><$ TD $>\quad</$ TD $><$ TD $>$ wto $</$ TD $><$ TD $>$ TiO $<$ sub $>2</$

sub $></ T D></ T R>$

$<$ tr $><$ td scope $="$ row" $>$

COMPOSITION $:\langle/$ TD $>\langle$ TD $>$

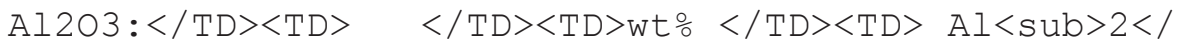

sub $>0<$ sub $>3</$ sub $></ T D></ T R>$

$<$ tr $><$ td scope $="$ row" $>$

COMPOSITION: $</$ TD $><$ TD $>$ Cr2O3: $</$ TD $><$ TD $>$

$</$ TD $><$ TD $>$ wt $\%</$ TD $><$ TD $>$ Cr $<$ sub $>2</$

sub $>0<$ sub $>3</$ sub $></$ TD $></$ TR $>$

$<$ tr $><$ td scope $="$ row" $>$

COMPOSITION: $</$ TD $><$ TD $>\quad$ V2O3: $</$ TD $><$ TD $>\quad</$ TD $><$ TD $>$ wt $\%</$ TD $><$ TD $>$ V $<$ sub $>2</$

sub $>0<$ sub $>3</$ sub $></ T D></ T R>$

$<$ tr $><$ td scope $="$ row" $>$

COMPOSITION $:</$ TD $><$ TD $>\quad$ Fe203: $</$ TD $><$ TD $>$

$</ \mathrm{TD}>\langle\mathrm{TD}>$ wt $\%</ \mathrm{TD}><\mathrm{TD}>$ Fe $<$ sub $>2</$

sub $>0<$ sub $>3</$ sub $></ T D></ T R>$

$<$ tr $><$ td scope $="$ row" $>$

COMPOSITION $:</$ TD $><$ TD $>$

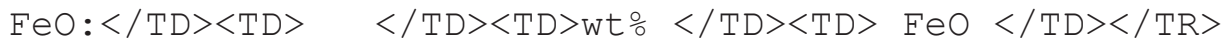

$<$ tr $><$ td scope $="$ row" $>$

COMPOSITION: $\langle/$ TD $>\langle$ TD $>$

$<$ tr $><$ td scope="row" $>$

COMPOSITION: $\langle/$ TD $\rangle\langle$ TD $>$

$<$ tr $><$ td scope $="$ row" $>$

COMPOSITION $:\langle/$ TD $\rangle\langle$ TD $>$

$<$ tr $><$ td scope $="$ row" $>$

COMPOSITION $:\langle/$ TD $\rangle\langle$ TD $>$

$<$ tr $><$ td scope $="$ row" $>$

COMPOSITION $:\langle/$ TD $\rangle\langle$ TD $>$

$<$ tr $><$ td scope="row" $>$

COMPOSITION $:\langle/$ TD $\rangle\langle$ TD $>$

$<$ tr $><$ td scope $="$ row" $>$

COMPOSITION : $</$ TD $><$ TD $>$

$<$ tr $><$ td scope="row" $>$

COMPOSITION $:</$ TD $><$ TD $>$

sub $>0</$ TD $></ T R>$

$\mathrm{NiO}:</ \mathrm{TD}><\mathrm{TD}>$

$</$ TD $><$ TD $>$ wt $\%</$ TD $><$ TD $>$ NiO $</$ TD $></$ TR $>$

$\mathrm{MnO}:</ \mathrm{TD}><\mathrm{TD}>$

$</ \mathrm{TD}\rangle\langle\mathrm{TD}>$ Wto $</ \mathrm{TD}><\mathrm{TD}>\mathrm{MnO}</ \mathrm{TD}\rangle</ \mathrm{TR}>$

$\mathrm{MgO}:</ \mathrm{TD}><\mathrm{TD}>$

$</ \mathrm{TD}><\mathrm{TD}>$ wt $\%</ \mathrm{TD}\rangle\langle\mathrm{TD}>\mathrm{MgO}</ \mathrm{TD}\rangle</ \mathrm{TR}>$

$\operatorname{SrO}:</ T D><T D>$

$</ \mathrm{TD}\rangle\langle\mathrm{TD}>$ Wto $</ \mathrm{TD}\rangle\langle\mathrm{TD}>\mathrm{SrO}</ \mathrm{TD}\rangle\langle/ \mathrm{TR}\rangle$

$\mathrm{ZnO}:</ \mathrm{TD}><\mathrm{TD}>$

$</ \mathrm{TD}><\mathrm{TD}>$ wto $</ \mathrm{TD}><\mathrm{TD}>\mathrm{ZnO}</ \mathrm{TD}\rangle</ \mathrm{TR}>$

$\mathrm{BaO}:</ \mathrm{TD}><\mathrm{TD}>$

$</ \mathrm{TD}\rangle\langle\mathrm{TD}>$ wto $</ \mathrm{TD}\rangle\langle\mathrm{TD}>\mathrm{BaO}</ \mathrm{TD}\rangle\langle/ \mathrm{TR}\rangle$

$\mathrm{CaO}:</ \mathrm{TD}><\mathrm{TD}>$

$</ \mathrm{TD}><\mathrm{TD}>$ wt $\%</ \mathrm{TD}><\mathrm{TD}>\mathrm{CaO}</ \mathrm{TD}></ \mathrm{TR}>$

Li20: $\langle/ T D><T D>$

$</$ TD $><$ TD $>$ wt $\frac{\circ}{0}</$ TD $><$ TD $>$ Li $<$ sub $>2</$

$<$ tr $><$ td scope $="$ row" $>$

COMPOSITION $:</$ TD $><$ TD $>$

sub $>0</ \mathrm{TD}\rangle</ \mathrm{TR}>$

$\mathrm{Na} 2 \mathrm{O}:</ \mathrm{TD}><\mathrm{TD}>$

$</$ TD $><$ TD $>$ Wt $\%</$ TD $><$ TD $>$ Na $<$ sub $>2</$

$<$ tr $><$ td scope="row" $>$

COMPOSITION $:</$ TD $><$ TD $>$

$\mathrm{K} 2 \mathrm{O}:</ \mathrm{TD}><\mathrm{TD}>$

$</$ TD $><$ TD $>$ wt $\%</$ TD $><$ TD $>$ K $<$ sub $>2</$ sub $>0$

$</ \mathrm{TD}\rangle\langle/ \mathrm{TR}\rangle$

$<$ tr $><$ td scope="row" $>$

COMPOSITION $:</$ TD $><$ TD $>$

$\mathrm{P} 205:</ \mathrm{TD}\rangle\langle\mathrm{TD}\rangle$

$</ \mathrm{TD}><\mathrm{TD}>$ wt $\%</ \mathrm{TD}><\mathrm{TD}>\mathrm{P}<$ sub $>2</$

sub $>0<$ sub $>5</$ sub $></$ TD $\rangle</$ TR $>$

$<$ tr $><$ td scope="row" $>$ 


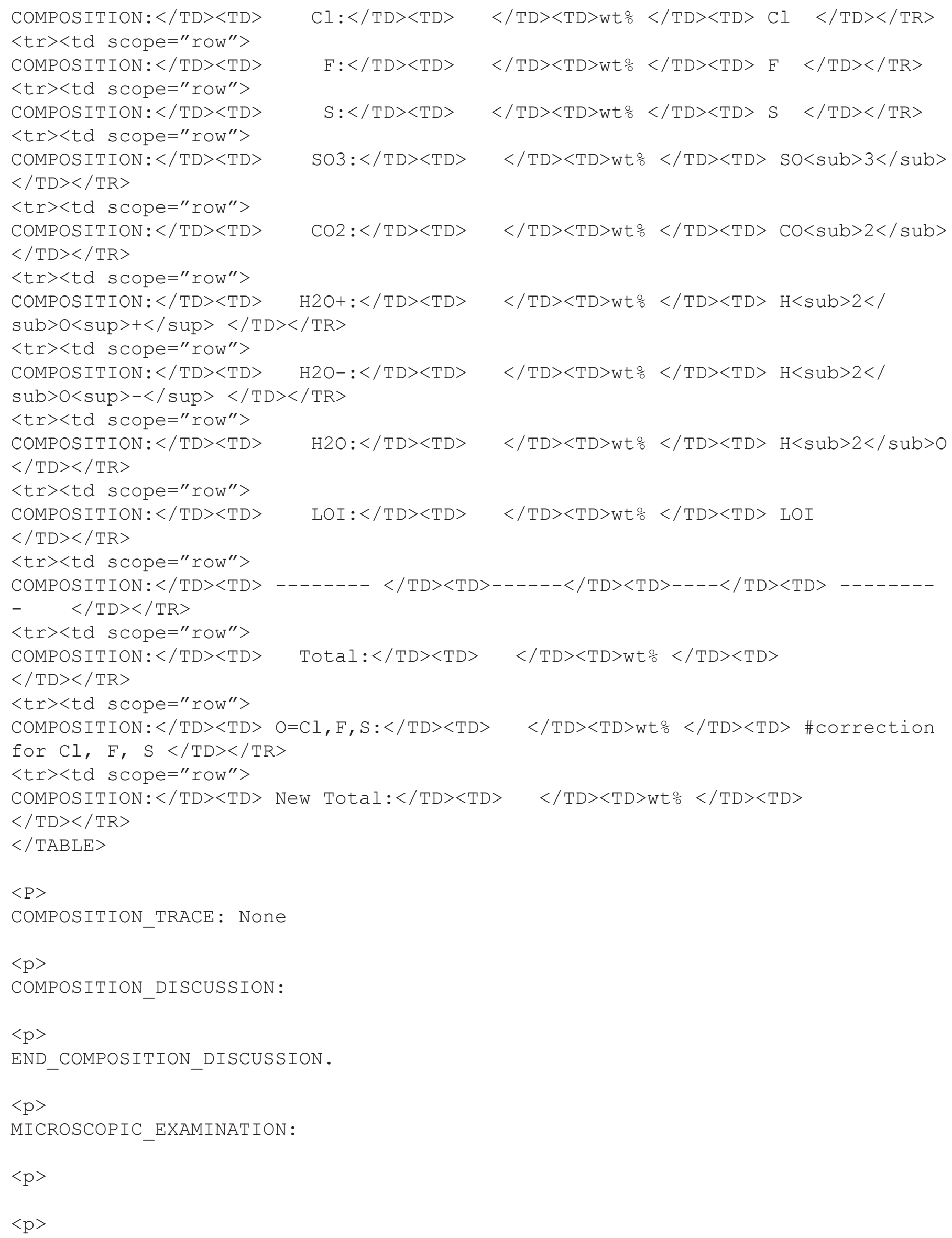


END_MICROSCOPIC_EXAMINATION.

$<\mathrm{p}>$

SPECTROSCOPIC_DISCUSSION:

$<\mathrm{p}>$

END_SPECTROSCOPIC_DISCUSSION.

$<\mathrm{p}>$

SPECTRAL_PURITY: $1{ }_{2}{ }_{-}{ }^{-}{ }^{4}-\# 1=0.2-3,2=1.5-6,3=6-25,4=20-150$ microns

$</$ html $>$

\section{3-2. Template for $\mathrm{S}=$ Soils (including rocks, and mineral mixtures) and $\mathbf{C}=$ Coatings}

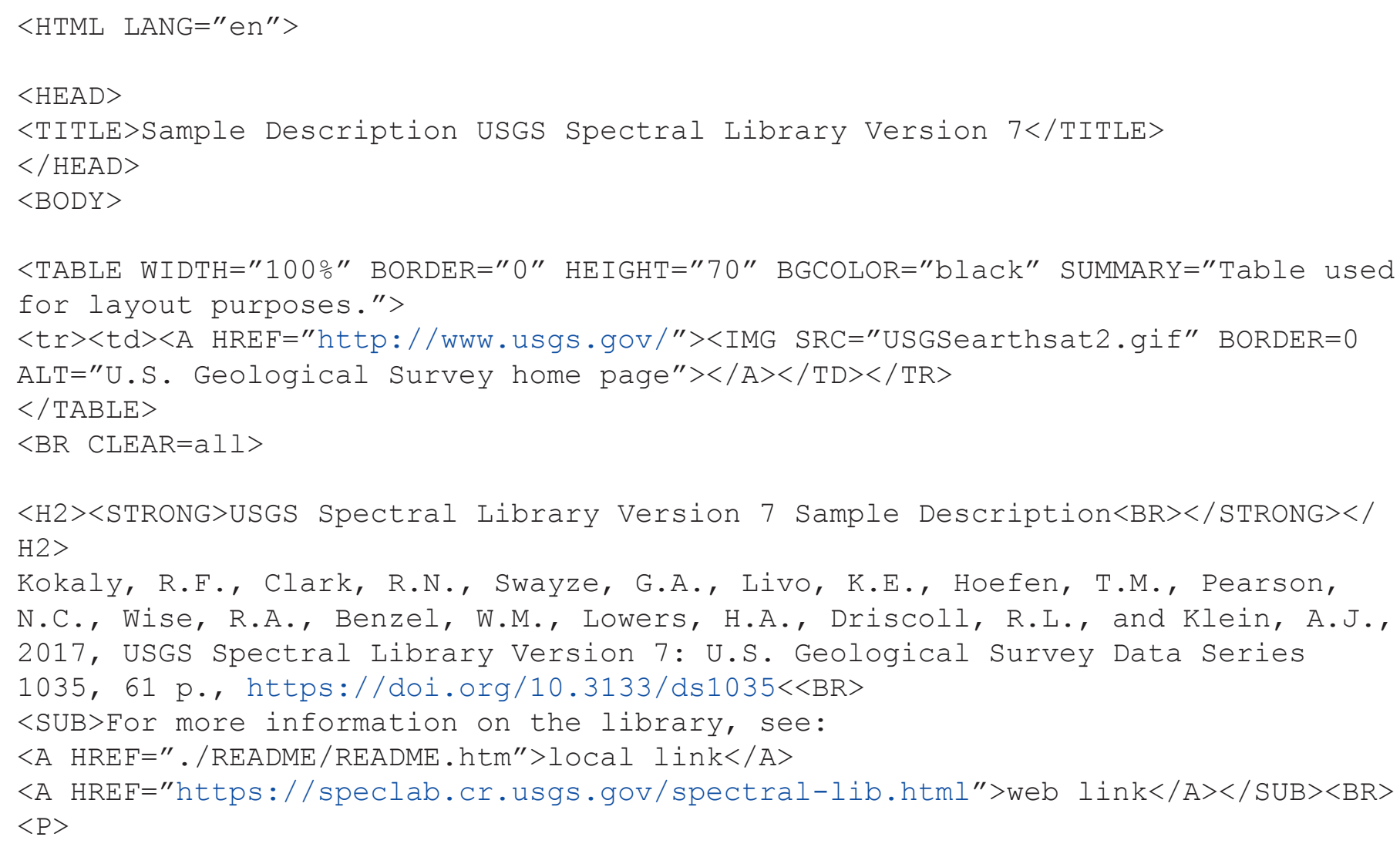




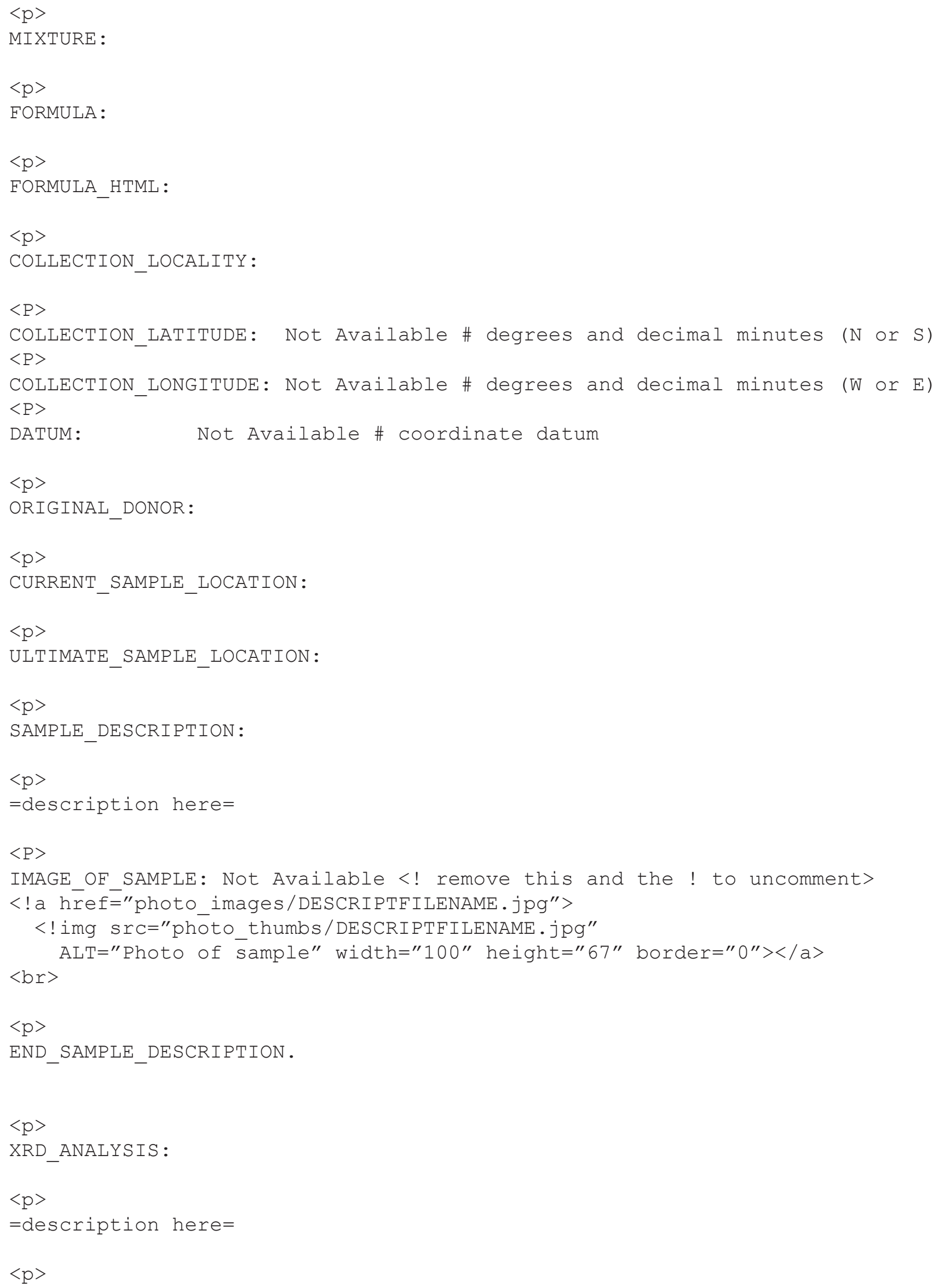




\section{$48 \quad$ USGS Spectral Library Version 7}

END_XRD_ANALYSIS.

$<\mathrm{p}>$

COMPOSITIONAL_ANALYSIS_TYPE: None \# XRF, EPMA, ICP(Trace), WChem

$<\mathrm{P}>$

$<$ TABLE BORDER=1 SUMMARY="Table of compositional results">

$<\mathrm{TR}>$

$<$ TH scope $="$ COl" $>$ COMPOSITION $<$ br $>$

KEYWORD $</$ th $>$

$<\mathrm{TH}$ scope $=" \mathrm{COl} ">\mathrm{Oxide}<\mathrm{br}>$

$<$ em $><$ acronym $>$ ASCII $</$ acronym $></$ em $></$ th $>$

$<\mathrm{TH}$ scope $=" \mathrm{COl} ">$ Amount $</$ th $>$

$<\mathrm{TH}$ scope $=" \mathrm{COl} ">$ Weight $<$ br $>$

Percent, $\frac{\circ}{2} /$ th $>$

$<$ TH scope="col" $>$ Oxide $<$ br $><$ acronym $>$ html $</$ acronym $></$ th $>$

$</ \mathrm{TR}>$

$<$ tr $><$ td scope $="$ row" $>$

COMPOSITION: $</$ TD $><$ TD $>$ SiO2: $</$ TD $><$ TD $>\quad</$ TD $><$ TD $>$ wt $\%</$ TD $><$ TD $>$ SiO $<$ Sub $>2</$

sub $></ T D></ T R>$

$<$ tr $><$ td scope="row" $>$

COMPOSITION: $</$ TD $><$ TD $>$ TiO2: $</$ TD $><$ TD $>\quad</$ TD $><$ TD $>$ wto $</$ TD $><$ TD $>$ TiO $<$ sub $>2</$

sub $></ T D></ T R>$

$<$ tr $><$ td scope $="$ row" $>$

COMPOSITION: $</$ TD $><$ TD $>$ Al203: $</$ TD $><$ TD $>\quad</$ TD $><$ TD $>$ wt $\%</$ TD $><$ TD $>$ Al $<$ sub $>2</$

sub $>0<$ sub $>3</$ sub $></$ TD $></$ TR $>$

$<$ tr $><$ td scope $=" r o w^{\prime \prime}>$

COMPOSITION: $</$ TD $><$ TD $>\quad$ Cr203: $</$ TD $><$ TD $>\quad</$ TD $><$ TD $>$ wt $\%</$ TD $><$ TD $>$ Cr $<$ Sub $>2</$

sub $>0<$ sub $>3</$ sub $></$ TD $></$ TR $>$

$<$ tr $><$ td scope $="$ row" $>$

COMPOSITION: $</$ TD $><$ TD $>\quad$ V2O3: $</$ TD $><$ TD $>\quad</ T D><$ TD $>$ wto $</$ TD $><$ TD $>$ V $<$ Sub $>2</$

sub $>0<$ sub $>3</$ sub $></$ TD $></$ TR $>$

$<$ tr $><$ td scope $="$ row" $>$

COMPOSITION: $</$ TD $><$ TD $>$ Fe203: $</$ TD $><$ TD $>\quad</$ TD $><$ TD $>$ wt $\%</$ TD $><$ TD $>$ Fe $<$ Sub $>2</$

sub $>0<$ sub $>3</$ sub $></$ TD $></$ TR $>$

$<$ tr $><$ td scope $="$ row" $>$

COMPOSITION $:\langle/$ TD $\rangle\langle$ TD $>$

$<$ tr $><$ td scope="row" $>$

COMPOSITION: $</$ TD $><$ TD $>$

$<$ tr $><$ td scope="row" $>$

COMPOSITION $:</$ TD $><$ TD $>$

$<$ tr $><$ td scope="row" $>$

COMPOSITION $:</$ TD $><$ TD $>$

$<$ tr $><$ td scope="row" $>$

COMPOSITION $:</$ TD $\rangle\langle$ TD $>$

$<$ tr $><$ td scope="row" $>$

COMPOSITION $:</$ TD $><$ TD $>$

$<$ tr $><$ td scope="row" $>$

COMPOSITION $:</$ TD $><$ TD $>$

$<$ tr $><$ td scope="row" $>$

COMPOSITION $:</$ TD $><$ TD $>$

$<$ tr $><$ td scope $="$ row" $^{\prime \prime}>$

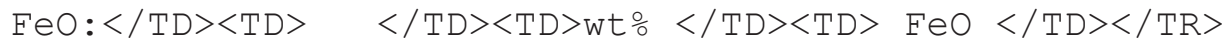

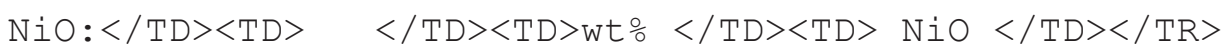

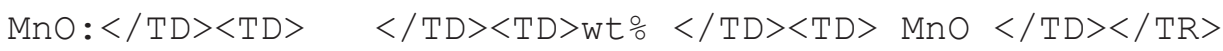

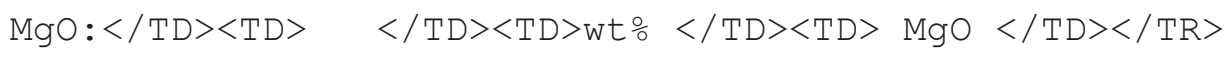

$$
\begin{aligned}
& \mathrm{SrO}:\langle/ \mathrm{TD}\rangle\langle\mathrm{TD}\rangle \quad\langle/ \mathrm{TD}\rangle\langle\mathrm{TD}\rangle \mathrm{Wt} \% \quad\langle/ \mathrm{TD}\rangle\langle\mathrm{TD}\rangle \text { SrO }</ \mathrm{TD}\rangle\langle/ \mathrm{TR}\rangle \\
& \mathrm{ZnO}:\langle/ \mathrm{TD}\rangle\langle\mathrm{TD}\rangle \quad\langle/ \mathrm{TD}\rangle\langle\mathrm{TD}\rangle \text { Wt } \%</ \mathrm{TD}\rangle\langle\mathrm{TD}\rangle \text { ZnO }</ \mathrm{TD}\rangle\langle/ \mathrm{TR}\rangle
\end{aligned}
$$

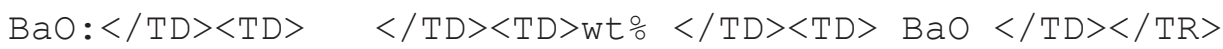

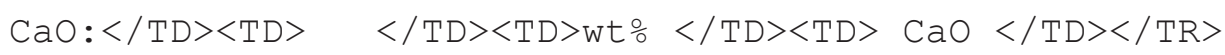




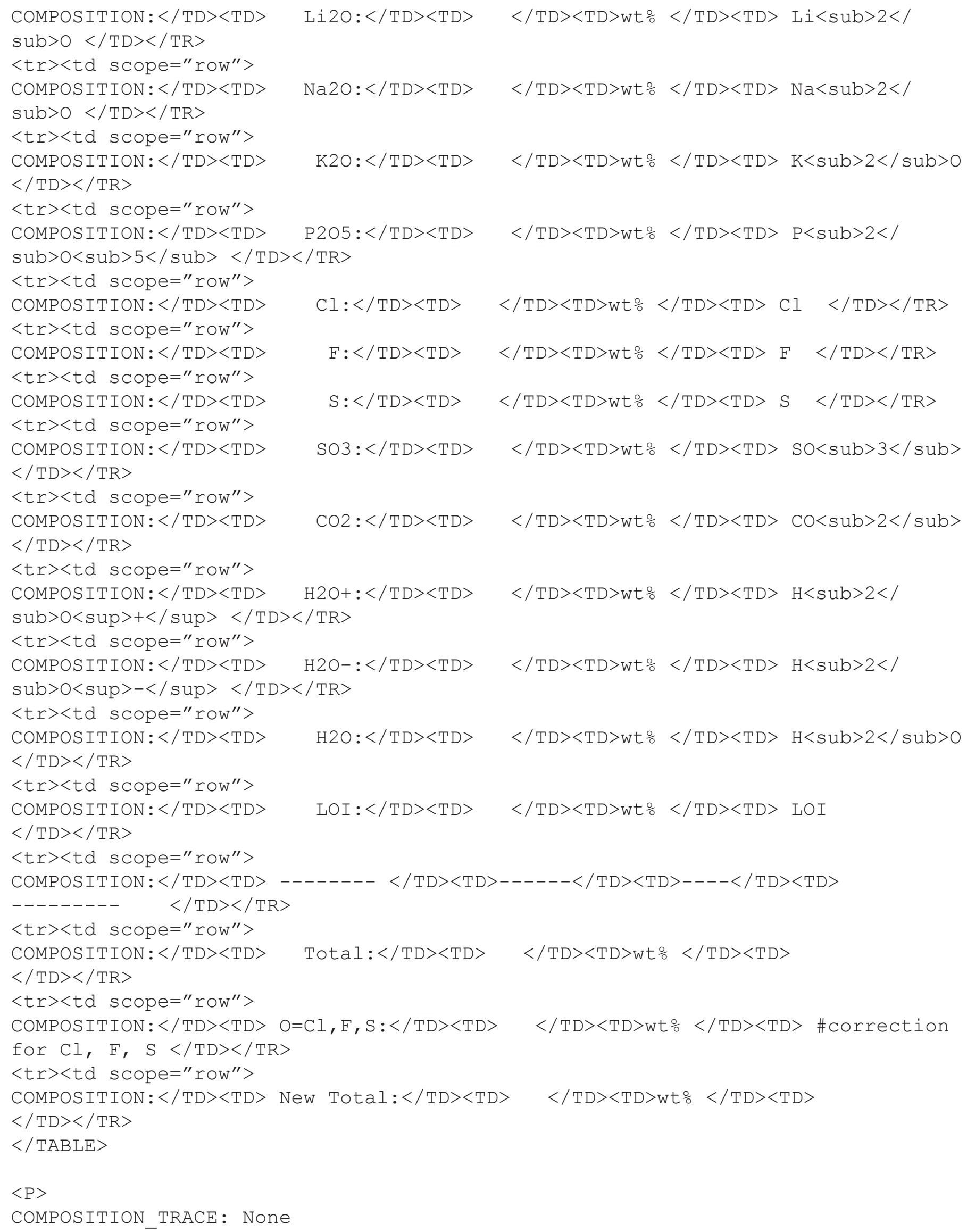




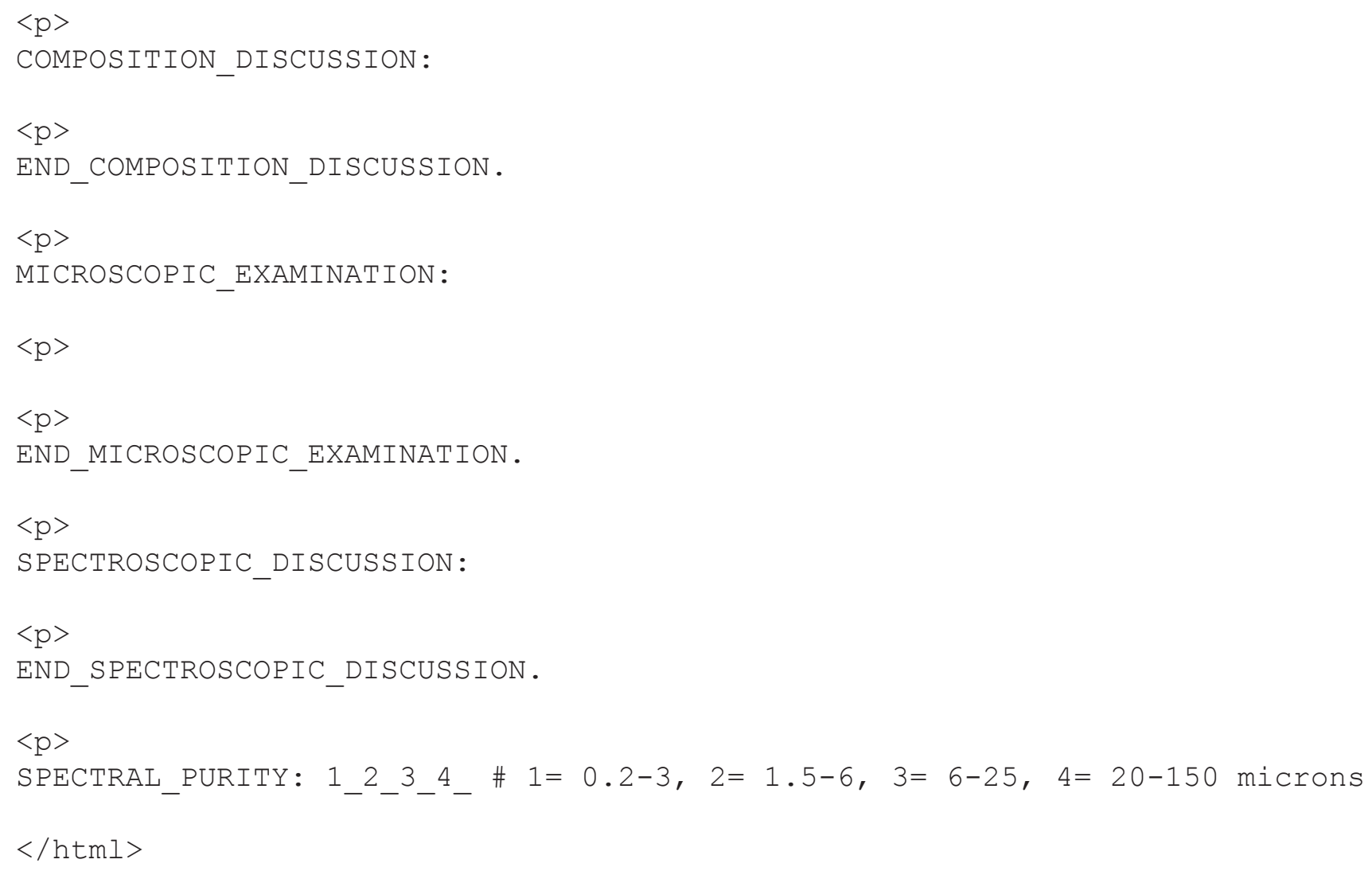

3-3. Template for $=$ Liquids (including mixtures of liquids, water and other volatiles, and frozen volatiles)

$<$ HTML LANG="en">

$<$ HEAD $>$

<TITLE>Sample Description USGS Spectral Library Version $7</$ TITLE $>$

$</$ HEAD $>$

$<B O D Y>$

<TABLE WIDTH="100\%" BORDER="0" HEIGHT="70" BGCOLOR="black" SUMMARY="Table used for layout purposes." $>$

$<t r><t d><A$ HREF="http://www.usgs.gov/" $><$ IMG SRC="USGSearthsat2.gif" BORDER=0

ALT="U.S. Geological Survey home page" $>\langle/ A\rangle\langle/ T D\rangle\langle/ T R\rangle$

$</$ TABLE $>$

$<$ BR CLEAR=all>

$<$ H2 $><$ STRONG $>$ USGS Spectral Library Version 7 Sample Description $<$ BR $></$ STRONG $></$ $\mathrm{H} 2>$

Kokaly, R.F., Clark, R.N., Swayze, G.A., Livo, K.E., Hoefen, T.M., Pearson, N.C., Wise, R.A., Benzel, W.M., Lowers, H.A., Driscoll, R.L., and Klein, A.J., 2017, USGS Spectral Library Version 7: U.S. Geological Survey Data Series 1035, 61 p., https://doi.org/10.3133/ds1035<<BR $>$ $<$ SUB $>$ For more information on the library, see: $<\mathrm{A} H \mathrm{HEF}="$ "/README/README.htm">local link</A $>$ 
$<$ A HREF="https://speclab.cr.usgs.gov/spectral-lib.html" $>$ web link $</ A\rangle\langle/$ SUB $><$ BR $>$ $<\mathrm{P}>$

TITLE :

$<\mathrm{p}>$

DOCUMENTATION_FORMAT: VOLATILE

$<\mathrm{p}>$

SAMPLE_ID:

$<\mathrm{p}>$

MATERIAL_TYPE:

$<\mathrm{p}>$

MATERIAL :

$<\mathrm{p}>$

FORMULA :

$<\mathrm{p}>$

FORMULA_HTML:

$<\mathrm{p}>$

COLLECTION_LOCALITY: USGS Denver Spectroscopy Laboratory faucet

$<\mathrm{P}>$

COLLECTION_LATITUDE: Not Available \# degrees and decimal minutes (N or $\mathrm{S}$ ) $<\mathrm{P}>$

COLLECTION_LONGITUDE: Not Available \# degrees and decimal minutes (W or E) $<\mathrm{P}>$

DATUM: $\quad$ Not Available \# coordinate datum

$<\mathrm{p}>$

ORIGINAL_DONOR:

$<\mathrm{p}>$

CURRENT_SAMPLE_LOCATION:

$<\mathrm{p}>$

ULTIMATE_SAMPLE_LOCATION:

$<\mathrm{p}>$

SAMPLE_DESCRIPTION:

$<\mathrm{p}>$

$<\mathrm{P}>$

IMAGE_OF SAMPLE: Not Available <! remove this and the ! to uncomment> $<$ ! a href="photo_images/DESCRIPTEILENAME.jpg">

$<$ ! img srC="photo_thumbs/DESCRIPTFILENAME.jpg"

ALT="Photo of sample" width="100" height="67" border="0" $></ a\rangle$ 


\section{$52 \quad$ USGS Spectral Library Version 7}

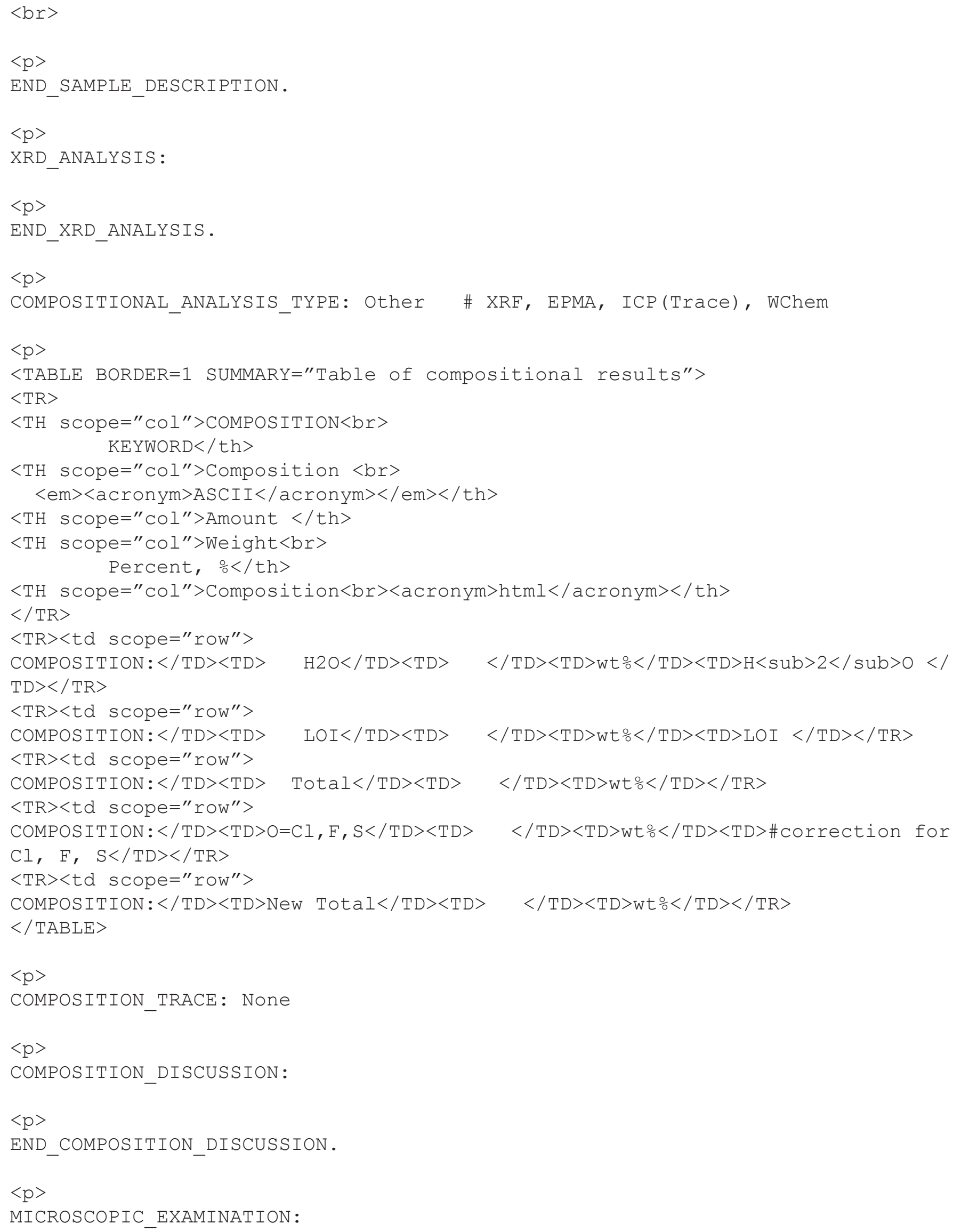




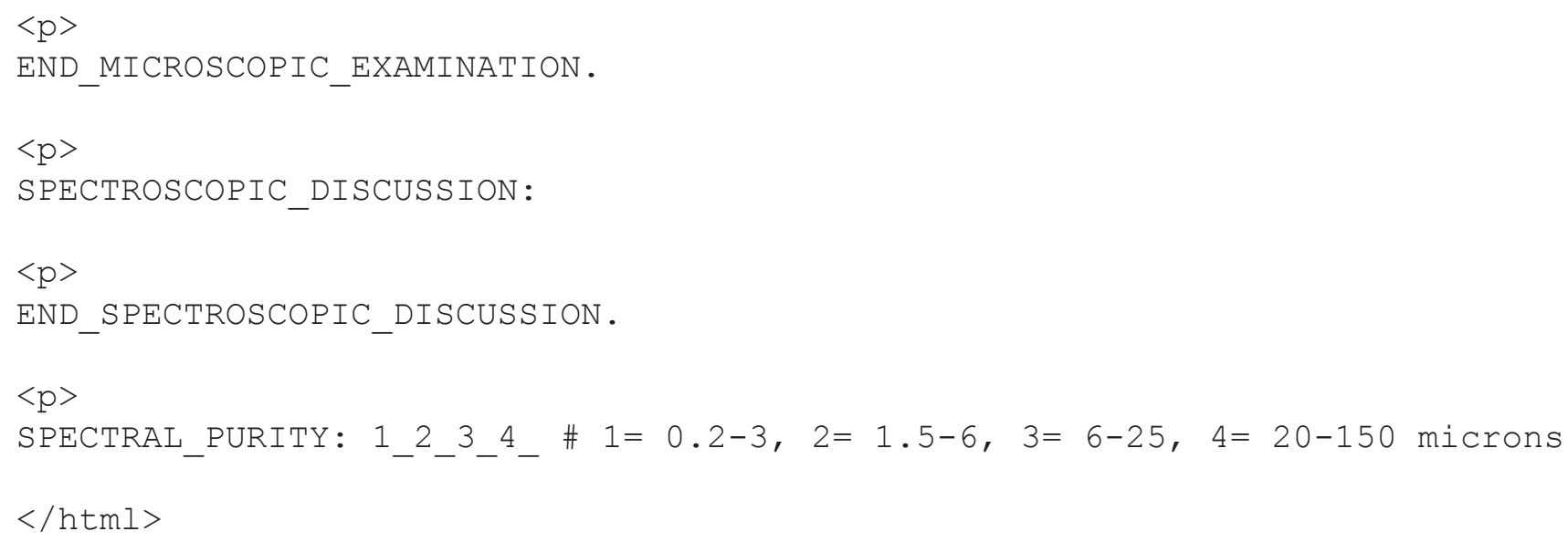

\section{3-4. Template for $0=$ Organics (including biochemical constituents of plants and chemical compounds not in Chapter 4)}

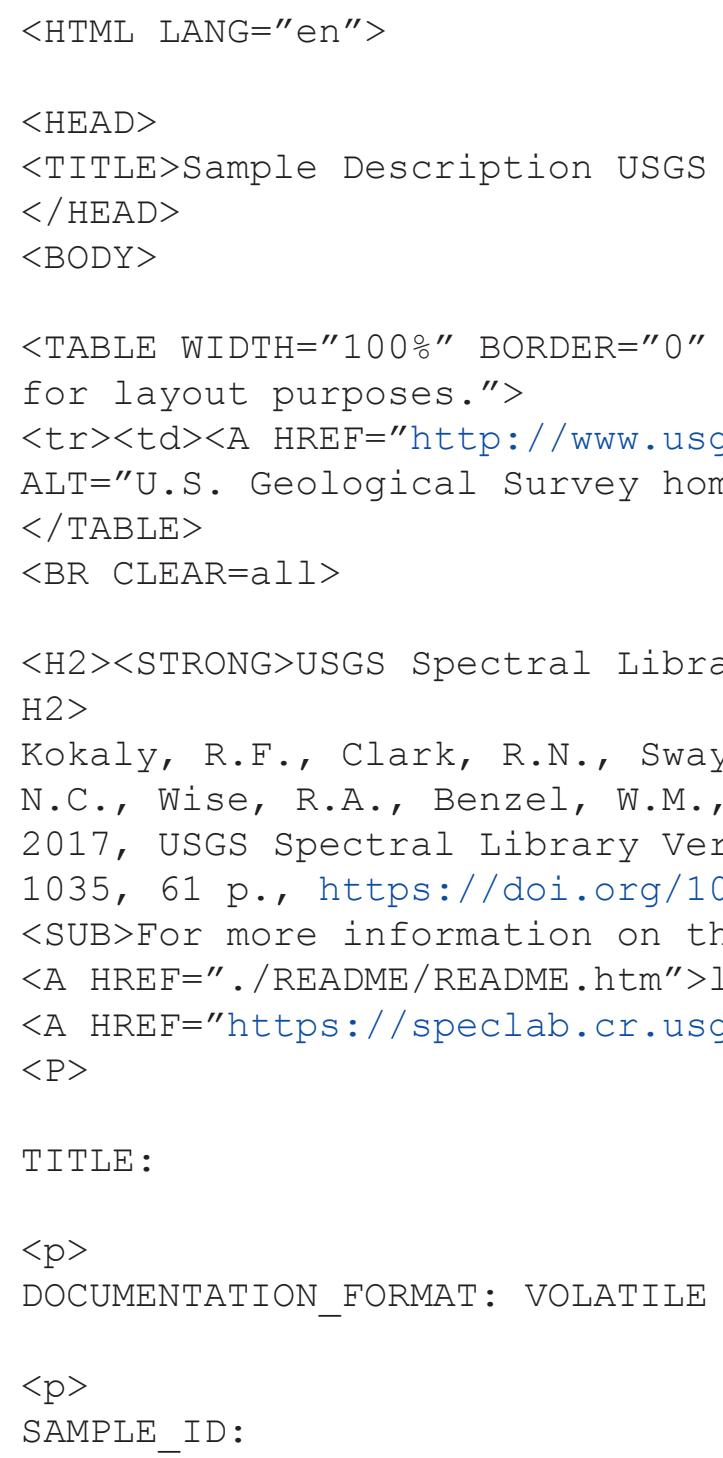




\section{$54 \quad$ USGS Spectral Library Version 7}

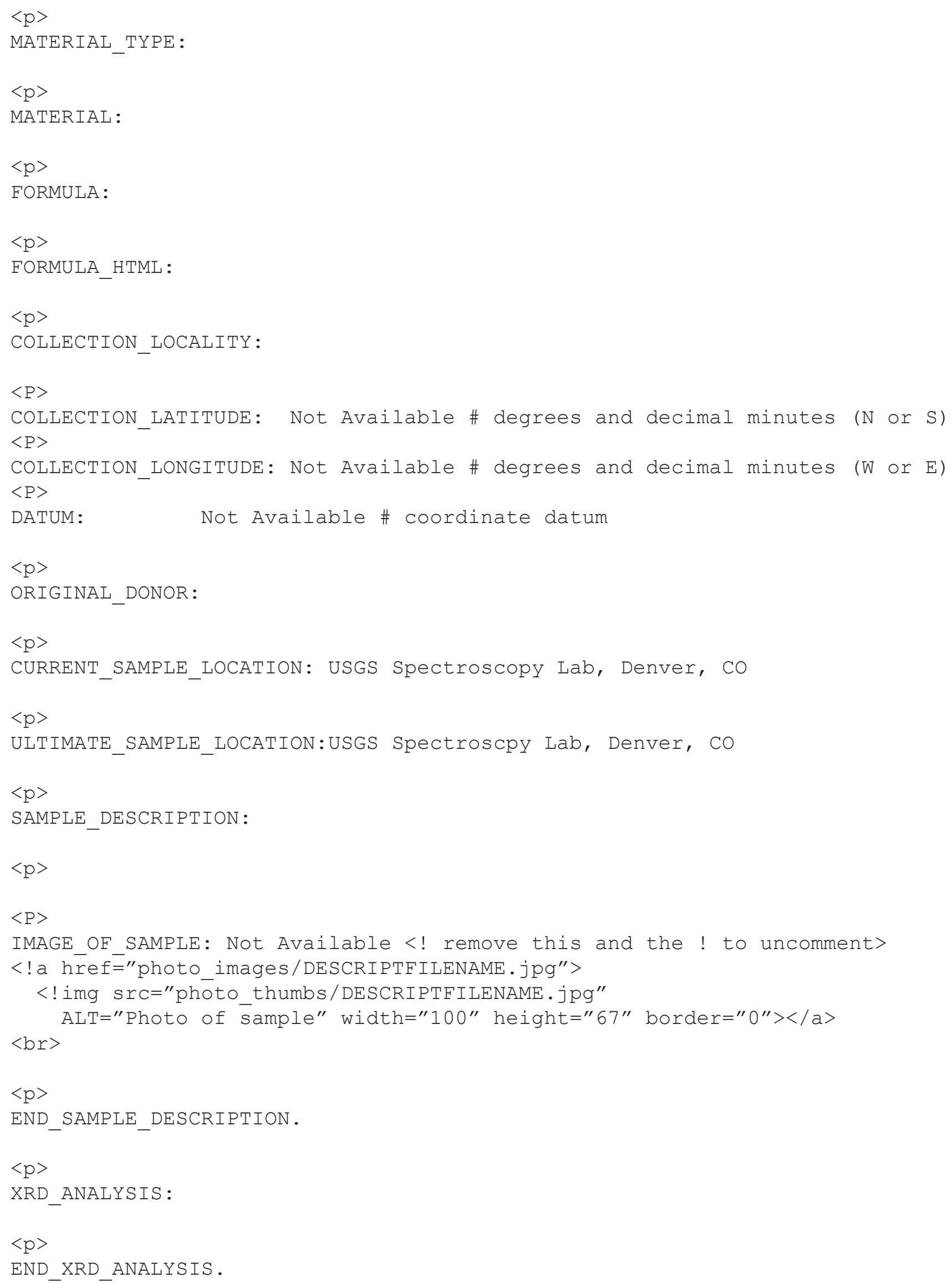




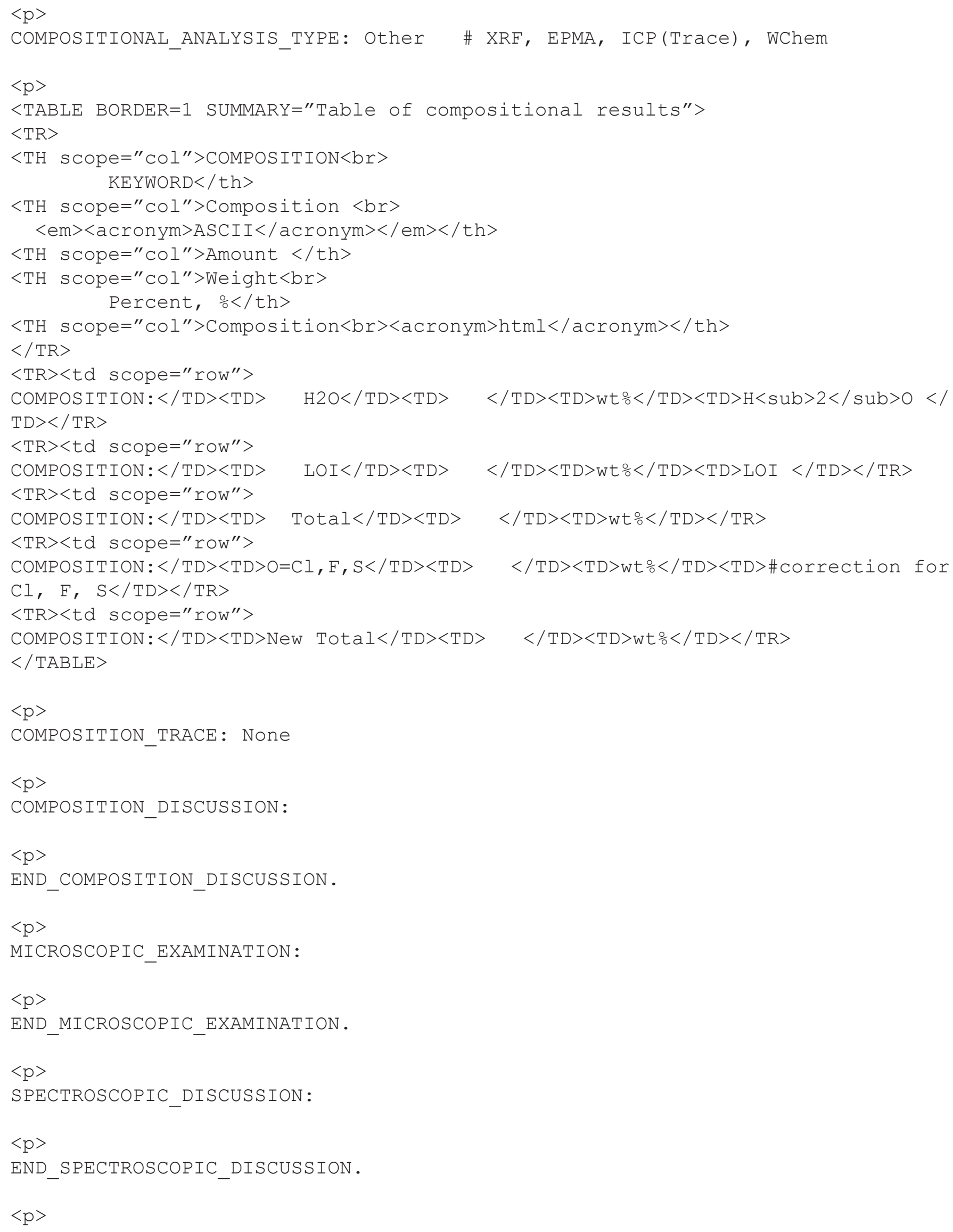


SPECTRAL_PURITY: 1_2_3_4_\# $1=0.2-3,2=1.5-6,3=6-25,4=20-150$ microns $</$ html $>$

3-5. Template for $A=$ Artificial (manmade materials, including manufactured chemicals, processed materials, paint pigments, and materials introduced into the environment by human activity)

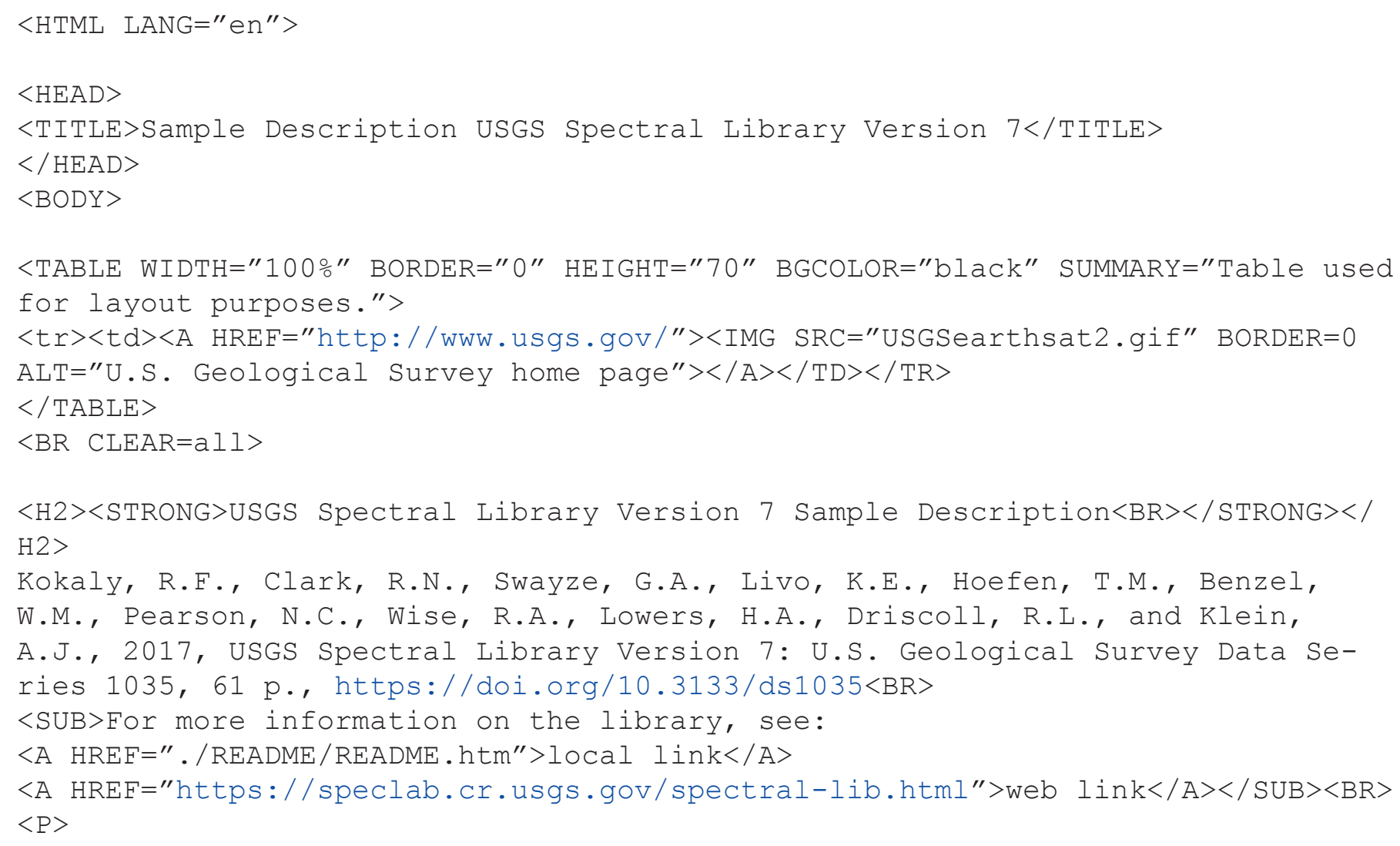




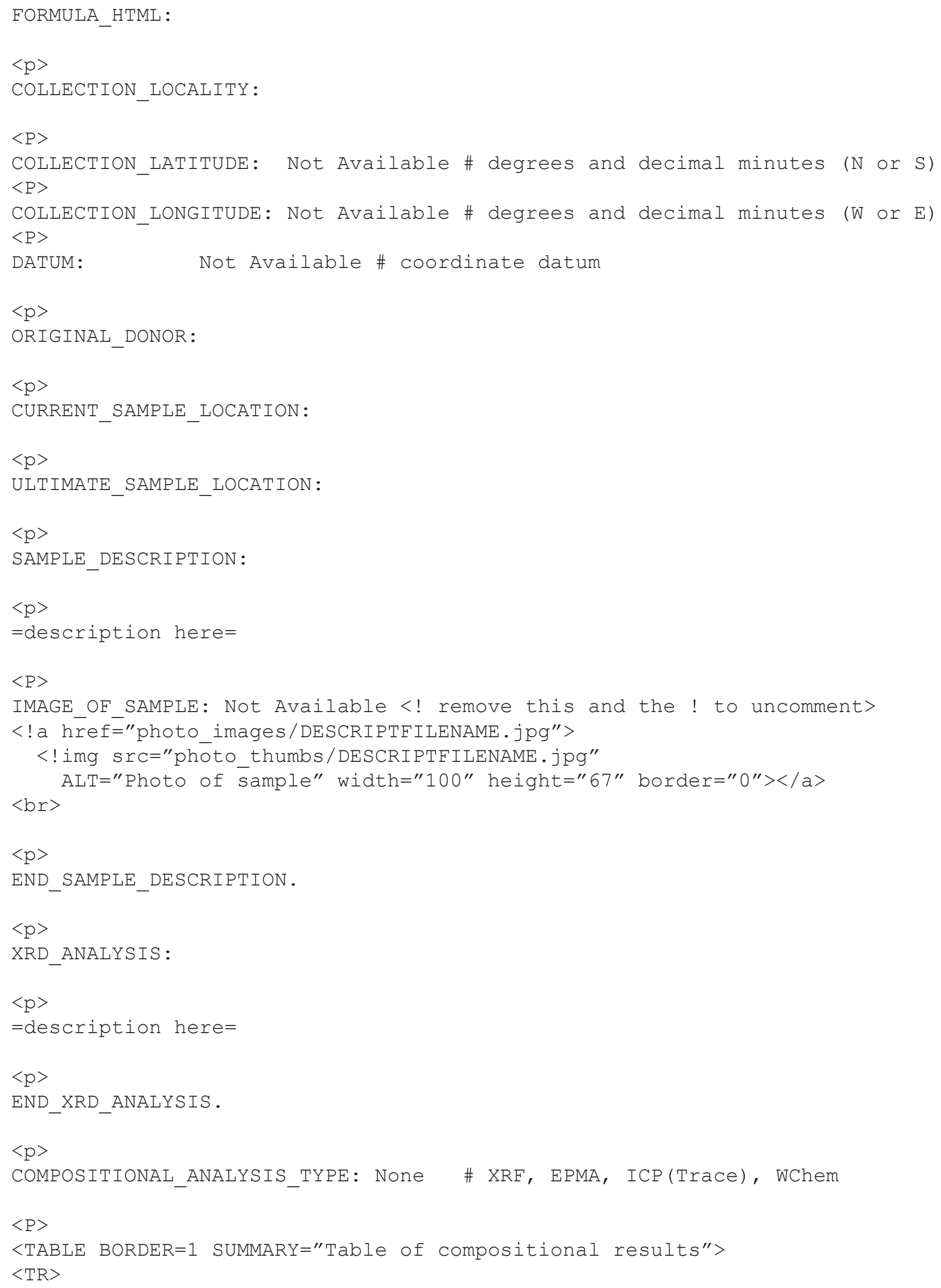




\section{$58 \quad$ USGS Spectral Library Version 7}

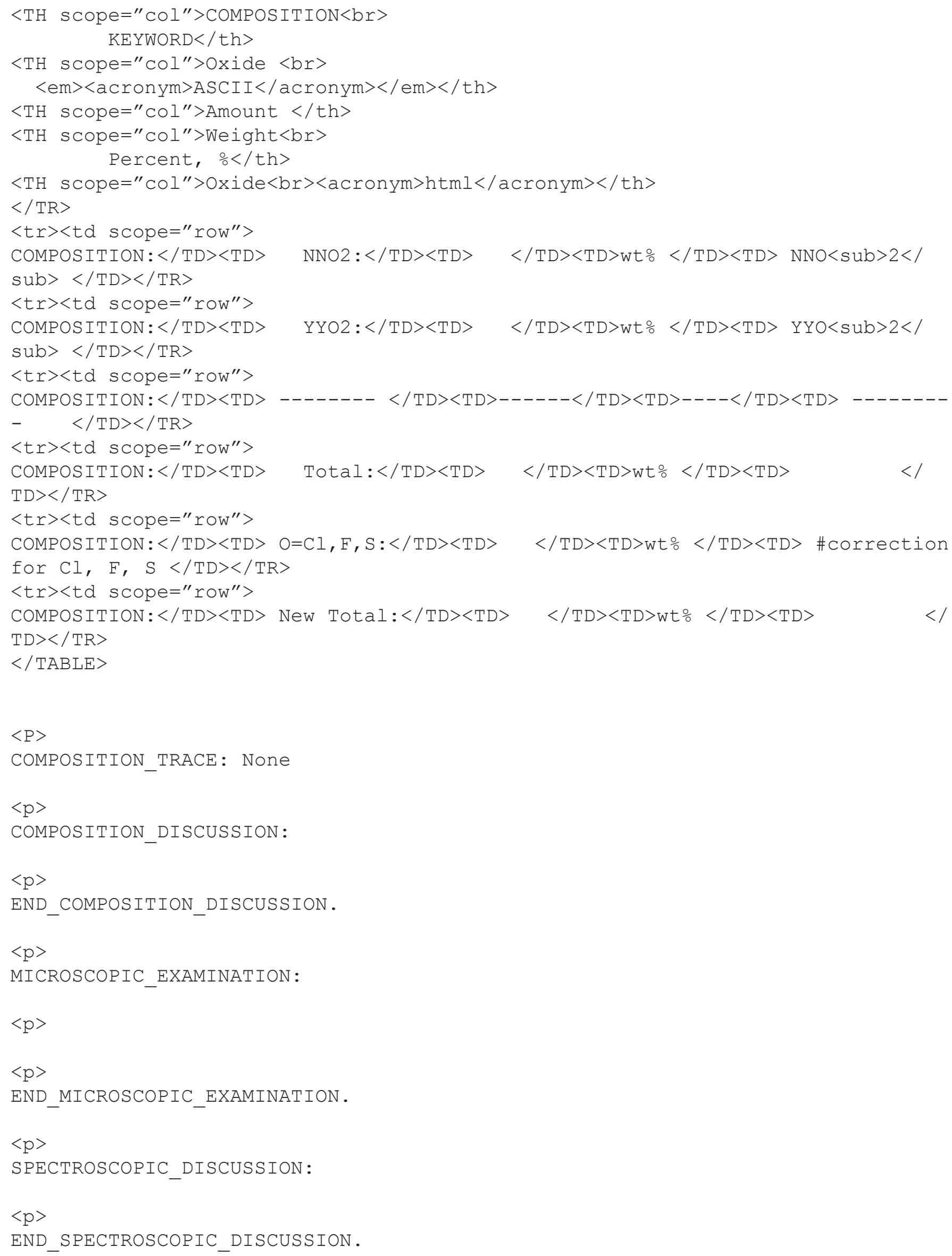


$\langle\mathrm{p}\rangle$

SPECTRAL_PURITY: $1{ }^{2}{ }_{-}{ }^{-4}{ }^{4}$ - $\# 1=0.2-3,2=1.5-6,3=6-25,4=20-150 \mathrm{microns}$

$</$ html $>$

3-6. Template for $V=$ Vegetation (including biological materials, plant components such as leaves, flowers, and bark, vegetated areas having more than one species present, lichens, biological soil crusts, and mixtures with vegetation)

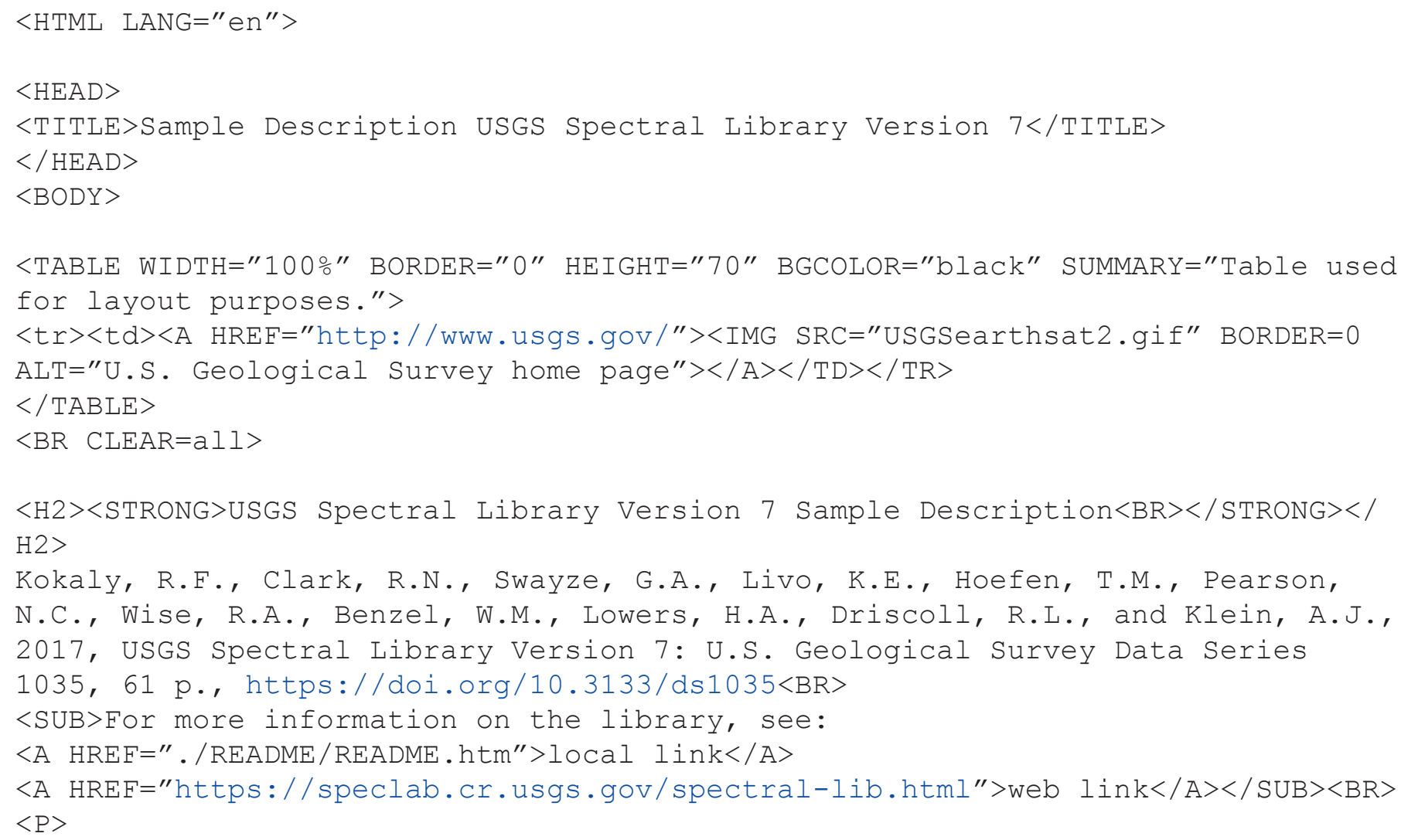


$<\mathrm{P}>$

COLLECTION_LOCALITY:

$<\mathrm{P}>$

COLLECTION_LAtITUDE: Not Available \# degrees and decimal minutes (N or $\mathrm{S}$ ) $<\mathrm{P}>$

COLLECTION_LONGITUDE: Not Available \# degrees and decimal minutes (W or E) $<\mathrm{P}>$

DATUM: $\quad$ Not Available \# coordinate datum

$<\mathrm{P}>$

ORIGINAL_DONOR:

$<\mathrm{P}>$

SAMPLE_DESCRIPTION :

$<\mathrm{P}>$

$==$ sample description goes here ==

$<\mathrm{P}>$

IMAGE_OF_SAMPLE: Not Available <! remove this and the ! to uncomment> $<$ ! a href="photo_images/DESCRIPTFILENAME.jpg" >

$<$ ! img srC="photo_thumbs/DESCRIPTEILENAME.jpg"

ALT="Photo of sample" width="100" height="67" border="0" $></ a\rangle$

$<\mathrm{br}>$

$<\mathrm{P}>$

END_SAMPLE_DESCRIPTION.

$<\mathrm{P}>$

COMPOSITIONAL_ANALYSIS_TYPE: None \# XRF, EPMA, ICP(Trace), WChem

$<\mathrm{P}>$

$<$ TABLE BORDER=1 SUMMARY="Table of compositional results">

$<\mathrm{TR}>$

$<\mathrm{TH}$ scope $=" \mathrm{COl} ">$ COMPOSITION $<$ br $>$

KEYWORD $</$ th $>$

$<\mathrm{TH}$ scope="COl" $>$ Composition $<$ br $>$

$<$ em $><$ acronym $>$ ASCII $</$ acronym $></$ em $></$ th $>$

$<\mathrm{TH}$ scope="COl" $>$ Amount $</$ th $>$

$<\mathrm{TH}$ scope="COl" $>$ Weight $<$ br $>$

Percent, $\frac{\circ}{\circ} /$ th $>$

$</ \mathrm{TR}>$

$<$ tr $><$ td scope $="$ row" $>$

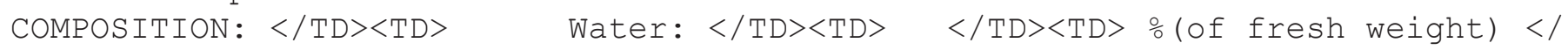

$\mathrm{TD}></ \mathrm{TR}>$

$<$ tr $><$ td scope="row" $>$

COMPOSITION: </TD $>\langle$ TD $>$ Total_Chlorophyll: $\langle/ T D\rangle\langle$ TD $\rangle \quad\langle/$ TD $\rangle\langle$ TD $\rangle$ \% (of fresh

weight) $</ T D></ T R>$

$<$ tr $><$ td scope $="$ "row" $>$

COMPOSITION: </TD $><\mathrm{TD}>$ Chlorophyll_A: $</ \mathrm{TD}\rangle\langle\mathrm{TD}\rangle \quad</ \mathrm{TD}\rangle\langle\mathrm{TD}\rangle \frac{\circ}{\circ}$ (of fresh

weight) $</ T D></ T R>$ 


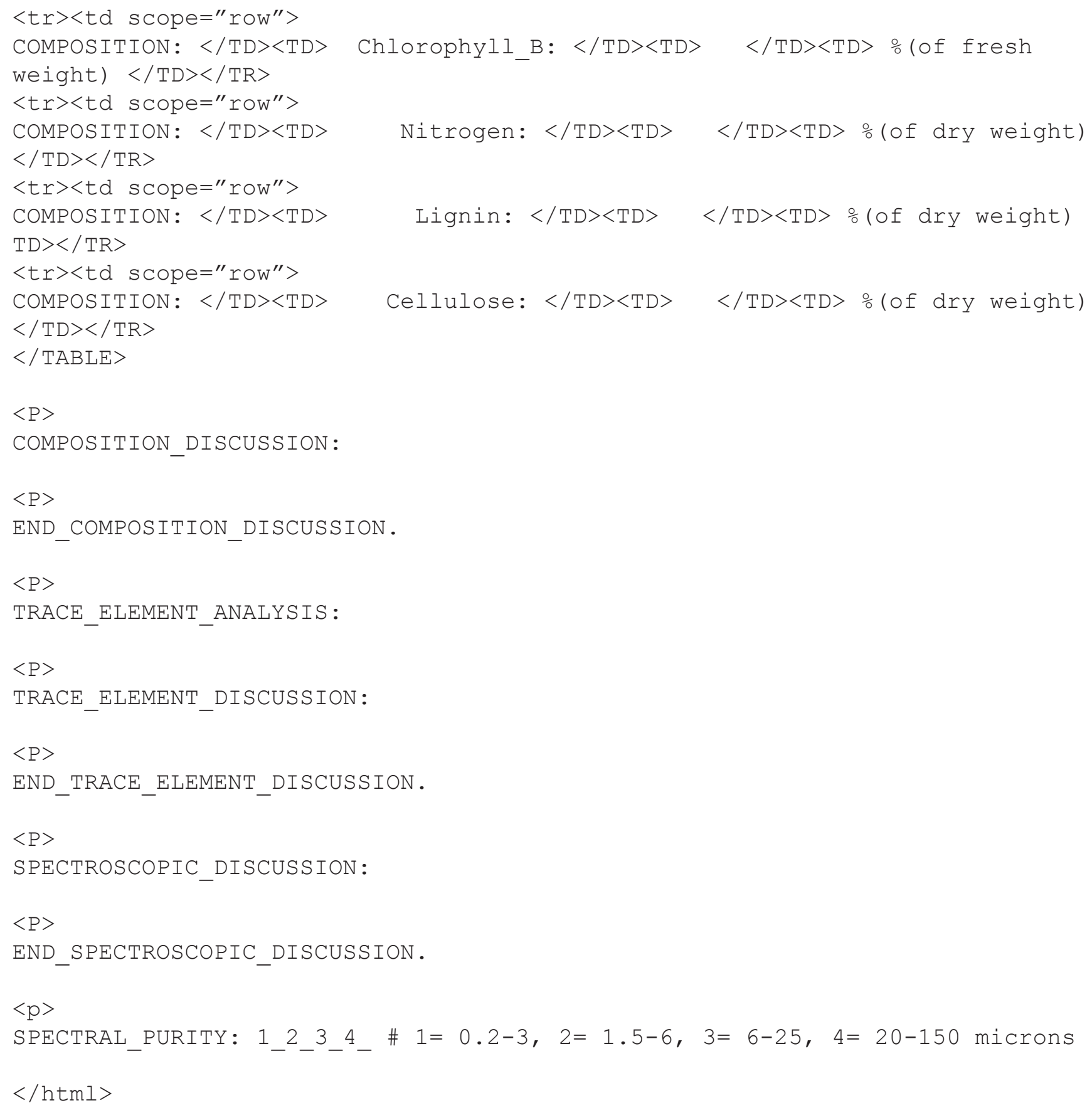




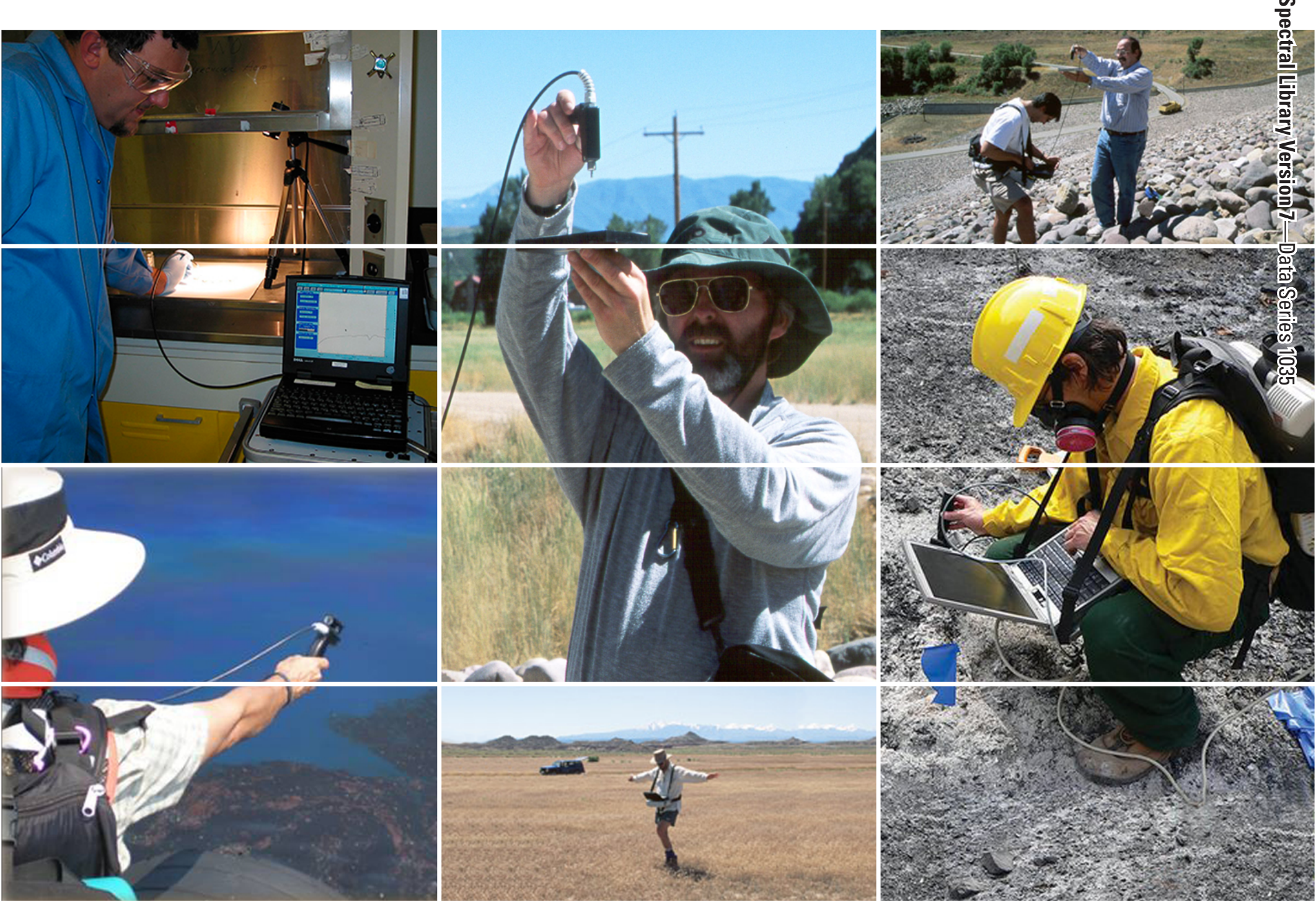

